\title{
INFLUÊNCIA DA INTERPOSIÇÃO DE BASES NA INFILTRAÇÃO MARGINAL EM CAVIDADES CLASSE II (MOD), RESTAURADAS COM RESINAS COMPOSTAS PARA DENTES POSTERIORES
}

Celiane Mary Carneiro Tapety

Dissertação apresentada à Faculdade de Odontologia de Bauru da Universidade de São Paulo, como parte dos requisitos para obtenção do título de Mestre em Odontologia Área de Dentística.

(Edição Revisada) 


\section{INFLUÊNCIA DA INTERPOSIÇÃO DE BASES NA INFILTRAÇÃO MARGINAL EM CAVIDADES CLASSE II (MOD), RESTAURADAS COM RESINAS COMPOSTAS PARA DENTES POSTERIORES}

Celiane Mary Carneiro Tapety

Dissertação apresentada à Faculdade de Odontologia de Bauru da Universidade de São Paulo, como parte dos requisitos para obtenção do título de Mestre em Odontologia - Área de Dentística

Orientador: Prof. Dr. Mário Honorato da Silva e Souza Júnior

(Edição Revisada) 


\section{TAPETY, Celiane Mary Carneiro}

T162i Influência da interposição de bases na infiltração marginal em cavidades classe II (MOD), restauradas com resinas compostas para dentes posteriores./Celiane Mary Carneiro Tapety,--Bauru, 2000.

xix, $140 \mathrm{p}$ : il. ; $29,7 \mathrm{~cm}$

Dissertação (Mestrado) - Faculdade de Odontologia de Bauru, Universidade de São Paulo

Orientador: Prof. Dr. Mário Honorato da Silva e Souza Júnior

Autorizo, exclusivamente para fins acadêmicos e científicos, a reprodução total ou parcial desta dissertação por processos fotocopiadores e/ou meios eletrônicos.

Assinatura do(a ) autor(a)

Data 


\section{Celiane Mary Carneiro Tapety}

18 de setembro de 1974

Oeiras - PI

$1994-1997$

$1998-1999$

$1999-2001$

Associações
Nascimento

$\begin{array}{lcr}\text { Curso de } & \text { Graduação em } & \text { em } \\ \text { Odontologia, na Faculdade } & \text { de } \\ \text { Farmácia, } & \text { Odontologia r } & \text { e } \\ \text { Enfermagem } & \text { da Universidade } \\ \text { Federal do Ceará (FFOE/UFC) }\end{array}$

Curso de Especialização na área de Dentística Restauradora, na Faculdade de Odontologia de Bauru - USP.

Curso de Pós-Graduação em Dentística Restauradora, com equivalência a Mestrado, na Faculdade de Odontologia de Bauru - USP.

ABO - Associação Brasileira de Odontologia - Seç̧ão Ceará, desde 1994.

GBPD - Grupo Brasileiro dos Professores de Dentística, desde 2000.

IADR - International Association for Dental Research, desde 1999. 
"Eu tenho uma espécie de dever de sonhar,

$$
\text { de SONHAR SEMPRE. }
$$

pois sendo mais do que um espectador de mim mesmo,

eu tenho que ter o melhor espetáculo que posso.

E assim me construo a ouro e sedas.

Em salas supostas, invento palco, cenário para viver o meu sonho entre luzes brandas e músicas invisíveis.

( Eernando Pessoa) 


\section{PEGADASNOCAMINHO}

Certa noite, um homem sonhava que caminhava pela praia, passo a passo com o Senhor.

Na tela do céu, revia cenas de sua vida. Percebeu, em cada cena, dois pares de pegadas na areia: um par seu e outro do Senhor. Tendo revisto a sua vida, cena por cena, no espeltho do céu, voltou-se para ver as pegadas na areia e notou que, ao longo de sua vida, muitas vezes havia apenas um par de pegadas. Apenas um par! E justamente nos momentos mais tristes ou difíceis!

Senhor! - disse o homem- Vós dissestes que andaríeis comigo sempre e sempre, se eu vos seguisse. Vejo, entretanto, que há apenas um par de pegadas no caminho enquanto duraram os tempos mais difíceis da minha vida. Não compreendo porque o meu SENH $O R$ me abandonou, exatamente, quando eu mais necessitava.

$$
\text { E。 Sentior replicou: }
$$

Meu filtho, meu amado filtho,

o meu amor não te deixaria nunca!

Onde vês apenas um par de pegadas,

Ali te levava em Meus braços.

\section{ADEUS}

Que sempre me carregou

quando não conseguia andar;

Me conduziu

quando estava cega;

Me abriu os olhos

quando estava emada;

Permaneceu ao meu lado,

mesmo quando não o percebia...

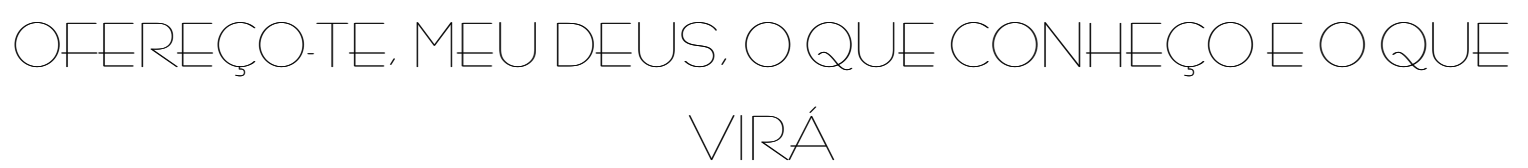

Agradeço também

a Santa Rita de Cássia.

por quantas vezes intercedeu por mim junto ao $P$ ai. 
Dedico este trabalho

\section{QUEDASEFERIMENTOS, tratados. ENSINAMENTOS, sem punições. BRINCADEIRAS, sem preocupações. REFEIÇÖES, em familia. CARINHO, de pai e mãe. LIBERDADE com bons exemplos...}

Coisas que uma criança precisa!

De que pude desfrutar, em algum momento da minha vida, por ser privilegiada: ter como avós duas pessoas que sempre tomaram para si a responsabilidade do mundo.

Citar-thes todas qualidades seria impossível, pois que são exemplos vivos de como um ser humano deveria passar por esta vida.

Dedico este trabaltho àqueles que, inconscientemente, Conduziram-me até aqui, MEUS AVÓS.

Afinal, eu nunca poderia ser o que hoje sou, se não os tivesse conhecido. 


\section{Dedico também...}

Aos meus irmãos (Celana, Selindo, Celma, Célia, Maurício e Celene) pelo apoio emocional e financeiro que me permitiu a realização de mais este sonho.

Aos meus DEZ sobrintios (Celma, Camila, Selindo, Marcele, Marcel, Janaína, Jéssica, Geovane, Israel e lsadora) por me estimularem a dar o exemplo e por tornarem a minha vida mais feliz.

Cada vez que ouço suas vozes ao telefone, encho-me de alegria e me contento em sentir o entusiasmo com cada nova descoberta.

As minhas mães (Benedita e Conceição) que "perturbam" DEUS e seus anjos para que me protejam, já que elas não possuem este poder.

Saibam que está dando certo. Continuem assim!

Aos meus tios e primos, pelo apoio às vezes intelectual, às vezes religioso, sempre com o objetivo de me verem crescer.

Aos meus cunhados e cunhadas, por aceitarem mais uma filtha e por permitirem que seja dividido o pão de cada dia.

Ao meu cunhado Ivanildo, por vir sendo para mim mais um irmão, além de pai.

Alguém por quem cultivo profunda admiração.

Ao meu pai, que sempre foi um exemplo de luta, um exemplo de que sempre conseguimos, quando realmente queremos. 


\section{Ao Eduardo,}

que carregou pesos físicos e psicológicos durante todo o tempo de convivência,

agradeço-the pela compantia durante as madrugadas de trabaltho na Faculdade; pelo auxilio técnico e intelectual nesta pesquisa; por ter sido incansável em resolver meus problemas durante todo o tempo de reclusão para escrever esta tese; pelos momentos de descanso e de carinho que me proporcionou; finalmente, não só por ter sido a minha família ao longo de todo esse tempo, mas também por ter me presenteado com a sua família, que aprendi a respeitar e a amar como se fosse minha.

Amo você por tudo que é e sempre será na minha vida!

Com todas as possiveis ironias do destino.

A Luciana Cavalcante e Rita Noélia, minhas amigas que sempre, apesar da distância, enviam força e carinho. Amigas que são para mim duas irmãs, pessoas extremamente importantes, pois são parentes não por imposição divina, mas por escoltha. Obrigada por serem quem são e por provarem que ainda se pode ter $A M I G \bigcirc S$ no mundo, e que não existe distância nem tempo que possa apagar uma amizade, quando essa é verdadeira. Amo vocês como amo cada membro da minha própria família, pois sei que como eles, independente do motivo, vocês estarão sempre ao meu lado. Poucos podem ter o privilégio de carregar consigo essa certeza.

Eu carrego! 


\section{Agradecimentos Especiais}

\section{Prof. Dr. Mário Honorato da Silva e Souza Júnior.}

A humildade que faz com que todos se sintam iguais;

A sabedoria que atrai os que a querem sugar:

A solidariedade que estimula os menos favorecidos a buscarem o que necessitam;

bom humor que fascina aqueles que procuram um pouquinho de leveza;

A bondade que beneficia pessoas desconhecidas que pelos corredores pedem tratamento;

A calma que causa inveja e que todos procuram, sem sucesso;

profissionalismo que adapta o de que gosta às obrigações;

pai e o marido que corre para chegar à hora exata.

Nunca fique bravo, ainda quando todos se aproximam para aproveitar todas essas qualidades! Tudo isso é uma dádiva.

Tenha certeza de que você sempre será uma das boas lembranças que levaremos de Bauru.

Esteja certo de que, mesmo quando eu tentava ajudar, apenas aprendi.

Obrigada por tudo, já que não me é possível enumerar cada razão ou motivo.

A Patrícia, agradeço-the pelo carintio e amizade.

Ao Daniel e ao Vinícius, agradeço-thes pelos momentos de descontração e pelas brincadeiras, que me permitiram matar a saudade daqueles que estão tão distantes (meus sobrinhos). 
A Profa $D_{r}{ }^{a}$ Maria Teresa Atta Alves Bastos, um sen humano que consegue reunir qualidades como o charme, a inteligência e a humildade; que traz consigo a dádiva da simplicidade e da solidariedade,

Agradeço-the por ser quem você é

e por, em tantos momentos de conversa e de trabalho,

ter-me feito acreditar no SER LEVE, além do ser humano.

A $P_{r o f}{ }^{a} D_{r}{ }^{a}$ Alaíde Hermínia de Aguiar Oliveira, alguém que entende de solidariedade, amizade, carinho, determinação e ascensão após cada queda,

Agradeço-the pela base deste trabaltho e por, muitas vezes, ajudar-me a levantar.

Você é uma pessoa que apesar da distancia e dos anos, jamais esquecerei.

Ao Prof. Dr. Haroldo César Pinheiro Beltrão, por quem sinto um imenso carinho e uma enorme admiração,

Agradeço-the pelo exemplo tumano e profissional.

Caso possa eu um dia ser chamada de MESTRE, ficarei feliz: não terei apenas defendido uma tese, terei, sobretudo, aprendido o que o senhor hoje é.

Ao Drof. Dr. Ricardo Marins de Carvalho, sempre disposto a ajudar, fazendo consideraçōes sempre pertinentes, que apenas reforçam sua grande capacidade e perspicácia,

Agradeço-the pela ajuda e pelas consideraçôes feitas acerca do presente trabalho. 


\section{Meus agradecimentos e reconhecimento}

Aos Professores do Departamento:

Profa Dra Maria Fidela de L ima Navarro, um exemplo de resistência e determinação que carregarei sempre,

Agradeço-the por quanto me auxiliou quando da minha chegada; pelas oportunidades que me ofereceu; pelo empentio em me ajudar quando estive doente e precisei que alguém tomasse as rédeas e não me deixasse amefecer o ânimo.

Obrigada!

Prof. Dr. José Mondelli, um exemplo de força e dedicação ao trabaltho, que para mim era um mito e hoje é realidade.

Observálo a trabalhar, além de um grande aprendizado, é gratificante e mesmo divertido. Poder ajudá-lo é sempre uma oportunidade de crescimento, mas também de paciência, pois que a poucos foi dada a aptidão para acompanhar raciocínio tão vívido.

De uma imagem de alguém quase intocável, surgiu um ser humano, a quem agradeço pelos últimos trabalhos e pela oportunidade de aprender Odontologia Clínica.

Ao Prof. Dr. José Carlos Pereira, com quem foi extremamente reconfortante conviver, com quem foi tão aprazível aprender um pouco de como é ser um professor,

Agradeço-the pela cordialidade e pelo bom humor com os quais sempre me tratou.

Aos demais professores da disciplina de Dentística: Prof. Dr. Aquira |shiquiriama; Prof. Dr. Carlos Eduardo Erancischoni; Prof. Dr. Eduardo Batista Eranco; Prof. Dr. João Lúcio Coradazzi; Prof. Dr. Rafael Erancisco Lia Mondelli;

Agradeço-thes pelos conhecimentos que me transmitiram.

Aos professores da disciplina de Materiais Dentários, especialmente ao Prof. Dr. Paulo Amarante,

Agradeço-thes pela forma descontraída e acolhedora com que sempre me receberam. 


\section{Meus Sinceros Agradecimentos,}

A Karen, sempre disposta a resolver os problemas de todos e de cada um, mesmo quando não está disponível

\section{Agradeço-the por ser meu "anjo da guarda" dentro do Departamento.}

Ao Nelson, à Dona Bem (Rosinha), à lô (L orisvalda) e ao Alcides, que nunca souberam dizer um não às minhas solicitações,

Agradeço-thes também pela amizade e pelo carintio.

Aos demais funcionários da disciplina de Dentística e de Materiais Dentários meu eterno obrigada pelo tratamento a mim dispensado e pela incessante disposição para ajudar, ajudar e ajudar.

Aos funcionários da biblioteca, que fazem do seu trabaltho um exemplo de seriedade, de competência, de convivência, o que torna receptivo o ambiente, onde é extremamente gratificante trabalthar,

Agradeço-thes pela atenção e tratamento dispensados, dignos de primeiro mundo.

Aos funcionários da pós-graduação, sempre prestativos, agradeço-thes pelo tratamento a mim dispensado e pelo empentio em ajudar. 
Meus Agradecimentos não menos especiais

A Eaculdade de Odontologia de Bauru da Universidade de São Paulo, pela recepp̧ão.

A Eaculdade de Farmácia, Odontologia e Enfermagem da Universidade Federal do Ceará, onde me formei, por me ter proporcionado aquisição de conhecimentos que contribuiram para a realização deste sonho.

A todos os professores e funcionários da disciplina de Dentística do curso de $\bigcirc$ dontologia da Faculdade de Farmácia, Odontologia e Enfermagem da Universidade Federal do Ceará (Dr. Haroldo, Dra Heloísa, Emanuel, Vicente, Lidiany, Carlinhos, Serginho e a eterna Martinha), por todo o carinho, tanta atenção, e principalmente pela amizade que a mim dispensaram.

Espero fazer parte dessa familia pela vida afora, independentemente de onde eu esteja.

Ao Dr. Paulo Beltrão pela presteza em ajudar, nunca esquecerei que mesmo sem me conhecer - Sr. sempre se mostrou extremamente solidário.

A FAPESP, pela concessão da Bolsa de Mestrado, que foi de extrema importancia para a realização do curso, da parte experimental, para aquisição de materiais e equipamentos, e para divulgação do trabalho nas diversas reuniöes, contribuindo, assim, para pesquisa cientifica na $F \bigcirc B /$ JSP, conseqüentemente em todo o país.

A。SENAl de Bauru pela prontidão em atender nossas solicitaçōes. 


\section{...E AOS MEUS AMIGOS QUERIDOS. MEUS AGRADECIMENTOS BEM MAIS QUE ESPECIAIS}

Aos amigos do mestrado (Amanda, Bárbara, Eábio, Fernanda, Júlio, Lawrence, Linda, Paulo, Rosa, Renatinha, Paulo Boer, Pedro e Wiliam), pela convivência, descontração e solidariedade.

A Dani (Daniela Francisca Gigo Cefaly), além de amiga de mestrado, uma irmã, sempre disposta a me ajudar.

Nunca esquecerei de que, em um dos momentos mais difíceis da minha vida, você e sua família estiveram ao meu lado, demonstrando o mesmo empenho e desvelo que dedicam a um membro da família.

Que DEUS a proteja, e também aqueles que a cercam, pelo resto de suas existências!

Ao João e Marcelo pelos conhecimentos a mim passados, pela disposição em ajudar-me, ainda e principalmente pela amizade que me devotaram.

Ao Dr. Onildo, um exemplo de profissional e de ser humano, agradeço-the pelo apoio e por me ter levantado quantas vezes pensei cair.

Sem você talvez eu não tivesse conseguido sequer escrever essas poucas linhas.

A Roberta, uma pessoa que provou que morar sobre o mesmo teto pode ser legal e até necessário

Agradeço-the pela honra de ser, hoje, sua amiga.

Obrigada por tudo, Rô!

Ao Eá, meu eterno vizinho e meu "anjo do computador"; agradeço-the por sempre estar disposto a resolver meus problemas de relacionamento com o "micro" e também pela amizade, compantia e pelo colo.

A Bia, que todo mês me traz os ventos da minha terra, além da alegria, companheirismo e da meiguice.

Sempre me lembrarei de você com muito carinho.

A Sul, que me faz tanta falta; agradeço-the pela amizade, pela ótima convivência, por seu exemplo de nordestina "porreta", principalmente. 
Ao Nonato, pessoa de quem me lembro com muito carinho, por ter marcado tão positivamente toda minha infância e adolescência; agradeço-the, especialmente, pela começão gramatical e ortográfica desta dissertação.

Muito obrigada por me permitir um sono de anjo, enquanto você, madrugada a fora, cormigia essa tese com tanto desprendimento e atenção.

Você é, sem dúvida, alguém muito especial. Possui o dom da INTELIGENCIA, loucura e simplicidade.

A todos os meus amigos (Livia, Lu Reis, Dani Rios, Heitor, Jef, Alê, Milena, Eduardo Bresciani...) aos que apenas citei e a todos os outros (que fazem parte das reticências, mas que moram no meu coração), agradeço-thes por estarem em minha vida.

Se não foram responsáveis diretos pela confecção da tese, foram responsáveis pelos momentos de descanso que entremearam o árduo trabalho de sua elaboração.

Segue o teu destino

Rega as tuas plantas,

Ama as tuas rosas

$O$ resto é sombra

De árvores alheias

(Ricardo Reis) 


\section{SUMÁRIO}

LISTA DE ABREVIATURAS................................................................... xvi

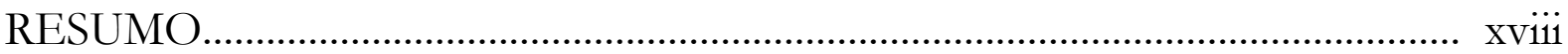

1 INTRODUÇÃ

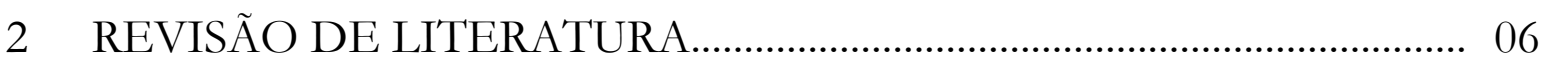

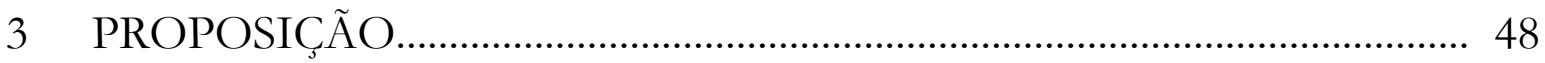

4 MATERIAIS E MÉTODOS.................................................................... 50

4.1 Obtenção e preparo dos dentes................................................................ 51

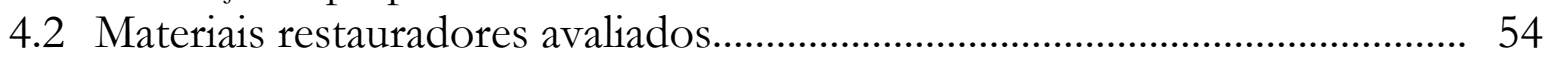

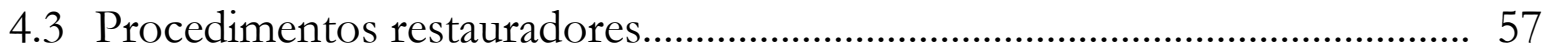

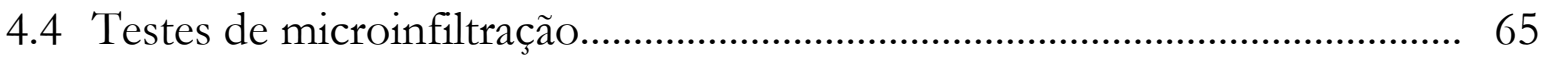

4.5 Análise dos resultados................................................................................ 72

4.6 Diagrama resumo de Materiais e Métodos.................................................... 73

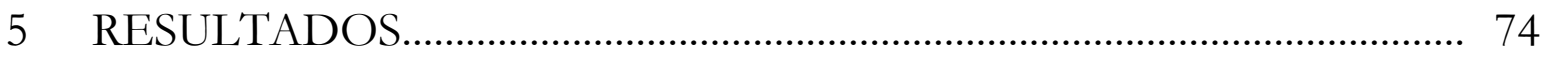

6 DISCUSSÃO

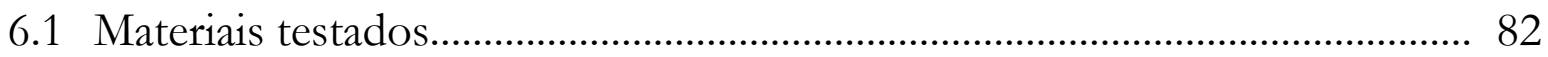

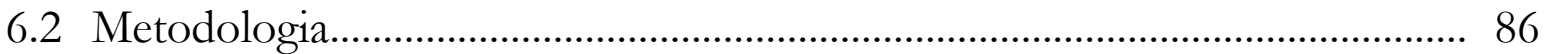

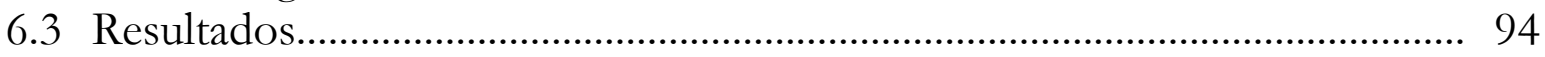

$7 \quad$ CONCLUSÃO

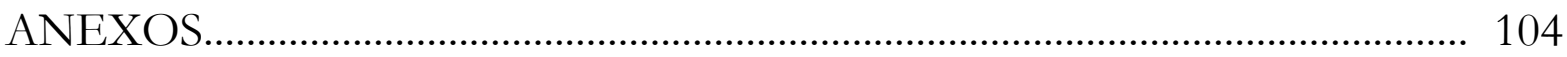

REFERÊNCIAS BIBLIOGRÁFICAS........................................................... 124

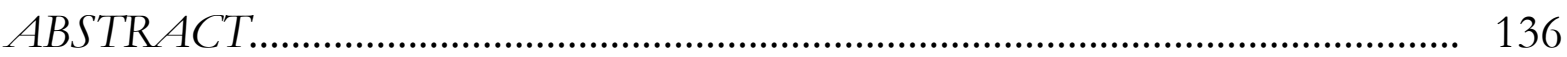




\section{LISTA DE ABREVIATURAS E SÍMBOLOS}

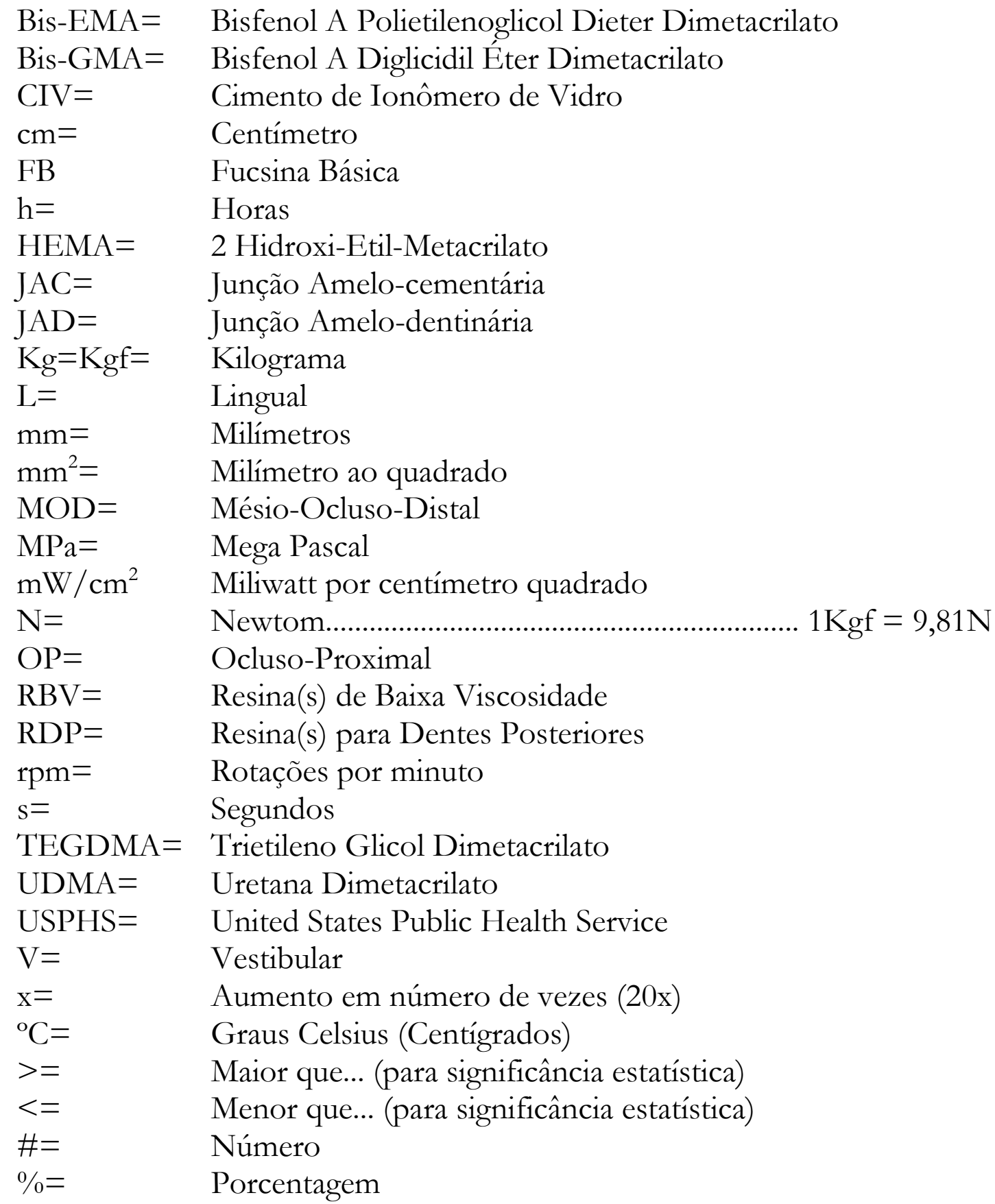


Resumo 


\section{RESUMO}

Este estudo avaliou, in vitro, os níveis de microinfiltração em cavidades Classe II restauradas com três sistemas restauradores para dentes posteriores (P60/Single Bond-3M; Solitaire/Gluma One Bond-Kulzer e SureFil/Prime \& Bond 2.1-Dentsply), com interposição de bases (uma resina de baixa viscosidade - Flow-It!/Jeneric Pentron; e um ionômero de vidro modificado por resina Vitremer/3M); nos grupos controle nenhuma base foi utilizada. Em 90 dentes pré-molares humanos, extraídos por razões ortodônticas, foram confeccionadas cavidades de Classe II (MOD) padronizadas, com margens cervicais localizadas da seguinte forma: na caixa distal: $1 \mathrm{~mm}$ aquém do limite amelo-cementário; na caixa mesial: $1 \mathrm{~mm}$ além do limite amelo-cementário. Os dentes foram divididos em 9 grupos de 10 espécimes, como a seguir descritos: grupos I, II e III: receberam Flow-It! como base, nas paredes de fundo (axial e pulpar) e circundante (gengival) e foram restaurados com P60, Solitaire e SureFil, respectivamente; grupos IV, V e VI: foram apenas restaurados com as mesmas resinas (P60, Solitaire e SureFil), respectivamente: grupos VII, VIII e IX: receberam Vitremer como base e foram restaurados com P60, Solitaire e SureFil, respectivamente. As bases foram mantidas na parede gengival ao nível da junção amelo-dentinária, na caixa distal, e a $1 \mathrm{~mm}$ do cavo-superficial, na caixa mesial. Passadas 24 horas da confecção das restaurações, estas foram submetidas a estresse mecânico (1-17kg, 10x a cada dia/7 dias). Após esse tempo, com as superfícies dentárias devidamente protegidas com esmalte para unhas, os espécimes foram armazenados em fuccina básica por 24 horas. Em seguida, foram lavados em água corrente, também por 24 horas. Foram incluídos em moldes de resina ortoftálica e seccionados, donde se obtiveram cortes de aproximadamente $0,8 \mathrm{~mm}$. Com um "scanner", foram tomadas imagens, previamente selecionadas com lupa (10x), da secção mais infiltrada de cada 
dente. A área de penetração do corante foi demarcada e calculada pelo programa ImageTool (UTHSCSA) e os resultados submetidos à análise de variância (ANOVA) a três critérios e à comparação individual de Tukey-Kramer. A análise dos resultados demonstrou que as margens em esmalte apresentaram menores áreas infiltradas, independentemente do material utilizado e das associações entre eles $(p<0,05)$. A presença de base não resultou em redução da infiltração marginal significante para as resinas, P60 e SureFil, independente da margem avaliada $(p>0,05)$. A resina Solitaire apresentou os maiores níveis de infiltração quando empregada sem a presença de base $(\mathrm{p}<0,05)$. Assim, concluise que a presença de base pode minimizar os níveis de infiltração, nas margens em esmalte e dentina, porém está na dependência do sistema restaurador empregado. 


\section{1-Introdução}




\section{1- INTRODUÇÃO}

Atualmente as resinas compostas têm sido largamente utilizadas, devido às suas características estéticas, à baixa condutibilidade térmica que apresentam e à preservação de estrutura dental sadia ${ }^{27}$. O maior interesse por esses materiais tem levado, nos últimos 30 anos, a um maior desenvolvimento e, conseqüentemente, a melhorias em suas propriedades. Assim é que, nos dias de hoje, não são tidas como um possível substituto do amálgama, mas constituíram-se em uma alternativa para as restaurações em dentes posteriores.

As restaurações feitas com as resinas compostas apresentam ainda limitações, como a infiltração marginal e o desgaste. A infiltração marginal está relacionada, em parte, à contração de polimerização e à rigidez, o que pode resultar em desajustes oclusais, em desadaptação marginal, com conseqüente recidiva de cárie ${ }^{1,20,23,29,53,57}$, 79, 80, 84, 95, 96. Esses fatores podem ser minimizados pelo profissional, que, conhecendo o substrato sob o qual vai atuar ${ }^{13,96}$, o material e a técnica restauradora a serem utilizados, pode optar por associações de materiais.

Nas duas últimas décadas, têm surgido algumas modificações na composição das resinas, de modo a melhorar suas propriedades mecânicas. EHRNFORD, em 1988, desenvolveu um material composto basicamente de fibras de vidro de soda cáustica, envolvidas por matriz de BisGMA ou UDMA ${ }^{57}$. Devido a problemas de ordem mecânica, mas também por sofrerem hidrólise no meio bucal, esses materiais foram retirados do mercado. Alguns anos mais tarde, foi desenvolvido e patenteado, nos Estados Unidos, um material composto de fibras cerâmicas conectadas, Polimeric Rigid Inorganic Matrix Material (PRIMM), formando um esqueleto rígido, também envolvido por resina à base de BisGMA, com propriedades de condensabilidade, de maior profundidade de polimerização e alto módulo flexural. Como as fibras cerâmicas não suportavam a pressão de condensação, fraturavam e diminuiam a sua resistência final. 
Recentemente, surgiram no mercado as resinas de alta densidade de carga, também chamadas "condensáveis" grande quantidade de carga (entre 65\% e $80 \%$ em peso), com pequenas variações entre os vários fabricantes $3,33,40,51,56,57,59,96$. A porção orgânica foi alterada para obtenção de um material mais estável dimensionalmente e com menor contração de polimerização. Acredita-se que, em face de suas características, essas resinas são mais resistentes ao desgaste e mais facilmente manipuladas, por possuírem uma consistência mais favorável à sua inserção em cavidades de dentes posteriores, obtendo-se um contato proximal mais adequado ${ }^{3,40,51}$.

Além das características relacionadas ao material, outro fator de relevância é a localização das margens cavitárias. A estrutura dentária apresenta variações, principalmente a dentina; que se apresenta permeável, com variações regionais de morfologia e de fisiologia que podem, em maior ou menor grau, interferir na adesão ${ }^{13,74,75}$. Assim, cavidades classe II ou V, com margens cervicais bcalizadas em dentina, merecem atenção especial e maior rigor técnico no momento de serem restauradas, pois é sabido que os níveis de desadaptação e de infiltração marginal nessas regiões são relativamente altos ${ }^{11,42,62,74,75,87,88}$.

Outro fator que interfere na adesão é a concentração de esforços na interface de união entre dois materiais, que pode ser analisada em função da elasticidade das resinas compostas e de estruturas dentárias. A rigidez das estruturas dentárias e das resinas dificulta a assimilação de tensões geradas durante a mastigação e durante a própria contração de polimerização. Acredita-se que ocorra, com o passar do tempo, uma desadaptação das margens cavitárias, possibilitando a passagem de bactérias, fluidos, moléculas ou íons ${ }^{44,53,94,102}$, caracterizando, assim, a microinfiltração.

Os materiais odontológicos deveriam possuir propriedades físico-mecânicas semelhantes às da estrutura dentária, para que discrepâncias entre os mesmos fossem evitadas e problemas como: localização das margens cavitárias, condutibilidade térmica e elétrica, concentração de esforços na interface, dentre outros, não 
acarretassem em problemas de comportamento clínico. Infelizmente ainda não existe um material com essas características. Uma das formas de reunir as propriedades desejadas numa mesma restauração é a associação dos materiais utilizados. Muitas associações entre resinas compostas e materiais como cimento de ionômero de vidro e resinas fluidas têm sido propostas por diversos autores ${ }^{10,38,59,71}$, visando ao aprimoramento da técnica restauradora.

Devido às suas características de biocompatibilidade, adesão, liberação de flúor e de baixo coeficiente de expansão térmico linear, os cimentos de ionômero de vidro têm sido indicados como bases nas restaurações de resina composta. A aplicação de base de ionômero de vidro proporciona uma diminuição da contração de polimerização das resinas, pela diminuição do seu volume; além de, a longo prazo, minimizar a incidência de cárie, por liberar flúor ${ }^{69,71,96,97}$. Com o surgimento dos ionômeros de vidro modificados por resina, suas propriedades mecânicas e estéticas sofreram melhorias, o que possibilitou o uso desses materiais nas margens das cavidades localizadas em dentina; melhorando, portanto, o selamento marginal de restaurações confeccionadas em resina composta (técnica do sanduíche aberto) ${ }^{71,89,97}$. Apesar de não terem resistência adesiva muito elevada, os cimentos de ionômeros de vidro apresentam resultados que confirmam sua atuação na redução dos níveis de microinfiltração marginal, independentemente da qualidade do substrato; o que nem sempre é observado quando usados os adesivos resinosos ${ }^{25,96}$.

Recentemente, foram lançadas no mercado as RBV, que possuem um menor conteúdo de carga $(60 \% \text { a } 70 \% \text { em peso })^{81}$, maior fluidez e baixo módulo de elasticidade. Sua indicação como base de restaurações de resina composta baseia-se na hipótese de que a interposição de um material com baixo módulo de elasticidade poderá servir como camada elástica, assimilando os estresses gerados durante a polimerização e as deformações decorrentes das forças mastigatórias, minimizando a desadaptação que porventura ocorra nesse momento ${ }^{10,59,86,105}$.

Devido a essa denominação ser confusa, uma vez que os sistemas adesivos também são considerados resinas fluidas, as próximas referências à essas resinas será: Resinas de Baixa Viscosidade - RBV. 
Alguns fabricantes e autores ${ }^{2,10,51,105}$ afirmam que a maior fluidez possibilita a penetração do material nas irregularidades, melhorando a adaptação nas paredes cavitárias, aumentando a resistência adesiva e conseqüentemente minimizando a infiltração marginal, principalmente quando em associação com as resinas de alta densidade de carga que, por possuírem menor conteúdo orgânico, são de difícil adaptação.

Logo, partindo-se dessa premissa e de que os cimentos de ionômero de vidro são eficazes na redução dos níveis de infiltração, objetivou-se avaliar o efeito da interposição de resina de baixa viscosidade (Flow-It! ${ }^{\boldsymbol{(}}$ ) e do ionômero de vidro modificado por resina (Vitremer*) na microinfiltração em cavidades Classe II (MOD), com margens em esmalte e em dentina, restauradas com resinas para dentes posteriores, P-60`; Solitaire ${ }^{\circledR}$; SureFil. *

3M Dental Products Division St. Paul MV. 
2-Revisão de
literatura 


\section{2- REVISÃO DA LITERATURA*}

ASMUSSEN $^{7}, \mathbf{e m ~ 1 9 7 4 , ~ e s t u d o u ~ o ~ e f e i t o ~ d a ~ m u d a n c ̧ a ~ d e ~ t e m p e r a t u r a ~ s o b r e ~}$ a formação de fendas em restaurações confeccionadas com 4 resinas compostas (Adaptic/Johnson \& Johnson; Blendànt/Kerr; Concise/3M e Opotow/Opotow dental MFG.) e 2 resinas acrílicas (Sevriton Simplified/De Trey e Swedon/Svedia Dental Industri). As restaurações foram confeccionadas em dentes humanos, armazenadas a $37^{\circ} \mathrm{C}$, por 64 dias. Após esse tempo, foram submetidas a acabamento e polimento. Para cada marca comercial, foram confeccionados 12 espécimes, dos quais 6 (a metade) não foram submetidos a termociclagem (grupo controle). Os grupos experimentais foram submetidos a temperaturas de aquecimento $\left(50^{\circ} \mathrm{C} \mathrm{e} 60^{\circ} \mathrm{C}\right)$ e de resfriamento $\left(37^{\circ} \mathrm{C}\right)$ por 2 e 5 segundos em 1,10 , 100 e 1.000 ciclos. Para as resinas compostas, independentemente do número de ciclos, as variações de temperatura de $37^{\circ} \mathrm{C}-50^{\circ} \mathrm{C}$ não influenciaram na formação de fendas. A temperatura de $60^{\circ} \mathrm{C}$ influenciou na formação de fendas para a resina composta Opotow e para as duas resinas acrílicas. Os autores concluíram que as alterações dimensionais das restaurações, quando submetidas às variações de temperatura, dependem do tamanho e da forma da cavidade, da utilização (ou não) de base cavitária, bem como do coeficiente de expansão térmica e do limite de elasticidade dos materiais restauradores empregados. As temperaturas, em que as fendas foram mais evidentes devem ser consideradas apenas como um parâmetro ou uma aproximação das temperaturas observadas in vivo.

KIDD $^{53}$, em 1976, apresentou uma extensa revisão sobre microinfiltração, definindo-a como sendo a passagem de bactérias, fluidos, moléculas ou íons na interface material/estrutura dentária, causando problemas como hipersensibilidade, descoloração marginal e formação de cáries secundárias. Foram especificados os tipos de testes utilizados para análise da microinfiltração, subdivididos em testes in

\footnotetext{
* Neste capítulo as Resinas para Dentes Posteriores (RDP) e as Resinas de Baixa Viscosidade (RBV) serão chamadas de condensáveis e fluidas, respectivamente; por serem assim nomeadas pelos autores aqui referenciados.
} 
vitro e in vivo. Sobre os testes in vitro, a autora, procurou especificar vantagens e desvantagens, dar noções das técnicas utilizadas, tais como: uso de corantes, isótopo radioativo, pressão a ar, bactéria, análise da ativação de nêutrons e cáries artificiais. A técnica do traçado de corantes orgânicos foi definida como o método mais antigo, porém o mais comumente usado para a detecção de microinfiltração. Os testes in vivo foram caracterizados como os mais fiéis, por reproduzirem as condições bucais; porém mais difíceis de serem realizados, pois que é necessária a extração do dente em questão, de humanos ou de animais. De acordo com a autora, os testes laboratoriais são questionáveis, pela ausência de pressão pulpar e de placa bacteriana; além de atestar dados conflitantes entre os resultados de microinfiltração encontrados em testes in vivo e in vitro. Com relação às resinas compostas, apesar de poucos trabalhos, a autora afirmou haver evidências de que produziam bom selamento.

A relação entre as mudanças de temperatura e o aparecimento de fendas marginais em restaurações de resinas acrílicas e compostas, após expansão pela sorpção de água, foi estudada por ASMUSSEN, JÖRGENSEN ${ }^{\mathbf{8}}$, em 1978, em uma revisão do trabalho feito, em 1952, por NELSEN et al., primeiro autor a falar sobre percolação térmica de vários materiais, dentre eles, as resinas acrílicas e o cimento de silicato. Os autores também procuraram comparar estudos já realizados sobre adaptação marginal de resinas acrílicas e, finalmente, reconsiderar a importância clínica do coeficiente de expansão térmica e linear para restaurações de resinas compostas. $\mathrm{O}$ s autores observaram que a infiltração marginal de resinas acrílicas e compostas está relacionada com a contração de polimerização, que gera estresses e provoca formação de fendas. Sendo que essa contração depende da composição do monômero e independe do conteúdo de carga inorgânica. A sorpção de água pela resina composta reduz a largura das fendas em alguns materiais, podendo a expansão higroscópica ser suficiente para compensar a contração de polimerização. Os autores concluíram que o alto coeficiente de expansão térmica 
das resinas compostas não necessariamente implica um alto grau de percolação marginal e, ainda, que a presença da expansão higroscópica, nas faixas de temperatura condizentes com a realidade clínica, contribui para manutenção da integridade marginal.

Aspectos relacionados aos testes utilizados para análise da microinfiltração foram considerados por SHORTALL ${ }^{94}$, em 1982, numa extensa revisão de literatura. $\mathrm{O}$ autor procurou enfatizar as técnicas utilizadas para análise da microinfiltração, salientando as vantagens e desvantagens de cada uma. Quanto ao teste laboratorial onde se utilizam corantes orgânicos para o traçado da infiltração, foi considerado que, apesar de ser um dos mais antigos, também é um dos mais utilizados pelos pesquisadores, em face da facilidade que propicia e do seu custo. Algumas desvantagens inerentes a esse teste foram descritas pelo autor, tais como: sua subjetividade no momento da quantificação da infiltração, já que baseada apenas em pontos localizados, com valores pré-determinados (escores); além da não quantificação total da infiltração, pois que é analisada em superfícies obtidas de uma ou algumas secções do dente/restauração. O autor ainda considerou a importância dos testes laboratoriais para a determinação da mic roinfiltração, sendo estes representativos do exame inicial, que posteriormente poderá (ou não) ser confirmados através de testes in vivo.

QVIST $^{85}$, em 1983, realizou um estudo in vivo, comparando a adaptação marginal em restaurações de classe $\mathrm{V}$, feitas em terceiros molares, com e sem o respectivo antagonista. Para tal, foram confeccionadas 57 cavidades classe V (2 $\mathrm{mm}$ de diâmetro por $3 \mathrm{~mm}$ de profundidade) em 24 pacientes. Das cavidades, 29 possuíam antagonista e 28 não mantinham contato oclusal. As restaurações foram confeccionadas com Concise (3M). As técnicas de condicionamento ácido e de aplicação seguiram as recomendações do fabricante, sendo o polimento realizado uma semana depois. Os dentes foram extraídos após quatro meses, por motivos profiláticos ou pela presença de cáries oclusais, sendo fixados e, posteriormente, 
submetidos a corte (vestíbulo-lingual) com envolvimento das restaurações. Trinta e sete (37) seções de cada cavidade restaurada foram obtidas e submetidas a análise microscópica para verificação de presença de bactérias. Os resultados demonstraram um aumento de infiltração bacteriana de $28 \%$ para $71 \%$ quando os dentes foram submetidos a cargas oclusais pela presença do antagonista. Os autores concluíram, então, que a mastigação exerce maior influência na integridade marginal de restaurações de resina composta que outros fatores do meio ambiente bucal, tais como: estresse térmico, desgaste, etc.

Em 1986, DONLY; JENSEN ${ }^{27}$, compararam os estresses gerados sobre as paredes de cavidades classe II (MOD) submetidas a diferentes técnicas de inserção de resina (P30/3M). Para o estudo, foram utilizados 10 segundos molares decíduos (5 superiores e 5 inferiores). Após confeccionadas, as cavidades classe II (MOD) receberam condicionamento ácido e aplicação do adesivo (Scotchbond/3M), para posteriormente serem restauradas, utilizando-se as três técnicas: técnica I incremento único, com polimerização por 2 minutos; técnica II - dois incrementos, o primeiro sendo inserido no fundo da cavidade e envolvendo as paredes gengival, axial, vestibular e lingual, e o segundo incremento preenchendo o restante da cavidade (cada incremento sendo polimerizado por 1 minuto); e técnica III - o primeiro incremento foi da parede vestibular a aproximadamente $1,5 \mathrm{~mm}$ da parede lingual, e o segundo preencheu o restante da cavidade (incrementos polimerizados por 1 minuto). Cada dente foi restaurado usando-se as três técnicas, sendo que, após conseguida a medida da quantidade de estresse sofrida pelo dente em uma técnica, a restauração era removida e o dente era restaurado novamente, utilizandose outra técnica. Os resultados demonstraram que o procedimento de inserção de um único incremento provocou maior estresse que as demais técnicas; e que a técnica III (2 incrementos vestíbulo-linguais) criou menores tensões, provavelmente por unir menor número de paredes. 
As variáveis que afetam a mensuração das forças oclusais durante os processos de deglutição, mastigação e esforço máximo de mordida foram estudas por FIELDS et al. ${ }^{\mathbf{3 6}}$, em 1986. Três (03) faixas etárias foram estudadas: crianças (6 a 12 anos), adolescentes (11 a 15 anos) e adultos jovens (24 a 35 anos). Para cada faixa etária, foram aplicados testes de mordida, para medição da força máxima aplicada (média), nas condições acima especificadas. Os valores encontrados demonstraram que a média da força mastigatória para adultos jovens foi de 17,6 kg, com abertura bucal de $20 \mathrm{~mm}$. Os autores ainda ressalvaram que outros estudos têm demonstrado resultados conflitantes e inconscientes, pela falta de controle sobre variáveis, tais como: sexo, idade, estado da dentição, metodologia, postura, registros uni e bilaterais, etc.

LUTZ; KREJCI; OLDENBURG ${ }^{61}$, avaliaram, in vitro, em 1986, a influência do condicionamento ácido e da interposição de base de ionômero de vidro (Ketac Bond/ESPE) na microinfiltração em cavidades classe II (MOD), restauradas com resina composta (Brillant Lux/Coltène AG). Para o teste, foram utilizados 24 molares, em que foram confeccionadas cavidades MOD, divididos em 4 grupos, para serem restaurados de diferentes formas. $\mathrm{O}$ uso de cunhas reflectivas e a aplicação da técnica de três incrementos (gengival, vestibular e lingual) foram realizados em todos os grupos. A variação dos grupos foi a seguinte: grupo I - restaurados sem condicionamento ácido; grupo II - restaurados posteriormente ao condicionamento ácido do esmalte; grupo III - utilização de base de ionômero de vidro com posterior condicionamento do esmalte ; grupo IV uso de ionômero de vidro com condicionamento posterior de sua superfície e do esmalte. Após restaurados, os dentes foram submetidos a estresse mecânico (72,5N - 1,6 Hz / 500.000 ciclos) e termociclagem $\left(2.500\right.$ ciclos, $\left.5^{\circ}-55^{\circ} \mathrm{C}\right)$, com posterior imersão em corante (fucsina básica a $0,05 \%$ ) por 20 horas. Foram, então, avaliados a micromorfologia das interfaces e o grau de infiltração do corante. Os melhores resultados foram atribuídos ao grupo III, que utilizou ionômero de vidro como base 
e condicionamento apenas do esmalte. Os autores concluíram que esse resultado provavelmente se deve à não adesão do ionômero de vidro à resina, pela ausência de ataque ácido, permitindo a manutenção da adesão da base com a superfície dentinária. A união entre a resina e o ionômero, através do condicionamento da superfície deste (grupo IV), no momento da contração da resina, provavelmente levou ao deslocamento do ionômero, apresentando, devido a isso, resultados não satisfatórios.

Em 1889, CRIM ${ }^{16}$ comparou a compatibilidade do agente de união Scotchbond Dual Cure $(3 \mathrm{M})$ a diversos sistemas restauradores resinosos, além de investigar a influência do tipo de resina composta na infiltração marginal. Utilizando 160 cavidades classe V (em 80 dentes), com margem cervical localizada ligeiramente abaixo da junção amelo-cementária, o autor dividiu o experimento em duas fases. A primeira consistiu na análise da compatibilidade do agente adesivo Scotchbond, onde 10 grupos foram testados, sendo que 5 deles foram restaurados com 5 sistemas restauradores diferentes (Adaptic 2 - Johnson \& Johnson Dentin Bond Agent/ Johnson \& Johnson; Certain - Johnson \& Johnson Dentin Bond Agent / Johnson \& Johnson; Command UF - Bondlite/Kerr, Quantum - Quantum Bond/ Block; Visio-Fil - Visio Bond/ESPE); os outros 5 grupos, restaurados com as mesmas resinas, utilizando-se, entretanto, o Scotchbond como agente de união. $\mathrm{Na}$ segunda fase, seis grupos foram restaurados com a resina microparticulada Silux (3M), variando os adesivos. Os espécimes foram submetidos a termociclagem e a imersão em corante orgânico. A profundidade de infiltração foi calculada através de microscópio, com aumento de 50x. Para a primeira fase, não foi encontrada diferença estatisticamente significante entre os grupos onde se utilizaram os adesivos específicos ou Scotchbond. A utilização de resina microparticulada diminuiu a infiltração, independentemente do sistema de união aplicado, em comparação com os grupos da primeira fase. $\mathrm{O}$ autor concluiu que a maior 
viscosidade e o maior valor de sorpção de água de alguns compósitos talvez influencie adversamente a infiltração, sem levar em conta o adesivo utilizado.

A comparação do grau de infiltração na margem cervical em cavidades classe II restauradas com resina composta para dentes posteriores (Kerr), em associação com agente de união (Bondlite/Kerr) ou com base de ionômero de vidro (KetacBond/Premier), foi avaliada por HEMBREE JÚNIOR ${ }^{49}$, em 1989. O autor utilizou 48 molares, nos quais foram preparadas cavidades classe II (distooclusal e mésio-oclusal) com margem cervical localizada na junção amelocementária. Os espécimes foram divididos em dois grupos e submetidos a tratamentos restauradores diferenciados: 24 dentes ( a metade) receberam apenas agente adesivo e resina composta; o restante deles (a outra metade) recebeu base de ionômero de vidro localizada na parede gengival e axial, além do adesivo e da resina. Para análise da microinfiltração, foi utilizado o teste laboratorial com traçado de isótopo radioativo. Através dos resultados, foi possível, para o autor, concluir que a utilização do cimento de ionômero de vidro em associação à resina composta foi capaz de reduzir significantemente a infiltração.

KOENIGSBERG; FUKS; GRAJOWER ${ }^{55}$, em 1989, compararam técnicas de inserção de resina e avaliaram a influência positiva na redução da infiltração marginal gengival e oclusal. Molares e pré-molares com cavidades classe II (mesial e distal) foram utilizados para o estudo. Os dentes foram restaurados com a resina P-30 (3M), fazendo-se uso de matriz transparente, apenas modificando a forma de inserção do material restaurador. No grupo 1 a resina foi inserida em três incrementos, condensados primeiramente na caixa proximal (parede gengival), e fotopolimerizada por 60 segundos, posteriormente à completa inserção de todos os incrementos. No grupo 2, os incrementos foram inseridos da mesma maneira, mas fotopolimerizados logo após cada inserção. No grupo 3, o primeiro incremento foi inserido juntamente à parede vestibular, a $1,5 \mathrm{~mm}$ da 
parede lingual; e um segundo incremento lingual preenchendo a cavidade; fotopolimerizados individualmente, por 60 segundos. Os resultados, após termociclagem e imersão no corante, mostraram haver diferença estatisticamente significante entre uma única inserção e inserções em incrementos. Não houve diferença estatisticamente considerável entre os grupos 2 e 3, apesar de nenhum grupo ter evitado a infiltração e de a infiltração oclusal ter-se mostrado significantemente menor que na parede gengival.

PRATI $^{83}$, em estudo feito em 1989, avaliou a microinfiltração inicial, logo após polimento, de restaurações classe II (MOD), com e sem interposição de base de ionômero de vidro, variando também resinas e adesivos. Os preparos foram feitos em 80 terceiros molares com parede gengival localizada próximo à JAC. Os espécimes foram divididos em 10 grupos, para serem restaurados com variações de sistemas resinosos (microparticulados e híbridos), com pré-tratamento de superfície e com utilização (ou não) de ionômero de vidro como base. Todos os dentes foram restaurados usando-se técnica incremental, com cada camada fotopolimerizada por 40 segundos. As restaurações foram polidas três minutos após polimerizadas e imediatamente imersas em eritrosina a $2 \%$ por 12 horas, a $37^{\circ} \mathrm{C}$. Cortes transversais foram obtidos (secção gengival, lateral e oclusal) para posterior análise, utilizandose de uma escala graduada. Os resultados mostraram que houve maior infiltração nos cortes gengivais que nos cortes oclusais e laterais das caixas proximais (vestibular e lingual); e que o uso de ionômero de vidro reduziu significativamente a infiltração da parede gengival, quando comparado ao uso dos sistemas adesivos de forma isolada, independentemente do sistema resinoso utilizado. $\mathrm{O}$ autor concluiu que o tipo de resina composta (e não o tipo do agente de união) é o principal fator que interfere na infiltração marginal.

Considerações clínicas sobre microinfiltração foram feitas por PASHLEY ${ }^{\mathbf{7 3}}$, em 1990. O autor reportou sobre a permeabilidade da dentina e sobre sua relação com a infiltração marginal, dando ênfase aos cuidados que devem ser tomados ao 
se realizar um preparo e, principalmente, ao se escolher os materiais restaurador e protetor. Em adição, a citotoxicidade de alguns materiais foi levantada e os possíveis danos que essa condição pode trazer à polpa. Um dos principais tópicos da revisão foi o tratamento ácido, indispensável às restaurações de resina composta, com o conseqüente aumento da permeabilidade da dentina e a passagem facilitada de substâncias tóxicas, proveniente dos sistemas restauradores resinosos.

A carga aplicada e o número de ciclos necessários para provocar estresse na interface dente-restauração (Scotchbond-P30/3M) foi avaliada por FISSORE; NICHOLLS; YUODELIS ${ }^{37}$, em 1991. Cavidades MOD foram confeccionadas em pré-molares, ocupando 1/3 da distância intercuspídea. Medidas dessa distância foram tomadas para posterior comparação com as medidas obtidas com o dente sobre carga oclusal. Os dentes foram restaurados com sistema restaurador resinoso (Scotchbond-P30/3M). Cada dente foi testado, variando a carga plicada (13, 16, 19 e 22 libras) com ciclos de aplicação de 75x. Medidas antes das restaurações e, posteriormente as mesmas, foram feitas após cada carga. Os resultados mostraram que para cargas menores foi preciso maior número de ciclos para provocar estresse na interface, e que falhas ocorreram em todas condições testadas (restauradas ou não restauradas), sendo que menores deflexões foram encontradas nos dentes restaurados.

LEINFELDER $^{56}$, em 1991, discutiu as condições sobre as quais as resinas compostas posteriores podem ser utilizadas com sucesso para restaurações próximo-oclusais. O autor deu ênfase a fatores importantes que devem ser considerados, tais como: localização dos contatos cêntricos e extensão da parede gengival nas superfícies proximais; já que, quanto mais apical, mais fino fica a estrutura remanescente de esmalte, diminuindo o potencial adesivo. Outro fator observado pelo autor foi a localização e o tamanho da restauração. Em geral, quanto mais distal for a restauração, maior será o desgaste por ela sofrido. O 
preparo cavitário deve ser bem realizado e acabado, sem biselamento do ângulo cavo-superficial e com uma abertura vestíbulo-lingual, na região de istmo, tão conservadora quanto possível. O autor ainda discutiu: os procedimentos restauradores, que devem ser feitos com isolamento absoluto; e as técnicas adesivas, realizadas com bastante critério, através de um condicionamento ácido adequado e aplicação do sistema adesivo, respeitando as condições de umidade da dentina. Para minimizar a infiltração, foram indicados o uso de ionômero de vidro como base e a técnica incremental de inserção da resina. Para o autor, o sucesso ou fracasso da resina composta como material restaurador depende da habilidade do profissional em entender as limitações e o correto uso da resina.

Em 1991, LUNDIN, NORÉN ${ }^{60}$ avaliaram, in vitro, a microinfiltração de restaurações classe II (MO e DO) feitas com dois sistemas restauradores resinosos, sobre carga oclusal, com e sem interposição de base de hidróxido de cálcio. Foram utilizados materiais restauradores com $71 \%$ de carga (Occlusin) e com $45 \%$ (Heliomolar/Vivadent) para restaurarem as cavidades classe II, com margens em esmalte e em dentina, confeccionadas em 48 pré-molares. Após preparados, os dentes foram divididos em dois grupos, para cada resina: grupo 1 - forramento com hidróxido de cálcio, grupo 2 - apenas material restaurador adesivo. Metade dos grupos (12 dentes) foram submetidos a 82 ciclos de carga por 1 minuto (350g), durante 100 minutos, em solução corante. A outra metade, não submetida a carga, foi imersa em solução corante pelo mesmo período de tempo. Os espécimes foram então seccionados, para avaliação de microinfiltração, que revelou uma infiltração significante nos grupos submetidos ao carregamento oclusal. Os autores concluíram que, em dentes posteriores, a aplicação repetida de cargas aumenta consideravelmente o risco de infiltração marginal. 
SILVA E SOUZA JÚNIOR et al. ${ }^{97}$, em 1991, estudaram a capacidade de selamento de cinco sistemas adesivos (ARM-Adaptic/Johnson \& Johnson, GlumaLumifor/Bayer Dental, Bondlite-Herculite/Kerr; Scotchbond-P30/3M; Glass Ionomer Liner - Scotchbond-P30/3M) em cavidades classe II (MOD). As margens cervicais das caixas proximais localizaram-se $2 \mathrm{~mm}$ além da JAC, em uma caixa, e $2 \mathrm{~mm}$ aquém da JAC, na outra caixa, de modo que o cavo-superficial estivesse em dentina e em esmalte, respectivamente. Os dentes foram restaurados com os sistemas acima especificados, termociclados durante uma semana, com realização de 105 ciclos/dia, nas temperaturas de $5^{\circ} \mathrm{C}, 37^{\circ} \mathrm{C}$ e $55^{\circ} \mathrm{C}$. Foram seccionados e corados com rodamina B a 0,1\%, para posterior avaliação por fluorescência, com atribuição de escores. Os níveis de infiltração nas margens em esmalte foram significantemente menores que nas margens em dentina, independentemente do sistema avaliado. Os autores também observaram menores níveis de infiltração no grupo onde foi aplicada base de ionômero de vidro. Nenhum dos materiais foi capaz de selar totalmente as cavidades, já que infiltração (em maior ou menor grau) foi encontrada em todos os grupos.

PERETI NETO $^{77}$, em 1992, verificou, in vitro, a deformação elástica e a infiltração marginal de restaurações classe II (MOD) de resinas compostas, submetidas a carga de compressão. Foram utilizados 80 dentes molares humanos, que foram divididos em 4 grupos de 20 dentes cada um, para serem restaurados com as seguintes resinas: P50 (3M), Adaptic II P (Johnson \& Johnson), Estilux P (Kulzer) e Isosit SR (Vivadent). Posteriormente, os dentes foram isolados com esmalte de unha, mantendo livres apenas a restauração e um espaço de $2 \mathrm{~mm}$ ao seu redor. De cada grupo, apenas 10 dentes foram submetidos a carga oclusal (10 ciclos de $17 \mathrm{~kg}-1 \mathrm{~kg}$ por $30 \mathrm{~s}$, por 6 dias). No sétimo dia a aplicação de carga foi feita com os dentes submergidos em fucsina básica a $0,5 \%$. A cada aplicação de carga, foram feitas medidas de deformação das restaurações. Os outros 10 dentes de cada grupo serviram como controle, sendo apenas imersos em fucsina por 10 minutos e 
lavados em água corrente por 24 horas. Os dentes foram então seccionados, no sentido mésio-distal, e analisados em microscópio ótico, com aumento de 40x, empregando-se o critério de escores. O grupo experimental apresentou infiltrações marginais em todas as restaurações, apesar de os resultados não serem significantes. A análise estatística da comparação entre a deformação e a infiltração marginal das restaurações com as resinas compostas testadas não apresentou correlação.

A influência da interposição de cimento de ionômero de vidro modificado por resina (Vitrebond/3M) na microinfiltração em restaurações classe II (MOD) feitas com resina composta (P-50/3M) foi estudada por RETIEF; McCAGHREN; RUSSEL $^{89}$, em 1992. Preparos classe II foram feitos em 30 primeiros e segundos molares permanentes, a parede gengival das caixas proximais estendendo-se $1 \mathrm{~mm}$ além da JAC mesial e $1 \mathrm{~mm}$ aquém da JAC distal. $\mathrm{O}$ ionômero de vidro foi inserido nas paredes pulpar, axial e gengival. Em 15 dentes o cimento foi estendido até o cavo-superficial gengival e nos 15 dentes restantes foi deixado a $1 \mathrm{~mm}$ da margem. Após polimerização do ionômero, foram realizados os procedimentos de condicionamento, aplicação do sistema adesivo e inserção incremental da resina, para posterior armazenamento dos espécimes em solução salina a $37^{\circ} \mathrm{C}$, por 1 semana. Os dentes foram então termociclados $\left(250\right.$ ciclos $/ 8^{\circ} \mathrm{C}$ $50^{\circ} \mathrm{C}$ ) em fucsina básica a $0,5 \%$ e seccionados. A extensão da infiltração nas margens de dentina e em esmalte foi determinada utilizando-se escores ( 0 a 3 ). A infiltração nas margens localizadas em dentina foi significantemente maior que em margens localizadas em esmalte, e reduzida de forma significante quando o Vitrebond foi estendido até o cavo-superficial.

RIGSBY et al. ${ }^{90}$, em 1992, avaliaram a ação da ciclagem térmica e/ou mecânica na microinfiltração de restaurações classe II (mesial e distal), restauradas com sistema resinoso (Herculite XR/Kerr). Preparos estritamente proximais foram confeccionados em 29 primeiros e segundos molares, com margens em esmalte e 
em dentina. As restaurações foram feitas seguindo o princípio de inserção incremental, fazendo-se uso do sistema restaurador da Kerr (ácido, primer, adesivo e resina). Os dentes foram divididos em 3 grupos, de 8 dentes cada um, e estocados em solução salina por 7 dias, para, posteriormente, serem submetidos a estresse: grupo $\mathrm{A}$ - térmico com ciclagem em fucsina básica a $0,5 \%\left(500\right.$ ciclos $\left./ 8^{\circ} \mathrm{C}-50^{\circ} \mathrm{C}\right)$, grupo B - apenas submetidos à carga oclusal de $34 \mathrm{Mpa}$, também em fucsina básica, grupo $\mathrm{C}$ - realizados os dois procedimentos já descritos. A infiltração foi mensurada a partir de escores pré-determinados ( 0 a 4), em ambas as margens. Em cinco restaurações o estresse causado na interface sobre carga oclusal também foi mensurado. Os resultados indicaram que a microinfiltração nas restaurações foi significantemente maior em dentina quando foram utilizadas carga oclusal e termociclagem. Os autores concluíram que restaurações colocadas em dentes expostos ao estresse mastigatório são mais susceptíveis à microinfiltração que as colocadas em dentes sem contato oclusal.

O efeito da variação de temperatura na microinfiltração de restaurações classe II foi estudado por WENDT; McINNES; DICKINSON ${ }^{106}$, em 1992. Em cinqüenta (50) molares, não cariados, foram feitas restaurações classe II padronizadas, com uma caixa proximal localizada em cemento e uma outra localizada em esmalte. As restaurações foram feitas com o sistema restaurador Scotchbond MP/ P-50 (3M), de acordo com as especificações do fabricante, e divididas em 5 grupos: grupo A - controle, sem termociclagem e imersão em fucsina básica (FB) por 24 horas; grupo B - termociclagem (250ciclos, $15 \mathrm{~s}, 5^{\circ}$ $55^{\circ} \mathrm{C}$ ) em água destilada, em seguida imersos em FB por 24horas; grupo C termociclagem semelhante ao grupo 2, porém feita em FB; grupo $\mathrm{A}^{\prime}$ - sem termociclagem e imersos em FB por apenas 4horas; grupo B' - semelhante ao grupo $\mathrm{B}$, modificando apenas o tempo de imersão, agora, apenas por 4h. Após submetidos a seccionamento e avaliação em microscópio, utilizando critério por escores, os autores chegaram a resultados que não demonstraram aumento 
significante nos níveis de infiltração para os grupos termociclados em comparação com grupos não termociclados, para as margens em dentina, independentemente do tempo de imersão e da solução (água ou fucsina).

DAVIDSON; ABDALLA ${ }^{22}$, em 1993, avaliaram, in vitro, a microinfiltração pela penetração de corante e a integridade marginal, por meio de microscopia eletrônica de varredura, de restaurações de resina composta em cavidades de Classe II. Noventa e seis (96) dentes extraídos foram utilizados, preparados e divididos em 6 grupos, nos quais se utilizaram 3 sistemas adesivos (Heliobond, Scotchbond 2 e Clearfil Photo Bond) e a combinação destes com ionômero de vidro Vitrebond. Metade das amostras de cada grupo foi submetida a termociclagem (500 ciclos de banhos a $\left.5^{\circ}-55^{\circ} \mathrm{C}\right)$ e a carga axial $(4.000$ ciclos de $12,5 \mathrm{~kg}$ ), com imersão simultânea em azul de metileno. A outra metade das amostras foi imersa, por 24 horas, no mesmo corante. Infiltração foi observada nos espécimes restaurados com resina composta e sistema adesivo após serem submetidas a estresses térmico e mecânico. Nos espécimes forrados com Vitrebond não houve alteração na infiltração marginal após aplicação dos dois tipos de estresse.

CRIM; CHAPMAN ${ }^{19}$, em 1994, avaliaram a influência de quatro técnicas restauradoras na infiltração marginal de restaurações classe II de resina composta. Cavidades mésio-oclusais e disto-oclusais foram confeccionadas em 20 molares humanos recentemente extraídos, onde todas as margens apresentavam-se confinadas em esmalte. Os dentes foram restaurados com uma das quatro técnicas: grupo 1 - matriz metálica, Fuji II LC, Prisma Universal Bond 3 Primer, Prisma Adhesive, resina APH; grupo 2 - matriz transparente, Prisma Universal Bond 3 Primer, Prisma Adhesive, resina APH; grupo 3 - matriz metálica, Prisma Universal Bond 3 Primer, Prisma Adhesive, resina APH ; grupo 4 - matriz metálica, sistema adesivo substituído pelo agente de união ao esmalte (Coltene Duo-Bond) e resina APH. Posteriormente aos procedimentos restauradores, os dentes foram 
armazenados em água destilada a $37^{\circ} \mathrm{C}$, por 24 horas, submetidos a ciclagem térmica $\left(100 \mathrm{x} / 23 \mathrm{~s}\right.$ a $37^{\circ} \mathrm{C}, 4 \mathrm{~s}$ a $12^{\circ} \mathrm{C}, 23 \mathrm{~s}$ a $37^{\circ} \mathrm{C}$ e $4 \mathrm{~s}$ a $\left.54^{\circ} \mathrm{C}\right)$. Após termociclagem, os dentes foram imersos em solução corante de fucsina básica durante 24 horas e, posteriormente, foram limpos e secionados para análise em microscópio óptico (50X). Os autores observaram que o grupo onde foi utilizado o CIV como base exibiu menor infiltração de corante, se comparado com os outros grupos; e que foi significativamente menor que nos grupos 3 e 4 . As restaurações confeccionadas com agente de união convencional demonstraram severa infiltração. Para os autores, a introdução de novas gerações de sistemas adesivos não solucionou, mas contribuiu para um melhor vedamento das restaurações de resina composta.

Numa revisão literária a respeito da capacidade de vedamento marginal das restaurações de resina composta, em associação com sistemas adesivos, RETIEF $^{\mathbf{8 8}}$, em 1994, discutiu os principais fatores que interferem no selamento dessas restaurações. Foram avaliados e discutidos fatores como: contração de polimerização, absorção de água, diferenças no coeficiente de expansão térmica linear, e influência que exercem na desadaptação das restaurações de resina composta. O autor afirma que nenhum sistema adesivo é capaz de eliminar completamente a microinfiltração e que o estresse mastigatório, in vivo, e a aplicação de carga, in vitro, promovem o aumento da infiltração; sendo, porém, possível minimizar falhas com o uso da técnica incremental de inserção da resina, bem como com o retardo dos procedimentos de acabamento e polimento. Esse retardo favorece a expansão higroscópica, sendo assim uma forma de minimizar a infiltração marginal.

Um estudo in vitro foi feito por DIETSCHI et al. ${ }^{26}$, em 1995, com o objetivo de avaliar a adaptação marginal e o selamento de restaurações em resina composta (Z100/3M ou Herculite XRV/Kerr) feitas em cavidades classe II, com 
configurações cavitárias diferentes (direta e indireta), com e sem interposição de base de ionômero de vidro. Cavidades ocluso-proximais, com margens localizadas $1 \mathrm{~mm}$ abaixo da JAC, foram confeccionadas, sendo feitos os ajustes nos grupos que seriam restaurados com técnica indireta (preparo intracoronário tipo Inlay). Os dentes receberam as restaurações conforme a tabela abaixo:

Tabela 2.1 - Grupos estudados

\begin{tabular}{lllcc}
\hline Grupos & Material & Agente de união & Técnica & Base \\
\hline 1 & Z100 & Scotchbond MP & Direta & Nenhuma \\
2 & Z100 & Scotchbond MP & Direta & Ketac-Bond (ESPE) \\
3 & Z100 & Scotchbond MP & Direta & Vitrebond (3M) \\
4 & Z100 & Scotchbond MP & Indireta & Nenhuma \\
5 & Z100 & Scotchbond MP & Indireta & Ketac-Bond \\
6 & Z100 & Scotchbond MP & Indireta & Vitrebond \\
7 & Herculite XRV & Optbond & Direta & Nenhuma \\
8 & Herculite XRV & Optbond & Direta & Ketac-Bond \\
9 & Herculite XRV & Optbond & Direta & Vitrebond \\
10 & Herculite XRV & Optbond & Indireta & Nenhuma \\
11 & Herculite XRV & Optbond & Indireta & Ketac-Bond \\
12 & Herculite XRV & Optbond & Indireta & Vitrebond \\
\hline
\end{tabular}

Após restaurados, os dentes foram submetidos a termociclagem (500 ciclos, $5^{\circ}$ - 55C, por 1 minuto). A microinfiltração foi avaliada através da penetração de corante; a adaptação marginal, através de réplicas e de microscopia eletrônica. Os resultados demonstraram que as restaurações diretas apresentaram maior grau de infiltração, quando comparadas com as restaurações indiretas. Nenhuma configuração cavitária foi capaz de eliminar completamente a infiltração, promovendo um perfeito selamento marginal. Para os autores, os novos sistemas adesivos parecem promover uma melhoria significativa na qualid ade do selamento marginal, já que, nos seus achados, os adesivos mostraram-se mais eficientes quando utilizados isoladamente que quando usados em associação com as bases de ionômero de vidro.

ROSSOMANDO, WENDT JUNIOR ${ }^{\text {91 }}$, em 1995, estudaram o efeito da duração de banhos (10 s ou 60 s), em cada temperatura, durante a ciclagem térmica. 
Para tal, foram utilizados 90 dentes com cavidades classe V padronizadas, com margem cervical localizada $2 \mathrm{~mm}$ além da JAC e margem oclusal localizada $2 \mathrm{~mm}$ aquém da JAC. Três técnicas para restaurações adesivas foram avaliadas: apenas resina, resina com adesivo, amálgama com adesivo. Foram utilizados 30 dentes para cada técnica. Após restaurados, os dentes de cada grupo foram subdivididos em 3 subgrupos de 10 espécimes, para serem (ou não) submetidos a termociclagem. O subgrupo controle foi apenas imerso em solução de fucsina básica; e os subgrupos experimentais, sujeitos a estresse térmico, diferenciando-se uns dos outros pelo tempo de imersão em cada banho (10 s e 60 s). Os autores observaram que o grau de infiltração, para as três técnicas restauradoras, foi maior para aqueles subgrupos submetidos ao maior tempo de imersão em cada banho (60 s). O que significa que a maior duração do estresse térmico é capaz de anular as propriedades de isolamento térmico do material. Quando o menor tempo de estresse térmico foi utilizados (10 s), tempo este mais compatível com a realidade clínica, não ocorreu diferença estatística, tomados em comparação os grupos de controle.

ABDALA; ALHADAINY ${ }^{1}$, em 1996, avaliaram, clinicamente, diferentes marcas de resina. Foi preparado um total de 120 cavidades de classe I, em molares permanentes, restauradas com 4 resinas: Clearfil Posterior (Kararay), Z100 (3M), Herculite e Heliomolar (Vivadent). Os procedimentos restauradores foram conduzidos sob anestesia local e isolamento absoluto. Os sistemas adesivos utilizados para cada resina constam na tabela 2.2. 
Tabela 2.2 - Combinação de material para grupo testado.

\begin{tabular}{|c|c|c|c|}
\hline $\begin{array}{l}\text { Pré-tratamento } \\
\text { da dentina }\end{array}$ & Primer & Adesivo & Resina composta \\
\hline 1. CA agente & SA primer & Clearfil Photobond & $\begin{array}{ll}\text { Clearfil } & \text { Photo } \\
\text { Posterior } & \end{array}$ \\
\hline $\begin{array}{l}\text { 2. } 10 \% \text { de ácido } \\
\text { maleico }\end{array}$ & Scotchprep & Scotchbond Multi uso & Z100 \\
\hline 3. & OptiBond primer & OptiBond dual cure & Herculite \\
\hline 4. & $\begin{array}{l}\text { Syntac primer e } \\
\text { adesivo }\end{array}$ & Heliobond & Heliomolar \\
\hline
\end{tabular}

Após as restaurações, foram realizados os ajustes, seguidos dos procedimentos de acabamento e polimento. Após 1 e 2 anos, respectivamente, estavam disponíveis 111 e 104 restaurações. As restaurações foram avaliadas segundo o critério da USPHS. Após 1 ano, pequenas alterações foram detectadas em relação à combinação de cor, à forma anatômica, à adaptação marginal e à descoloração do cavo-superficial. Após 2 anos, a deterioração de alguns materiais estava evidente. A pior "performance" do Herculite e Heliomolar em relação à forma anatômica foi atribuída a um volume menor que $60 \%$ das partículas de carga. Não foi observada descoloração do cavo-superficial. As resinas Z100, Clearfil e Herculite mostraram maior porcentagem de adaptação marginal. Houve melhor combinação de cor para a Z100 e para a Herculite que para a Clearfil e a Heliomolar, o que pode ser explicado pelas menores partículas, que diminuem a rugosidade superficial e alteração de cor das restaurações.

O efeito da ciclagem mecânica na capacidade de selamento de diferentes adesivos em restaurações de classe I foi estudado, in vitro, por ABDALLA; DAVIDSON $^{2}$, em 1996. Cavidades classe I, em 72 molares humanos, foram restauradas com os sistemas resinosos: Clearfil Liner Bond/Clearfil Photo Posterior (Kurraray), Scotchbond Multipurpose/Z100 (3M), Syntac/Heliomolar (Vivadent) e Gluma 2000/Pekalux (Bayer Dental), sendo 18 dentes para cada sistema. Para cada grupo, apenas a metade dos espécimes foi submetida a estresse oclusal (5000 
ciclos, $125 \mathrm{~N}$ ), em solução corante de azul de metileno a $2 \%$. A penetração do corante foi analisada, após seccionamento, fazendo-se uso do critério de escores. Os grupos de controle não apresentaram infiltração marginal. Quando o carregamento oclusal foi utilizado, os espécimes dos grupos 3 e 4 demonstraram aumento significativo nos níveis de infiltração. Os autores concluíram que a ciclagem mecânica pode afetar o selamento em restaurações classe I de resina composta, esse fato depende, no entanto, da resistência adesiva do agente de união utilizado, da interposição de material com baixo módulo de elasticidade e também do módulo de elasticidade da resina restauradora, que deve ser igual ou maior que o da dentina.

Em 1996, FARAH; POWERS ${ }^{32}$, avaliaram e compararam 4 resinas compostas de baixa viscosidade (Aelite-Flo/BISCO; CrystalEssence/Confi-Dental; Flow It!/JenericPentron; Revolution/E\&D) e 1 resina composta de múltiplo uso (Herculite XRV/Kerr). Os autores observaram que as resinas de baixa viscosidade possuem maior contração de polimerização, maior potencial para microinfiltração e menor resistência ao desgaste. The Dental Advisor, fundamentada nas propriedades das resinas fluídas e comparado-as com a resina convencional, recomendou o uso de: Aelite-Flo, Flow It! e Revolution.

GONÇALVES $^{45}$ em 1996, avaliou os efeitos de estresses mecânico e térmico e do forramento com ionômero de vidro fotopolimerizável (Vitrebond/3M) na microinfiltração marginal de restaurações classe II com dois sistemas resinosos (Scotchbond Multi-Uso - Z100/3M; Optibond - Herculite XRV/Kerr). Foram preparadas cavidades MOD em 60 pré-molares humanos, com margens localizadas $1 \mathrm{~mm}$ acima da JAC. Os dentes foram divididos em dois grupos de 30 dentes, para receberem os distintos sistemas resinosos restauradores. Todos os dentes receberam, previamente, Vitrebond na parede gengival de uma das caixas proximais. Após restauradas, as amostras foram armazenadas por 24 horas em 
solução fisiológica. Posteriormente os grupos foram subdivididos em 3 subgrupos, para os seguintes experimentos: 10 amostras submetidas a estresse mecânico com 10 ciclos diários de aplicação de carga (1 kg -17 kg/durante 7 dias); 10 amostras termociclados $\left(50\right.$ ciclos, $\left.5^{\circ}-55^{\circ} \mathrm{C}, 15 \mathrm{~s}\right)$; as 10 amostras restantes serviram como controle, não sendo submetidas a qualquer forma de estresse. Posteriormente, os dentes foram selados, protegidos e imersos em solução corante de fucsina básica por 24 horas. Após seccionados, a penetração do corante foi analisada através de lupa estereoscópica (com aumento de 40X), seguindo o critério de escores. Independentemente do estresse aplicado, nenhum sistema foi capaz de bloquear totalmente a infiltração marginal. Não houve diferenças significativas na infiltração entre as amostras termocicladas e as amostras do grupo controle, para ambos os materiais testados.

LEINFELDER; LYLES; RITSCO ${ }^{57}$, em 1996, descreveram modificações surgidas nas últimas décadas na composição das resinas compostas para dentes posteriores, de modo a melhorar suas propriedades mecânicas. Os autores descreveram a composição do material introduzido por Ehrnford, em 1988, o qual era composto basicamente de fibras de vidro de soda cáustica, envolvidas por matriz de BisGMA ou UDMA. Em face de as fibras não suportarem os esforços mastigatórios, além de sofrerem dissolução, esses materiais foram retirados do mercado. A evolução, no entanto, trouxe outro material, alguns anos mais tarde, desenvolvido e patenteado nos Estados Unidos, composto de fibras cerâmicas conectadas, Polimeric Rigid Inorganic Matrix Material (PRIMM). Esse material formava um esqueleto rígido, também envolvido por resina a base de BisGMA, com propriedades de condensabilidade, de maior profundidade de polimerização e alto módulo flexural. Os autores concluíram ser este material um possível substituto para o amálgama, em face das suas propriedade de condensabilidade, resistência ao desgaste, e efeito estético. 
MILLER et al. ${ }^{64}$, em 1996, estudaram o efeito exercido na infiltração marginal de restaurações classe II por materiais restauradores, como resinas de baixa ou alta viscosidade (Heliomolar/Vivadent, Bisfil 2B/Bisco ou Tetric/Vivadent) ou cimento de ionômero de vidro modificado por resina (Vitremer/3M). Para tal, após confeccionadas as cavidades classe II, com margem cervical localizada $1 \mathrm{~mm}$ além da JAC, os dentes foram divididos em 6 grupos: grupo 1 - Heliomolar em três incrementos; grupo 2 - incremento gengival feito com Bisfil 2B e Heliomolar em dois incrementos oclusais; grupo 3 - Vitremer e Heliomolar; grupo 4, 5,6 - à semelhança dos três primeiros grupos, substituindo apenas a resina Heliomolar pela Tetric. A intenção dos autores era avaliar os diversos tipos de material na parede gengival, estando em contato com esta; materiais esses que poderiam ser: de polimerização química (Vitremer e Bisfil 2B), de baixa viscosidade (Bisfil 2B), cimento de ionômero de vidro (Vitremer), ou as próprias resinas restauradoras com polimerização por luz e com uma viscosidade mais elevada (Heliomolar e Tetric). Após restaurados, foram realizados os procedimentos de termociclagem (100 ciclos $/ 5^{\circ}-55^{\circ} \mathrm{C}$ por $\left.8 \mathrm{~s}\right)$ e aplicação de carga (25.000 ciclos / $7.26 \mathrm{~kg}$ ), para posteriormente serem imersos em solução corante, seccionados e avaliados, em microscópio (de 40X de aumento), usando-se o critério de escores. Os resultados demonstraram que o ionômero de vidro mostrou-se significativamente mais eficiente que os outros materiais em minimizar a infiltração nas margens cervicais do preparo. Em adição, a resina Bisfil 2B, de baixa viscosidade e quimicamente polimerizada, mostrou-se mais eficiente que as demais resinas (Heliomolar e Tetric) em reduzir os níveis de infiltração. Para os autores, esse resultado presumivelmente se deve à maior capacidade da resina de baixa viscosidade de penetrar nas irregularidades, promovendo melhor adaptação; além de o processo de polimerização ser mais lento, causando menos estresse (polimerização química), ao contrário das resinas Heliomolar e Tetric. 


\section{SJÖDIN, UUSITALO, VAN DIJKEN ${ }^{98}$, em 1996, avaliaram os efeitos} dos cimentos de ionômero de vidro convencional (Chemfil II/Dentsply), modificados por resina (Fuji II LC/GC e Vitremer/3M) e do compômero (K71, produto experimental do Dyract) na microinfiltração de cavidades classe II e V, com margem cervical localizada abaixo e acima da JAC, restauradas com resina composta (Herculite XRV/Kerr). Para as restaurações classe V, foram utilizados 50 pré-molares, com os preparos localizados nas faces lingual e vestibular. Para as restaurações classe II, foram utilizados também 50 pré-molares. Após restaurados, os dentes foram termociclados $\left(180\right.$ ciclos, $\left.10 \mathrm{~s}, 5^{\circ} \mathrm{C}-37^{\circ} \mathrm{C}-60^{\circ} \mathrm{C}\right)$, estocados em azul de metileno a 5\%, por 24horas. Então lavados e seccionados, para avaliação em microscópio (com aumento de 20X), utilizando o critério de escores ( 0 a 4). O compômero e os ionômeros modificados por resina obtiveram melhores resultados que o CIV convencional. Para as margens em esmalte, o K71 apresentou menor índice de infiltração, seguido pelo Vitremer e pelo Fuji II LC. O compômero K71 e o Fuji II mostraram-se mais eficazes para minimizar a infiltração em margens em dentina. Os autores concluíram, todavia, que são necessárias ainda pesquisas clínicas para afirmar que um dos materiais testados é realmente melhor que outro.

Em 1996, SWIFT JUNIOR et al. ${ }^{99}$, avaliaram a influência do uso de resinas de baixa viscosidade na redução da microinfiltração em restaurações adesivas com cavidades Classe $\mathrm{V}$, com margens cervicais em cemento e em dentina, nas faces vestibular e lingual de 132 molares humanos extraídos. Um dos 5 sistemas adesivos (All Bond 2, Clearfil Liner Bond 2/Kuraray, Optibond, Prime \& Bond/Dentsply e Scotch bond Multi-Uso/3M) foi utilizado em uma das cavidades de cada grupo; e, na outra cavidade, o sistema adesivo selecionado foi associado a uma resina de baixa viscosidade (Optibond FL Adhesive ou Protect Liner F). Todos os dentes foram restaurados com resina Z100, submetidos a acabamento, armazenados em água por 24 horas, termociclados e, finalmente, imersos em nitrato de prata a 50\%, para avaliação da microinfiltração. O uso de resina de baixa 
viscosidade com All-Bond 2 e Prime \& Bond exerceu pequeno efeito no padrão de infiltração, mas o uso do Protect Liner $\mathrm{F}$ reduziu significativamente a microinfiltração, quando associado ao uso de Scotchbond Multi-Uso.

Uma revisão sobre os diversos métodos de detecção de microinfiltração foi

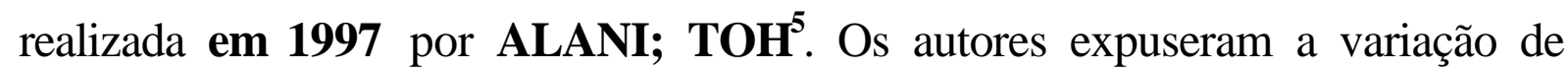
resultados de diversos trabalhos que questionam a influência (ou não) da termociclagem sobre a microinfiltração, em relação às faixas de temperatura utilizadas, à duração e aos intervalos dos banhos, além de: número de ciclos relacionados ao volume do material; condutibilidade e capacidade de sorpção de água do material restaurador. Sobre a ciclagem mecânica, os autores acreditam ser um método eficaz, podendo promover a deformação permanente ou temporária do material, simulando as condições do meio bucal. Para os autores, não existe um método eficaz de detecção da infiltração, já que todos possuem suas vantagens e limitações. A utilização de corante é um dos mais utilizados e baratos.

FRIEDL et al. ${ }^{41}$, em 1997, compararam a qualidade marginal de cavidades classe II, restauradas apenas com os sistemas resinosos ou em associação com cimento de ionômero de vidro (técnica sanduíche). Foram utilizados 48 molares humanos com cavidades classe II, restaurados com: grupo 1 - Scochbond MP, Z100/3M; grupo 2 - ProBond, Prisma TPH/Dentsply; grupo 3 - Vitremer na parede gengival, Scochbond MP, Z100/3M; grupo 4 - Dyract, ProBond, Prisma TPH/Dentsply. As margens foram avaliadas quanto à adaptação marginal, antes e depois de os dentes restaurados receberem tratamento termomecânico (5.000 ciclos, $5^{\circ}-55^{\circ} \mathrm{C} / 72,5 \mathrm{~N}$ ), por análise de microscopia eletrônica de varredura. Além de também serem avaliados quanto à microinfiltração, por penetração de corante, antes e depois da termociclagem. Para cada grupo de 12 dentes, seis (06) dentes (a metade) foram avaliados por microscopia; e o restante (a outra metade), por penetração de corante. Quanto à análise de adaptação marginal, o grupo 1 
(Scotchbond/Z100), em margens cervicais em dentina, apresentou maiores fendas marginais, antes e depois da termociclagem, que os outros grupos. Não houve diferença estatisticamente significante entre os grupos testados para margem em dentina. Os autores concluíram que a técnica sanduíche promove boa adaptação marginal e talvez seja uma alternativa para as restaurações adesivas com resina composta.

A capacidade de selamento de oito sistemas adesivos em restaurações classe II foi estudada, in vitro, por MELLO et al. ${ }^{63}$, em 1997, após ciclagem mecânica. Foram avaliados os seguintes sistemas adesivos: (OptiBond - Herculite XRV/Kerr; Scotchbond MP - Z100/3M; Prime \& Bond 2.0 - Prisma TPH/Dentsply; Clearfil Liner Bond 2 - Clearfil Photo Posterior/Kuraray Co; Pertac Universal Bond -Pertac Hybrid/ESPE; Imperva Bond-Lete - Fil II/Shofu; Syntac - Tetric/Vivadent; Gluma CPS - Pekafill NF/Bayer Dental). Oitenta pré-molares foram preparados, com a parede gengival localizada em dentina, restaurados com os sistemas já especificados. A metade de cada grupo foi submetida a carga oclusal (4.000 ciclos/ $2 \mathrm{~N}-125 \mathrm{~N}$ ) e depois imersa em solução corante por 48 horas. A outra metade apenas foi imersa em solução de azul de metileno, servindo assim como controle. Após seccionados, os dentes foram analisados por meio de microscopia óptica, com atribuição de escores. Os autores observaram que a penetração do corante foi maior nas margens cervicais em comparação com as margens oclusais, independentemente do sistema restaurador. Todas as restaurações com margens em dentina sofreram significativamente mais influência da ciclagem mecânica, comparadas com as margens oclusais em esmalte. Os autores concluíram que, para muitos sistemas adesivos, a contração de polimerização, isoladamente, não é capaz de promover desadaptação, necessitando de fatores coadjuvantes, como o estresse mecânico, que clinicamente é caracterizado pela carga mastigatória. Concluindo assim que a ciclagem mecânica é um critério eficaz para comparar as qualidades de vários sistemas restauradores. 
ALVES ${ }^{6}$, em 1998, avaliou, in vitro, a infiltração marginal em restaurações classe II de molares decíduos restaurados apenas com uma resina composta híbrida tradicional (Z100/3M), pela técnica de inserção horizontal ou com uma base de resina composta híbrida de baixa viscosidade (Natural Flow/DFL). Foram utilizados 10 molares decíduos, nos quais foram confeccionados preparos cavitários do tipo "slot" vertical, nas faces mesial e distal. No grupo 1, as restaurações foram feitas apenas com a resina Z100; e, no grupo 2, bases de resina Natural Flow foram confeccionas previamente à inserção da resina Z100. Os dentes foram termociclados ( 500 ciclos, $5^{\circ}-55^{\circ} \mathrm{C}, 30 \mathrm{~s}$ ), impermeabilizados e imersos, durante 4 horas, em solução de azul de metileno. Após lavados e incluídos em resina acrílica, foram submetidos a cortes, no sentido mésio-distal, e avaliados quanto à infiltração marginal. Os resultados demonstraram graus de infiltração para ambas as técnicas, não havendo diferença estatisticamente significativa entre as mesmas.

BAYNE et al. ${ }^{10}$, em 1998, avaliaram as propriedades mecânicas (viscosidade, desgaste, resistência à compressão, resistência à tensão diametral, resistência flexural biaxial e dureza) de 8 resinas de baixa viscosidade (Aelite flo/Bisco; CrystalEssence/Confi-Dental; FloRestore/Dent-Mat.; Flow-it/Jeneric Pentron, Revolution/Kerr; True-Look/Denpac; UltraSeal Xt Plus/Ultradent; Versaflo/centrix), usando como grupos de controle duas resinas convencionais (Prodigy/Kerr, Z100/3M). Os autores concluíram que nenhuma das resinas estudadas apresentou propriedades semelhantes às resinas convencionais, pois demonstraram menor resistência mecânica, embora alguns sistemas tenham demonstrado maior fluidez que as resinas convencionais. A resina Flow-It! apresentou maior conteúdo de fibras que as outras resinas testadas; apresentando resistências à compressão e à tensão diametral semelhantes às dos controles. Baseados nos resultados obtidos, os autores aconselharam que ainda é necessário cautela no uso desses compósitos e que, clinicamente, devem ter sua indicação 
limitada a áreas sujeitas a estresse, sendo bem indicadas como base de restaurações de Classe II.

ESTAFAN; ESTAFAN; ARTEAGA ${ }^{31}$, em 1998, avaliaram a microinfiltração de três resinas de baixa viscosidade: Flow-It! (Jeneric/Pentron), FloRestore (Den-Mat.) e Aelite-Flo (Bisco). Usaram como controle uma resina híbrida, TPH (TP). Foram preparadas cavidades Classe V em 60 dentes livres de cárie, divididos em 4 grupos, e restaurados de acordo com as recomendações dos fabricantes. Na seqüência, foi realizada termociclagem e armazenamento dos dentes em azul de metileno, por 24 horas. Após isso, os dentes foram seccionados com disco de diamante. A microinfiltração (a nível de esmalte, cemento e dentina) foi avaliada por escores. Os autores concluíram que as resinas fluidas analisadas demonstraram menor microinfiltração tanto em margens de esmalte quanto em cemento e dentina.

Em 1998, FARAH, POWERS ${ }^{33}$ avaliaram a resina condensável para dentes posteriores, Solitaire (KULZER) e observaram que 92\% dos clínicos aprovaram sua utilização, principalmente devido às boas características de manipulação e à facilidade para obtenção do ponto de contato. Embora todos os consultores tenham recomendado o uso de resinas fluidas como agente intermediário, principalmente nas paredes de fundo (gengival e axial) de cavidades Classe II.

Os mesmos autores, em $\mathbf{1 9 9 8}^{33}$, descreveram as características clínicas, as vantagens e as desvantagens de 3 resinas condensáveis (Solitaire/kulzer, Alert/Jeneric Pentron, SureFil/Dentsplay) em comparação com 2 resinas convencionais (Tetric Ceram/Vivadent e Z100/3M), em relação à quantidade de carga, à resistência à compressão, à contração de polimerização e ao módulo flexural das resinas condensáveis. Baseados nesse estudo, a DENTAL ADVISOR 
recomendou a SureFil e a Alert, além de sugerir o uso das resinas de baixa viscosidade como base para selamento de caixas proximais.

HOOD; LOO $^{50}$, em 1998, estudaram a microinfiltração nas margens cervicais de restaurações Classe II de resina composta, em relação à técnica de inserção empregada. Cavidades Classe II foram confeccionadas em 30 molares humanos extraídos e divididos para receber os seguintes tratamentos: grupo 1 único preenchimento/adesivo apenas em esmalte; grupo 2 - técnica incremental/adesivo apenas em esmalte; grupo 3 - único preenchimento/ adesivo em dentina e esmalte, técnica incremental/adesivo em dentina e esmalte; grupo 4 único preenchimento /adesivo em dentina com 2 polimerizações; grupo 5 - técnica incremental/adesivo em esmalte e dentina/ 2 passos de polimerização. Os espécimes foram restauradas com resina Z100 (3M) e submetidos a termociclagem e carga oclusal. Os autores concluíram que a melhor combinação para diminuir a microinfiltração foi a de incrementos com 2 passos de polimerização.

Com os avanços sofridos, as resinas compostas tornaram-se substancialmente melhores. Muitos dos problemas associados à fórmula original estão sendo resolvidos. Mas muitos dos problemas ainda não foram sanados. Procurando avaliar as condições clínicas de uma nova resina composta, LEINFELDER; RADZ; NASH et al. ${ }^{58}$ em 1998, compararam clinicamente duas restaurações, uma feita com uma resina híbrida e a outra feita com uma dita " condensável " (Solitaire/Kulzer). Utilizando uma cavidade do tipo MO no dente ${ }^{\circ}$ 15 , feita com broca do tipo carbide, restaurou o dente com a resina híbrida. No dente $\mathrm{n}^{\mathrm{o}} 14$, com a mesma broca, confeccionou uma cavidade do tipo MOD. Em ambas, utilizou matrizes metálicas; e os incrementos das resinas foram colocados utilizando instrumentos para amálgama, e polimerizados por 20 segundos. O último incremento foi polimerizado por 40 segundos e o polimento foi realizado com pontas específicas. Os contatos proximais foram checados através da inspeção 
visual e com a ajuda de fio dental. Os resultados obtidos revelaram que a resina Solitaire apresentou um melhor contato interproximal, se comparada à outra resina usada. Em relação ao tempo de trabalho, também apresentou maior rapidez quando da sua confecção. Concluíram os autores que a resina Solitaire pode ser utilizada com técnicas muito similares às das restaurações de amálgama, tendo como vantagem uma maior facilidade de condensação, e permitindo um excelente vedamento marginal, com boas características de resistência ao desgaste.

RADA $^{86}$, em 1998, discorreu sobre as resinas fluidas e sua versatilidade. Dentre suas diversas indicações como: pequenos reparos em restaurações de amálgama, porcelana e resinas compostas; pequenas restaurações classe I e II; restaurações classe III e V (lesões de erosão, abrasão e abfração); selamento de cicatrículas e fissuras; uma das mais importantes é seu uso como base cavitária. A indicação das resinas fluidas como base caracteriza-se pelo seu baixo módulo de elasticidade e viscosidade. Uma maior adaptação, de acordo com os autores, é conseguida pela fluidez dessas resinas, preenchendo melhor as irregularidades das paredes cavitária, com relativo aumento da resistência adesiva. Outra vantagem do uso dessas resinas como base é o seu baixo módulo de elasticidade, absorvendo assim os estresses causados na interface pela contração de polimerização e pelo esforço mastigatório. Assim, são materiais com certa versatilidade e que podem minimizar as microinfiltrações em restaurações classe I e II, quando empregadas como material de base.

WILLERSHAUSEN; ERNST; MARTIN ${ }^{107}$, em 1998, avaliaram o comportamento clínico de 175 restaurações Classes I e II feitas com Solitaire (Kulzer), em 85 pacientes, utilizando do critério de Gunner Ryge. Todas as restaurações foram executadas com matriz metálica, usando como sistema adesivo o Solid Bond (Kulzer) com condicionamento total. Apenas $48 \%$ das cavidades foram forradas com Ketac Bond (ESPE). Os autores concluíram que a Solitaire 
pareceu ser um material com boas propriedades clínicas, porém advertiram que as restaurações devem sempre ser feitas sobre um substrato totalmente condicionado.

A microinfiltração gengival em margens localizadas em dentina produzidas por 3 resinas condensáveis, com e sem utilização de técnica incremental, foi estudada por AFFLECK et al. ${ }^{4}$, em 1999. Oitenta preparos classe II padronizados, com margem cervical com $1 \mathrm{~mm}$ além da junção amelocementária, foram preparados nas faces mesial e distal de molares humanos. Todas as cavidades foram condicionadas com ácido fosfórico a 37\%, aplicado o adesivo Prime \& Bond 2.1. Sistemas restauradores com alta densidade de carga (Alert/Jeneric Pentron; Solitaire/Kulzer; Surefil/Dentsply; Heliomolar/Vivadent) foram inseridos em 20 cavidades, para cada resina estudada, utilizando-se a técnica incremental na metade delas. As amostras foram termocicladas e imersas em corante de nitrato de prata, seccionadas e avaliadas quanto à microinfiltração. Infiltração marginal foi encontrada na parede gengival, atingindo a parede axial, em todas as amostras restauradas com Surefil e Solitaire. Não houve diferença significante entre nenhuma das resinas condensáveis testadas, com ambas as técnicas de inserção. Os autores concluíram que a infiltração marginal não pareceu ser dependente do material ou da técnica de inserção utilizados com as resinas condensáveis.

COSTA et al. ${ }^{15}$, em 1999, estudaram a microinfiltração em cavidades classe $\mathrm{V}$ restauradas com 3 resinas de baixa viscosidade (Flow-it!/Jeneric Pentron; Flowit! LF/Jeneric Pentron; Natural Flow/DFL), tendo como controle um grupo restaurado com ionômero modificado por resina (Vitremer/3M). Cavidades classe $\mathrm{V}$ foram preparadas nas faces lingual e vestibular de 16 molares humanos com margens cervicais em dentina. As amostras foram divididas aleatoriamente em 4 grupos de 4 dentes e restauradas de acordo com as instruções do fabricante. Após polimento, todas as superfícies foram protegidas com selante de superfície (Protectit!/Jeneric Pentron). Após termociclagem $\left(5^{\circ}-55^{\circ} \mathrm{C} / 2\right.$ horas), os dentes foram 
imersos em solução de nitrato de prata a 50\%, seccionados longitudinalmente e avaliados pela penetração do corante, seguindo-se o critério de escores. Os resultados demonstraram que os grupos restaurados com Vitremer e Flow-it! demonstraram maior resistência à microinfiltração, quando comparados com os outros grupos.

FRANCCI et al. ${ }^{38}$, em 1999, estudaram o efeito da resina composta, sistema adesivo e base de resina fluida na microinfiltração. Quatro preparos classe II (nas faces mesial, distal, vestibular e lingual) foram feitos em 30 molares humanos. As cavidades foram divididas em 12 grupos, para receberem os sistemas adesivos Prime \& Bond 2.1/Dentsply, Prime \& Bond NT e um adesivo experimental do mesmo fabricante. Os espécimes foram subdivididos em 4 combinações de restauração: 1- Heliomolar (Vivadent) apenas; 2- Heliomolar e Flow-it! (Jeneric Pentron) como base; 3- Surefil (Dentsply); 4 Surefil e Flow-it! como base. Após finalizadas as restaurações, os espécimes foram subdivididos, para receberem ciclagem mecânica e ciclagem térmica. As amostras foram imersas em azul de metileno a $0,5 \%$, por 4 horas; seccionadas longitudinalmente em duas direções perpendiculares (mésio-distal e buco-lingual); e escaneadas, para serem avaliadas através de um programa de computador. O uso da Flow-it! como base resultou em menor infiltração marginal, não havendo diferença estatística entre os sistemas adesivos testados. Os autores concluíram que as resinas condensáveis apresentaram maior grau de infiltração que a resina composta microparticulada Heliomolar.

Uma revisão sobre resinas compactáveis foi feita por LEINFELDER; BAYNE; SWIFT JUNIOR ${ }^{59}$, em 1999. Os autores definiram novas terminologias, sumarizaram as diversas propriedades associadas as esses materiais, discutindo quais são as propriedades ideais para materiais a serem utilizados em regiões posteriores, além de avaliarem as características de manipulação desses materiais. Assim, definiram ser o termo compactável mais indicado que o termo 
condensável, sendo as mesmas mais uma alternativa para restaurações em dentes posteriores, não um substituto do amálgama. Detalharam as características manipulativas e as propriedades das resinas Solitaire (Hareaus Kulzer), SureFil (Dentsply) e ALERT (Jeneric/Pentron) e resumiram as propriedades físicomecânicas de diversas resinas compactáveis disponíveis no mercado, concluindo que em muitas delas não ocorreu considerável modificação quando comparadas às resinas compostas tradicionais.

MIRANDA et al. ${ }^{65}$, em 1999, avaliaram qual a influência da ciclagem mecânica na microinfiltração de restaurações classe II restauradas com resina de alta densidade de carga (Solitaire/Kulzer; Alert/Jeneric Pentron; Charisma F/), com e sem interposição de resina fluida ( Wave/SDI). Cento e vinte cavidades MO e DO com limite cervical em dentina foram preparadas em molares humanos, divididos em dois grupos de 60 dentes, para receberem dois diferentes adesivo, Single Bond ou Etch \& Prime 3.0. Em cada grupo, vinte cavidades foram restaurada com Alert; outras vinte, com Solitaire; e as vinte restantes, com Charisma F (controle). Na metade de cada subgrupo foi aplicada a resina fluida como base. Todas as restaurações foram termocicladas $\left(750\right.$ ciclos, $\left.5^{\circ}-55^{\circ} \mathrm{C}\right)$, e a metade dos dentes de cada condição experimental foi submetida a ciclagem mecânica (100.000 ciclos, 8 $\mathrm{kg}$ ). Os espécimes foram imersos em azul de metileno a 0,5\%, seccionados e avaliados pela penetração do corante, seguindo-se o critério de escores. Os resultados mostraram que a infiltração foi maior quando os espécimes foram submetidos a ciclagem mecânica. Não houve diferença estatisticamente significativa entre as resinas condensáveis e a resina tradicional. A resina fluida não exerceu influência sobre o selamento marginal. Para os autores, dentro das limitações dos estudos in vitro, o uso de resinas condensáveis (com e sem interposição de resina fluida) não previne infiltração marginal em cavidades classe II com margens em dentina. 
OLIVEIRA $^{71}$, em 1999, avaliou, in vitro, a microinfiltração e a ação anticariogênica nas restaurações com sistema adesivo/resina composta (Glacier/Southerm) e nas associações com compômeros (Freedom/ Southerm, F200/3M, Dyract/Dentsply) ou ionômero de vidro modificado por resina (Vitremer/3M) em cavidades classe II amplas (MOD) com margem cervical $1 \mathrm{~mm}$ abaixo ou acima da junção amelocementária. Foram realizados 110 preparos em pré-molares e molares, para serem restaurados apenas com a resina ou seguindo a técnica de sanduíche aberto, com os compômeros e ionômeros apresentando altura de $2 \mathrm{~mm}$ na parede gengival. Os dentes foram submetidos a ciclagem mecânica (1kg-17 kg, 10 ciclos diários, 7dias), imersos em fucsina básica a 0,5\%, seccionados; escolhido o corte mais infiltrados de cada dente, escaneado e transferido para o programa de computador ImageTool. Á área de infiltração foi calculada pelo programa em $\mathrm{mm}^{2}$. Os resultados demonstraram que os dentes restaurados com a associação Vitremer/resina apresentaram menores áreas infiltradas nas margens cavitárias em dentina e em esmalte, em comparação com as demais associações. Com relação ao desafio cariogênico, realizado através de luz polarizada, demonstrou que as restaurações mistas e com o sistema adesivo/resina utilizadas nesse estudo apresentaram menores áreas desmineralizadas nas margens cavitárias em esmalte.

Em 1999, PEREIRA ${ }^{76}$ avaliou, in vitro, a infiltração marginal em cavidades classe II restauradas com dois tipos de resinas compostas, sobre o efeito do carregamento oclusal e de técnicas de inserção. Cavidades classe II (MOD) padronizadas foram preparadas em 180 molares, sendo que a parede gengival em uma caixa proximal ficou localizada em dentina e na outra, em esmalte. Os dentes foram divididos em três grupos de 60 dentes, de acordo com o sistema adesivo e com a resina inserida (Solidbond P e S - Solitaire/Kulzer; Snapbond/Cooley \& Cooley - Z100/3M; Singlebond - Z100/3M). Para cada grupo de 60 dentes, três técnicas de inserção foram empregadas: técnica A - inserção da resina em uma 
única porção por caixa (três incrementos); técnica B - incrementos dispostos diagonalmente (dois incrementos por caixa); técnica $\mathrm{C}$ - incremento simulando o esmalte proximal, dois incrementos diagonais até a altura do ângulo áxio-pulpar e dois incrementos até a altura da crista marginal; totalizando 20 dentes para cada condição, dos quais apenas 10 dentes foram submetidos a estresse mecânico (1 kg $17 \mathrm{~kg}, 70$ ciclos, 35 minutos). Para o teste de microinfiltração, os espécimes foram imersos em fucsina básica a 0,5\%; e a penetração do corante, avaliada por escores. Os resultados mostraram uma grande infiltração nas amostras submetidas a estresse mecânico, nas margens localizadas em dentina. Os espécimes restaurados com a técnica A apresentaram grandes índices de infiltração, quando comparados aos outros espécimes restaurados com as outras duas técnicas. A resina Solitaire, em todas as condições testadas, apresentou-se ineficiente em conter a infiltração. Para a resina Z100, no grupo onde foi utilizado o SingleBond, adesivo do mesmo fabricante, a infiltração foi ainda menor. No entanto, nenhum sistema ou técnica foi capaz de bloquear completamente a infiltração.

PERRY; KUGEL; LEINFELDER ${ }^{\mathbf{7 8}}$, em 1999, avaliaram o desempenho clínico de restaurações com a resina condensável SureFil (Dentsply), com 1 ano de vida útil. Foram realizadas 25 restaurações inseridas em cavidades Classe II, em primeiros e segundos molares, em pacientes com idades de 21 a 45 anos. Todos os pacientes incluídos nesse estudo apresentavam moderado ou baixo risco de cárie, boas condições periodontais e de higiene. Não mais que duas restaurações foram inseridas num mesmo paciente. Todos os dentes do estudo apresentavam-se em função e com oclusão normal; apresentando resposta favorável aos teste de sensibilidade pulpar, percussão e palpação, e imagem radiográfica condizente com a normalidade. Cavidades classe II foram confeccionadas e restauradas com o sistema resinoso SureFil/Primer \& Bond 2.1. Todas as restaurações foram fotografadas e moldadas, com finalidade de comparar com aspectos posteriores. Para avaliação do desempenho clínico, um ano após a inserção das restaurações, 
foram realizadas radiografias para verificar a presença de cárie secundária e a qualidade do contato proximal. Para verificar a qualidade do ponto de contato, uma fita de poliéster foi utilizada para medir a resistência oferecida. O índice Alfa/Bravo foi utilizado para classificar a restauração (Alfa $=$ excelente/ Bravo $=$ satisfatório/ Charlie $=$ insatisfatório). As diferenças inter e intra-examinadores foram analisadas com índice Kappa, que apresentou alto grau de confiança (85\%). As características analisadas durante o exame foram: retenção da restauração, estabilidade de cor, integrid ade marginal, textura de superfície, infiltração, desgaste, sensibilidade pósoperatória, saúde dos tecidos moles, manutenção do ponto de contato e presença de cárie secundária. No exame inicial, apenas dois dentes apresentaram sensibilidade pós-operatória. Tal sensibilidade desapareceu completamente na segunda semana e nenhum outro caso de sensibilidade foi constatado. Os exames clínicos foram realizados após 3, 6, 9 e 12 meses. Nesse estudo, o SureFil, material restaurador de alta densidade para dentes posteriores, demonstrou aceitável desempenho clínico em todas as categorias examinadas

RUSSELL; MAZER ${ }^{92}$, 1999, determinaram a extensão de infiltração em cavidades classe II restauradas com resina composta (Z100/3M), com interposição de base de resina fluida (Aelite Flo/Bisco, Florestore/, Tetric Flow/Vivadent). Cavidades classe II (MO ou DO) foram confeccionadas em 48 molares humanos, divididos em 4 grupos de 12 dentes, com 24 restaurações tendo as margens cervicais localizadas $1 \mathrm{~mm}$ aquém do cavo-superficial gengival . Os grupos foram restaurados usando a técnica incremental e seguindo as especificações dos fabricantes. Os grupos foram os seguintes: controle - onde apenas a resina Z100 foi aplicada com o adesivo específico; e grupos experimentais - onde cada uma das resinas fluidas foi aplicada com posterior emprego do sistema restaurador da resina Z100. Posteriormente às restaurações, os dentes foram submetidos a estresse mecânico $(100.000$ ciclos, $70 \mathrm{~N})$ e ciclagem térmica $\left(250\right.$ ciclos, $\left.5^{\circ}-55^{\circ} \mathrm{C}\right)$. Os espécimes foram seccionados no sentido mésio-distal para quantificação da 
infiltração, seguindo-se o critério de escores. Os resultados demonstraram que houve uma diferença estatisticamente significativa entre os graus de infiltração nas paredes oclusais, comparado o grupo controle com os demais grupos; essa diferença não foi encontrada, entretanto, nas paredes gengivais. Os autores concluíram que as resinas fluidas testadas não foram capazes de reduzir a infiltração ao longo da parede gengival, onde o esmalte é deficiente em termos de qualidade e de quantidade.

A adaptação marginal e a microinfiltração de restaurações classe II, com e sem interposição de base de ionômero de vidro (CIV), foram avaliadas por THONEMANN et al. ${ }^{101}$, em 1999. Sessenta molares humanos foram utilizados, nos quais foram confeccionadas cavidades classe II (OP) para serem restauradas com os seguintes sistemas restauradores: Syntac - Tetric/Vivadent; Gluma 2000 Pekafil/Bayer; Gluma - Pekafil/Bayer; Scotchbond Multi Purpose - Z100/3M e AllBond 2 - Bisfil P/Bisco. Doze dentes foram restaurados com cada sistema, sendo que em 6 (metade) era aplicada base de ionômero de vidro (Ketac Bond/ESPE) nas paredes axial e pulpar. Para o teste de adaptação marginal, foram feitas moldagens, antes e depois da aplicação do estresse térmico (5.000 ciclos, $\left.8^{\circ}-55^{\circ} \mathrm{C} / 30 \mathrm{~s}\right)$ e mecânico (500.000 ciclos, 72,5 N/1,6 Hz), para obtenção das réplicas e análise em microscópio eletrônico de varredura. Após as moldagens, os dentes foram sujeitos ao teste de microinfiltração com imersão dos mesmos em fucsina básica a 0,5\%, por 16 horas, a $37^{\circ} \mathrm{C}$. Com relação à adaptação marginal e à microinfiltração, os sistemas Scotchbond MP - Z100 e All-Bond 2 - Bisfil mostraram menor formação de fendas e infiltração marginal, após termociclagem, quando comparados às suas associações com base de CIV. Os autores concluíram que a redução da microinfiltração, em margens em dentina, pode ser alcançada apenas com utilização de alguns sistemas adesivos de última geração, sem necessidade de se interpor base de CIV. 
UNTERBRINK; LIEBENBERG ${ }^{105}$, em 1999, numa revisão de literatura, levantaram o uso de resinas de baixa viscosidade como alternativa para dissipação de tensões na interface adesiva. Os autores discorreram sobre os testes para análise da resistência adesiva, além de relatarem a evolução dos agentes de união. Foram abordados fatores relevantes na tentativa de minimizar o estresse gerado pela contração de polimerização como: preocupação com a geometria das cavidades, aplicação correta das técnicas, bem como conhecimento das características dos materiais restauradores. Dentre as formas de minimizar o estresse na interface, foi indicado o uso de resinas fluidas, levando-se em conta o conceito da "parede cavitária elástica”, que nada mais é que a aplicação de uma fina camada de resina de baixa viscosidade nas paredes cavitárias. Para os autores, a espessura e o baixo módulo dessas resinas são capazes de melhorar a adaptação, além de absorver o estresse gerado pela contração de polimerização na interface adesiva

YAMAUTI ${ }^{109}$, em 1999, avaliou a microinfiltração marginal de restaurações em resina composta, nas quais foram utilizadas duas técnicas de inserção do material e cinco formas de fotoativação distintas. Cavidades de classe $\mathrm{V}$ foram confeccionadas para serem restauradas com o sistema resinoso Single Bond/Z00 (3M) de 10 formas diferentes. G1 - inserção única com fotoativação a uma intensidade máxima $\left(560 \mathrm{~mW} / \mathrm{cm}^{2}\right)$; G2 - inserção única, partindo de uma intensidade mínima $\left(180 \mathrm{~mW} / \mathrm{cm}^{2}\right)$ com fotoativação gradual até atingir a intensidade máxima; G3 - inserção única com fotoativação gradual a partir de intensidade média $\left(280 \mathrm{~mW} / \mathrm{cm}^{2}\right)$ até alcançar a máxima; G4, G5 e G6 - inserção incremental e fotoativação de acordo com G1, G2 e G3, respectivamente; G7 inserção única com uma distância inicial de $10 \mathrm{~cm}$ entre a extremidade da ponta ativa da unidade fotoativadora até atingir a superfície da restauração (distância zero); G8 - inserção única com distância inicial de $5 \mathrm{~cm}$ até atingir uma distância zero; G9 e G10 - inserção incremental com a mesma forma de ativação que os grupos G7 e G8, respectivamente. Os espécimes foram submetidos a 
termociclagem $\left(500 \mathrm{x}, 5^{\circ} \mathrm{C}\right.$ e $\left.55^{\circ} \mathrm{C}, 30 \mathrm{~s}\right)$, imersos em solução de nitrato de prata a $50 \%$, seccionados; escolhido os cortes de maior infiltração, estes foram escaneados. A imagem digitalizada foi transferida para um programa de computador (ImageTool); e a extensão linear de infiltração, calculada em milímetros. Os resultados demonstraram que as formas de inserção e de fotoativação independem entre si no que se refere à infiltração marginal. A técnica incremental demonstrou um menor índice de infiltração em relação à técnica de inserção em incremento único. O método de fotoativação gradual, partindo de uma intensidade de luz média até atingir uma intensidade máxima, demonstrou os menores índices de infiltração. A técnica de fotoativação gradual, de forma geral, apresentou baixos índices de infiltração em relação à técnica convencional.

BATITUCCI et al. ${ }^{9}$, em 2000, avaliaram os efeitos da associação entre resina fluida e resina composta tradicional na microinfiltração em restaurações classe II. Dois preparos classe II (slot vertical) foram preparados em 20 terceiros molares, totalizando 40 cavidades. Após condicionamento com ácido fosfórico a $37 \%$, por 15 segundos, as cavidades foram lavadas e aplicado o sistema adesivo Prime \& Bond NT (Dentsply), de acordo com as instruções do fabricante. Os dentes foram divididos em 4 grupos: grupo 1- Flow-it! (Jeneric Pentron) + Surefil (Dentsply); grupo 2- Surefil; grupo 3- Flow-it! + Definite (Degussa); grupo 4 Definite. Após restaurados, os dentes foram estocados em água destilada por 24 horas. Depois foram polidos, termociclados $\left(500\right.$ ciclos, $\left.5^{\circ}-55^{\circ} \mathrm{C}\right)$, selados e imersos em solução de nitrato de prata a 50\%, por 24 horas. Após seccionados, os dentes foram avaliados, seguindo-se o critério de escores. Baseados nos resultados, os autores concluíram que as resinas de baixa viscosidade, quando associadas à Surefil e à Definite, foram eficientes na redução da microinfiltração em restaurações classe II. 
CHUANG; LIU; JIN ${ }^{14}$, em 2000, investigaram a influência de resinas fluidas, como base, em restaurações classe II, na microinfiltração e na adaptação marginal, determinando a correlação entre os dois métodos de avaliação do selamento marginal. Quarenta e oito (48) molares foram preparados, com caixas proximais, mesial e distal. Os dentes foram divididos em 4 grupos, restaurados com: Prodigy (Kerr); Prodigy/Revolution (Kerr); Tetri Ceram (Vivadent); Tetric Ceram/Tetric Flow (Vivadent). Os agentes adesivos de cada resina foram utilizados previamente às restaurações. Foram realizadas termociclagem (1500 ciclos, $5^{\circ}$ $60^{\circ} \mathrm{C}$ ) e estocagem em fucsina básica a $2 \%$, por 24 horas. A adaptação marginal e a microinfiltração foram avaliadas através de estereomicroscópio. Os resultados mostraram que não houve diferença estatisticamente significativa entre os grupos onde foi e onde não foi utilizada a resina fluida como base. Dentre os 4 grupos, aquele onde Prodigy/Revolution foi utilizado apresentou melhor selamento marginal. Os grupos onde as resinas fluidas foram aplicadas mostraram menor número de fendas na interface dente-restauração. Não houve correlação significativa entre os resultados de adaptação marginal e de microinfiltração. Os autores concluíram que a presença de resina fluida pode melhorar a adaptação, contudo a microinfiltração pode não ser influenciada.

HAGGE et al. ${ }^{46}$, em 2000, avaliaram a infiltração marginal de restaurações classe II de resina composta com interposição de 5 materiais intermediários. Preparos classe II foram feitos em 60 molares, com margens gengivais localizadas $1 \mathrm{~mm}$ além do limite amelocementário. Quatro grupos de 12 dentes foram condicionados por 20 segundos, lavados pelo mesmo tempo, e gentilmente secados. Prime \& Bond NT (Debtsply) foi aplicado e polimerizado; a resina Surefil foi aplicada em 2 incrementos, polimerizados por 40 segundos. Esse tratamento foi repetido em 3 grupos adicionais, porém com a inclusão de material intermediário de resina fluida (Revolution/E\&D), de compômero fluido (Dyract Flow/Dentsply) e de resina de polimerização química (Bisfil 2B/Bisco). O quinto grupo de dentes 
foi condicionado com ácido poliacrílico, por 10 segundos, lavado e seco; aplicado o ionômero de vidro modificado por resina Fuji II LC (GC) e fotopolimerizado para posterior aplicação da resina como nos grupos supra-especificados. Os dentes foram termociclados $\left(1.000\right.$ ciclos, $\left.5^{\circ}-55^{\circ} \mathrm{C}\right)$, selados e imersos em fucsina básica a 5\%, por 24 horas. Depois, seccionados para análise da microinfiltração. Os resultados demonstraram que nas restaurações onde o ionômero de vidro modificado por resina foi aplicado como base, a infiltração marginal foi significativamente menor que nos demais grupos. Os autores concluíram que a microinfiltração é significativamente menor na técnica em que o cimento de ionômero de vidro é aplicado em associação com a resina composta.

Uma recente revisão sobre as resinas compostas “condensáveis" foi realizada por JACKSON; MORGAN ${ }^{51}$, em 2000. Os autores descreveram as características das novas resinas, com suas propriedades físicas e manipulativas. Apesar das indicações dos fabricantes quanto a técnica de inserção e fotopolimerização de incrementos de até $5 \mathrm{~mm}$, os autores descrevem técnicas incrementais que acreditam ser mais seguras. Quanto à fotopolimerização, indicam incrementos menores para minimizar os efeitos da contração de polimerização e a sensibilidade pós-operatória e para garantir uma total polimerização. Acreditam na melhoria das propriedades das resinas, quando associadas aos, também novos, adesivos dentinários, que têm mostrado bons resultados. Clinicamente, consideram as novas técnicas, que utilizam as resinas ditas “condensáveis", mais fáceis e rápidas.

A microinfiltração marginal de duas resinas compostas condensáveis (Alert/Jeneric Pentron; Solitaire/Kulzer) e de uma resina composta tradicional (Z100/3M) foi avaliada por PRAKKI; CILLI; de ARAÚJO ${ }^{\mathbf{8 2}}$ em 2000. Quinze molares humanos livres de cárie foram utilizados. Preparos classe II (MOD) foram feitos em cada dente. A parede gengival de uma das caixas proximais foi localizada em esmalte; e, a outra, em dentina. Os dentes foram divididos em 3 grupos de 5 
dentes cada um: grupo A - restaurado com Alert; grupo S- restaurado com Solitaire; e grupo Z restaurado com Z100. Os espécimes foram termociclados, imersos em solução de nitrato de prata a $50 \%$ por 2 horas e seccionados, para avaliação por 3 examinadores calibrados, através de atribuição de escores. Nenhum dos sistemas testados foi capaz de prevenir a microinfiltração em ambas as margens avaliadas. $\mathrm{O}$ grupo $\mathrm{Z}$ apresentou, em esmalte, uma infiltração mínima.

No livro sobre estética: fundamentos e aplicações clínicas, SILVA e SOUZA Jr.; CARVALHO; MODELLI ${ }^{96}$, em 2000, enfocaram os as restaurações em resina composta de inserção direta, nas regiões anterior e posterior da cavidade bucal, dando ênfase aos fundamentos para realização desses das mesmas e chamando a atenção para aspectos mecânicos, biológicos e estéticos. Foi descrita a evolução das resinas compostas de inserção direta e sua evolução; chegando às novas tendências, as resinas compostas ditas "condensáveis" para restaurações em dentes posteriores, avaliando suas propriedades e aspectos de manipulação. Outro foco da discussão foi a diversidade das associações de materiais com as resinas compostas, visando ao aprimoramento da técnica restauradora, como as associações com ionômero de vidro, resina fluida, resina composta ativada quimicamente, compômeros, dentre outros. Os autores avaliam que, dentre os materiais utilizados em associações com resina composta, parece ser mais vantajosa a utilização de ionômero de vidro como base, em cavidades onde a margem gengival acha-se desprovida de esmalte.

Em 2000, a microinfiltração de resinas compostas condensadas, com e sem a interposição de resinas fluidas, em restaurações classe II, foi avaliada por TUNG; ESTEFAN; HSIEH ${ }^{103}$. Quarenta e cinco molares humanos foram utilizados no estudo, nos quais foram confeccionados preparos classe II com margem cervical a $1 \mathrm{~mm}$ do cavo-superficial gengival, localizando-se em dentina. Os dentes foram divididos aleatoriamente em 3 grupos: grupo 1- restaurados com Alert (Jeneric 
Pentron); grupo 2- restaurados com Alert + Flow-it! (Jeneric Pentron) como base; grupo 3- restaurados com Heliomolar (Vivadent), como controle. Todos os materiais foram colocados de acordo com as recomendações dos fabricantes. Realizou-se termociclagem (500 ciclos, $\left.5^{\circ}-55^{\circ} \mathrm{C}, 30 \mathrm{~s}\right)$ em todos os dentes, depois imersos na solução corante de fucsina básica a $0,2 \%$ por 24horas. Após as amostras terem sidos seccionadas, a penetração do corante foi analisada em microscópio com aumento de 30X. Os resultados mostraram microinfiltração significativamente menor nos espécimes onde a resina fluida foi utilizada como base.

TUNG, ESTAFAN; SCHERER ${ }^{104}$, em 2000, propuseram-se a investigar a infiltração marginal em dentes posteriores restaurados com Surefil (Dentsply). Sessenta cavidades classe II foram realizadas em molares humanos com margem cervical além da junção amelocementária. Os dentes foram divididos, aleatoriamente, em 4 grupos de 15 dentes, restaurados de acordo com as recomendações do fabricante. Grupo 1 - Surefil+Prime \& Bond NT (Dentsply); grupo 2 - Surefil+PQI (Ultradent); grupo 3 - Surefil+PremaFlow (Ultradent) +PQI; grupo 4 - Heliomolar (Vivadent) + Syntac single componet (Vivadent), como controle. Os espécimes foram termociclados $\left(500\right.$ ciclos, $\left.5^{\circ}-55^{\circ} \mathrm{C}\right)$, imersos em fucsina básica a $0,2 \%$ por 24 horas, seccionados longitudinalmente e horizontalmente, para avaliação da penetração de corante, fazendo-se uso de microscópio com aumento de 30X. Os resultados desse estudo indicaram que o grupo 3 mostrou significantemente menos infiltração que os grupos 1, 2 e 4 . Os autores concluíram que resinas fluidas, quando usadas como base, demonstraram resistência na microinfiltração em margens de esmalte e de dentina. 
3-Proposição 


\section{3 - PROPOSIÇÃO}

Avaliar, in vitro, o efeito da interposição de resina fluida (Flow-It! ${ }^{\star}$ ) ou de ionômero de vidro modificado por resina (Vitremer") na microinfiltração ocorrida em cavidades Classe II (MOD); com margens em esmalte e em dentina, restauradas com sistemas resinosos para dentes posteriores (P60/Single Bond ${ }^{\star}$; Solitaire/Gluma One Bond ${ }^{\circledR}$; SureFil/Prime \& Bond 2.1\%); considerando-se as seguintes hipóteses:

$\checkmark \quad$ O cimento de ionômero de vidro modificado por resina, usado como base, diminui a infiltração marginal em margens localizadas em esmalte e dentina.

$\checkmark \quad$ As resina de baixa viscosidade, usada como base, diminui a infiltração marginal em margens localizadas em esmalte e dentina.

$\checkmark \quad$ A infiltração marginal é consideravelmente maior em margens localizadas em dentina que em margens localizadas em esmalte. 


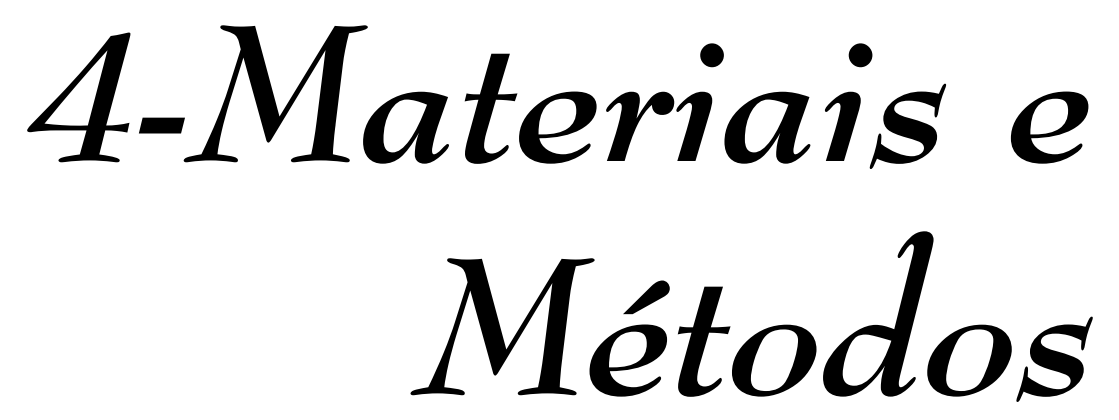




\section{4 - MATERIAIS E MÉTODOS}

\section{1 - OBTENÇÃO E PREPARO DOS DENTES.}

Foram utilizados 90 pré-molares humanos extraídos, isentos de cárie, sem trincas ou defeitos estruturais. Os dentes foram devidamente armazenados, em solução fisiológica com cristais de timol, sob refrigeração, até o momento dos testes, não excedendo o período de 5 meses. Antes do acondicionamento, realizou-se a limpeza das superfícies com espátula Lecron", seguida de uma profilaxia com escova de Robinson** e taça de borracha** com pedra pomes e água.

Cavidades tipo Classe II (MOD) foram padronizadas nas seguintes dimensões:

Caixa oclusal - largura vestíbulo-lingual de $2,5 \mathrm{~mm}$ e profundidade de $2 \mathrm{~mm}$.

Caixa proximal - parede cervical, na caixa mesial, localizada $1 \mathrm{~mm}$ abaixo da junção amelo-cementária (JAC) e, na caixa distal, 1 mm acima da JAC; com largura de $3 \mathrm{~mm}$ e profundidade de $1,5 \mathrm{~mm}$.

As dimensões foram devidamente controladas por meio de sonda milimetrada* e de paquímetro***, delimitando o preparo previamente, com a utilização de ponta grafite de $0,5 \mathrm{~mm}$.

Os preparos foram executados com turbina de alta velocidade (Rool-Air-3), sob refrigeração constante, com brocas carbide $n^{0} 245^{* *}$ em baixa velocidade com micromotor $^{\star}$ (tipo INTRAmatic) e contra-ângulo ${ }^{\star}$ (Tipo 1:1), aplicando-se movimentos intermitentes, também com brocas carbide $n^{\circ} 245^{* *}$. Para acabamento, foram utilizados também os instrumentos cortantes manuais do tipo recortadores de margem gengival*, machados* e enxadas*. As brocas foram substituídas a

\footnotetext{
* Dental Duflex, Juiz de Fora, Minas Gerais, Brasil.

** K G Sorensen Indústria e Comércio Ltda.

*** Starret do Brasil.

$\uparrow$ Kavo do Brasil S/A.
} 
cada 5 preparos. Após terminados, os preparos foram tratados com uma solução detergente (tergentol ${ }^{\dagger}$ ).

Após finalizados os preparos, as cavidades apresentavam as seguintes características:

\section{CAIXA OCLUSAL}

$\checkmark$ Paredes convergentes para oclusal;

$\checkmark$ Ângulos internos arredondados;

$\checkmark$ Profundidade de $2 \mathrm{~mm}$ do cavo-superficial;

$\checkmark$ Abertura vestíbulo-lingual de 2,5 mm;

$\checkmark$ Ângulo cavo-superficial nítido e sem bisel.

\section{CAIXAS PROXIMAIS}

$\checkmark$ Paredes vestibular e lingual convergentes para oclusal;

$\checkmark$ Ângulos internos arredondados;

$\checkmark$ Parede gengival plana no sentido vestíbulo-lingual;

$\checkmark$ Profundidade de $1,5 \mathrm{~mm}$;

$\checkmark$ Parede axial convergente para oclusal;

$\checkmark$ Abertura vestíbulo-lingual de $3 \mathrm{~mm}$;

$\checkmark$ Parede gengival mesial localizada $1 \mathrm{~mm}$ além da JAC;

$\checkmark$ Parede gengival distal localizada $1 \mathrm{~mm}$ aquém da JAC;

$\checkmark$ Ângulo cavo-superficial nítido e sem bisel. 


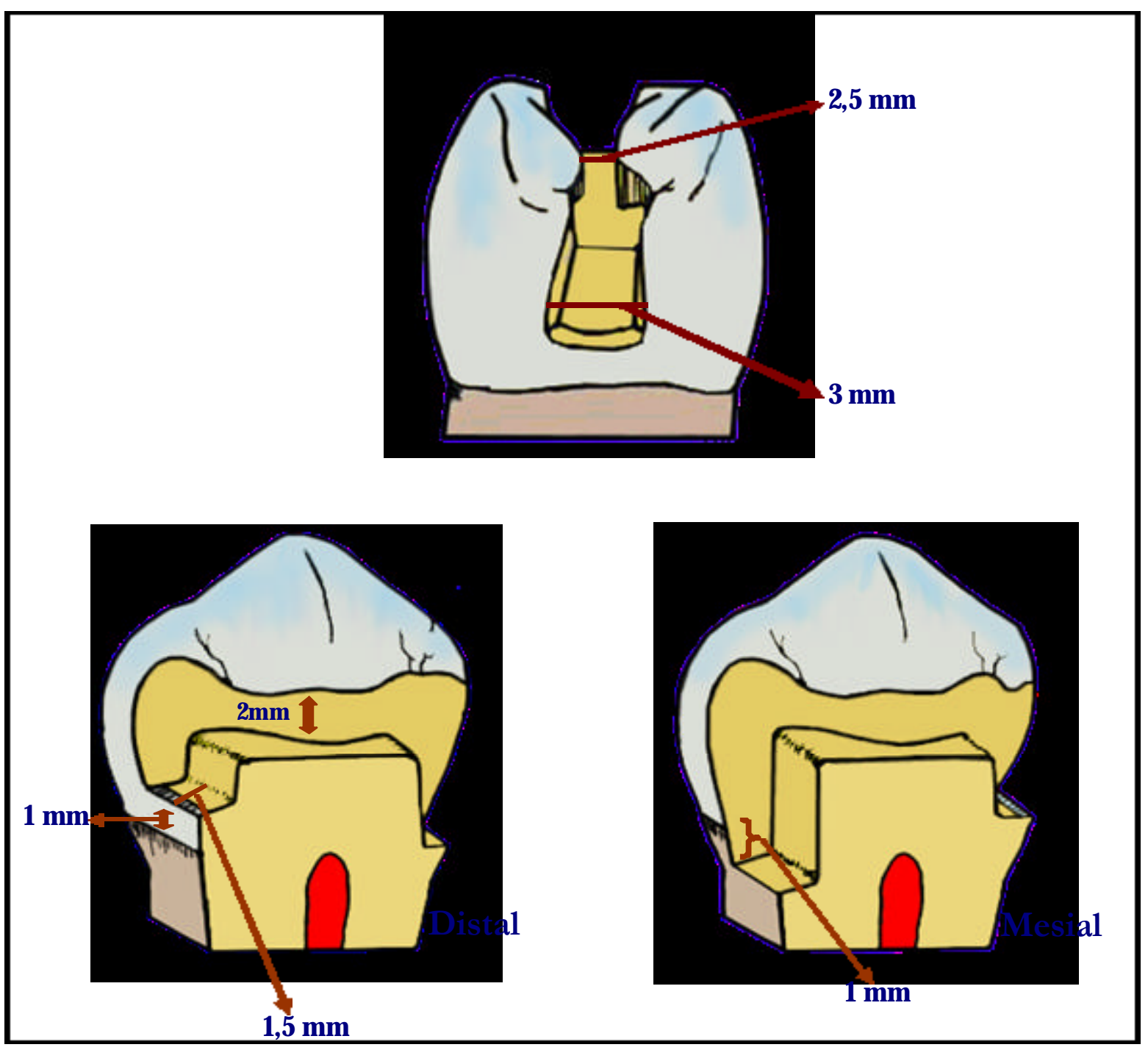

FIGURA 4.1 - Ilustração das característicdss cavidade. 


\section{2 - MATERIAIS RESTAURADORES AVALIADOS}

As Figuras $4.2 ; 4.3 ; 4.4 ; 4.5 ; 4.6$ e 4.7 apresentam os materiais utilizados na pesquisa com informações sobre a cor, a composição, o número do lote e seu fabricante.

\begin{tabular}{|c|c|c|c|}
\hline MATERIAL/COR & COMPOSIÇÃO & LOTE & FABRICANTE \\
\hline $\begin{array}{l}\text { P60 } \\
\text { Cor: A3 }\end{array}$ & $\begin{array}{l}\text {-Bis-GMA, TEGDMA UDMA e } \\
\text { Bis-EMA, iniciadores, } \\
\text { estabiliza-dores; } \\
\text {-Zircônia/Sílica (84\% em peso); } \\
\text {-TMP*: } 0.19-3.3 \mu \mathrm{m} .\end{array}$ & 32 & $\begin{array}{l}\text { 3M do Brasil Ltda - } \\
\text { Produtos Dentários. }\end{array}$ \\
\hline $\begin{array}{l}\text { Single Bond } \\
\text { Primer/Adesivo }\end{array}$ & $\begin{array}{l}-\mathrm{H}_{2} \mathrm{O} \text {, etanol, HEMA, Bis- } \\
\text { GMA, dimetacrilatos, ácido } \\
\text { politacôni-co, fotoiniciadores. }\end{array}$ & 9DP & $\begin{array}{l}\text { 3M do Brasil Ltda - } \\
\text { Produtos Dentários. }\end{array}$ \\
\hline
\end{tabular}

*TMP: Tamanho Médio de Partícula.

FIGURA 4.2 - Filtek $^{\mathrm{TM}}$ P60 Posterior Restorative System.

\begin{tabular}{|c|c|c|c|}
\hline MATERIAL/COR & $\overline{\text { COMPOSIÇÃO }}$ & LOTE & FABRICANTE \\
\hline $\begin{array}{l}\text { Solitaire } \\
\text { Cor: A3 }\end{array}$ & $\begin{array}{l}\text {-Polividro/Bis-GA, HPMA, } \\
\text { ETMA, iniciadores, estabili- } \\
\text { zadores; } \\
\text {-Vidros de bário-flúor-alumínio- } \\
\text { boro-silicato, óxido de silício } \\
\text { poroso (66\% em peso); } \\
\text {-TMP*: } 2.2 \mu \mathrm{m} .\end{array}$ & $9 \mathrm{~B} 5$ & $\begin{array}{l}\text { HARAEUS KULZER } \\
\text { South America Ltda. }\end{array}$ \\
\hline $\begin{array}{l}\text { Gluma One Bond } \\
\text { Primer/adesivo }\end{array}$ & $\begin{array}{l}\text {-Metacrilatos, acetona } \mathrm{e} \\
\text { iniciadores. }\end{array}$ & 125624 & $\begin{array}{l}\text { HARAEUS KULZER } \\
\text { South America Ltda. }\end{array}$ \\
\hline
\end{tabular}

*TMP: Tamanho Médio de Partícula.

FIGURA 4.3 - SOLITAIRE ${ }^{\circledR}$. 


\begin{tabular}{|l|l|l|l|}
\hline MATERIAL/COR & \multicolumn{1}{|c|}{ COMPOSIÇÃO } & LOTE & \multicolumn{1}{|c|}{ FABRICANTE } \\
\hline SureFil & $\begin{array}{l}\text {-BisGMA e UDMA modificado; } \\
\text {-Flúor-alumínio-silicato; vidro } \\
\text { de bário (82\% em peso); } \\
\text {-TMP*: } 0.8 \mu \mathrm{m} .\end{array}$ & $\begin{array}{l}\text { DENTSPLY Indústria e } \\
\text { Comércio Ltda. }\end{array}$ \\
\hline $\begin{array}{l}\text { Primer \& Bond 2.1 } \\
\text { Primer/Adesivo }\end{array}$ & $\begin{array}{l}\text {-Resinas PENTA, } \\
\text { elastoméricas, } \\
\text { hidrofluoreto de cetilamina, } \\
\text { fotoiniciadores, acetona. }\end{array}$ & 49566 & $\begin{array}{l}\text { DENTSPLY Indústria e } \\
\text { Comércio Ltda. }\end{array}$ \\
\hline
\end{tabular}

*TMP: Tamanho Médio de Partícula.

FIGURA 4.4 - SureFil ${ }^{\mathrm{TM}}$ High Density Posterior Restaurative.

\begin{tabular}{|l|l|l|l|}
\hline MATERIAL/COR & \multicolumn{1}{|c|}{ COMPOSIÇÃO } & LOTE & FABRICANTE \\
\hline Flow-It! & -BisGMA & 18939 & JENERIC/ PENTRON \\
-Vor: A2 & $\begin{array}{l}\text {-Vidro de boro-flúor-silicato de } \\
\text { boro (55\% em volume); } \\
\text {-TMP*: } 0,04-4 \mu \mathrm{m} .\end{array}$ & & \\
\hline $\begin{array}{l}\text { Bond 1 } \\
\text { Primer/Adesivo }\end{array}$ & $\begin{array}{l}\text {-PMGDM, HEMA, Bis-GMA, } \\
\text { fotoiniciadores, acetona. }\end{array}$ & 18769 & $\begin{array}{l}\text { JENERIC/ PENTRON } \\
\text { Incorporated - USA. }\end{array}$ \\
\hline
\end{tabular}

*TMP: Tamanho Médio de Partícula.

FIGURA 4.5 - Flow-It! ${ }^{\mathrm{TM}}$ Light Cure Flowable Composite.

\begin{tabular}{|c|c|c|c|}
\hline MATERIAL/COR & COMPOSIÇÃO & LOTE & FABRICANTE \\
\hline $\begin{array}{l}\text { Vitremer }^{\mathrm{TM}} \\
\text { Power } \\
\text { Cor: A3. }\end{array}$ & $\begin{array}{l}\text {-Vidro de silicato de flúor- } \\
\text { alumínio, persulfato de sódio, } \\
\text { ácido ascórbico. }\end{array}$ & $\begin{array}{l}9167 \\
0 \mathrm{AA}\end{array}$ & $\begin{array}{l}\text { 3M do Brasil Ltda - } \\
\text { Produtos Dentários. }\end{array}$ \\
\hline $\begin{array}{l}\text { Vitremer }^{\mathrm{TM}} \\
\text { Liquid }\end{array}$ & $\begin{array}{l}\text {-Solução aquosa de ácido } \\
\text { polialquenóico modificado, } \\
\text { HEMA, fotoiniciadores, } \mathrm{H}_{2} \mathrm{O} \text {. }\end{array}$ & 19981216 & $\begin{array}{l}\text { 3M do Brasil Ltda - } \\
\text { Produtos Dentários. }\end{array}$ \\
\hline $\begin{array}{l}\text { Vitremer }^{\mathrm{TM}} \\
\text { Primer }\end{array}$ & $\begin{array}{l}\text {-Polímero de ácido poliacrílico, } \\
\text { HEMA, álcool. }\end{array}$ & 19990115 & $\begin{array}{l}\text { 3M do Brasil Ltda - } \\
\text { Produtos Dentários. }\end{array}$ \\
\hline
\end{tabular}

FIGURA 4.6 - Vitremer ${ }^{\mathrm{TM}}$ Core Buildup/Restorative. 


\begin{tabular}{|l|l|l|l|}
\hline MATERIAL/COR & \multicolumn{1}{|c|}{ COMPOSIÇÃO } & LOTE & \multicolumn{1}{|c|}{ FABRICANTE } \\
\hline Conditionador & -Ácido fosfórico a 37\%; & 50026 & $\begin{array}{l}\text { DENTSPLY Indústria e } \\
\text { Dental Gel }\end{array}$ \\
& $\begin{array}{l}\text {-Tamponado óxido de zinco. } \\
\mathrm{pH}=0,2 .\end{array}$ & & \\
\hline
\end{tabular}

FIGURA 4.7 - Conditionador Dental Gel.

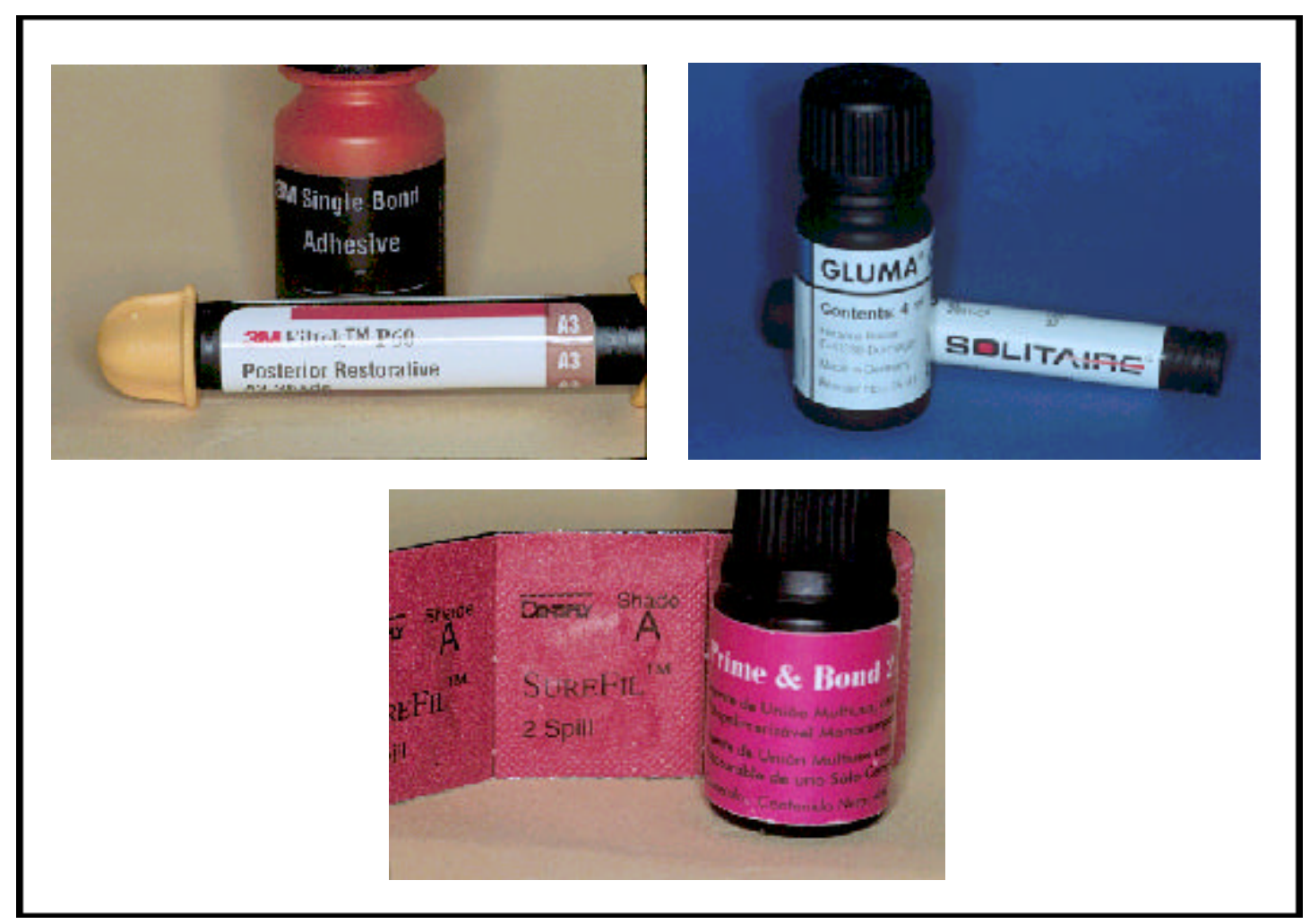

FIGURA4.8 - Resinas restauradoras e respectivos adesivos avaliandqsesquisa.

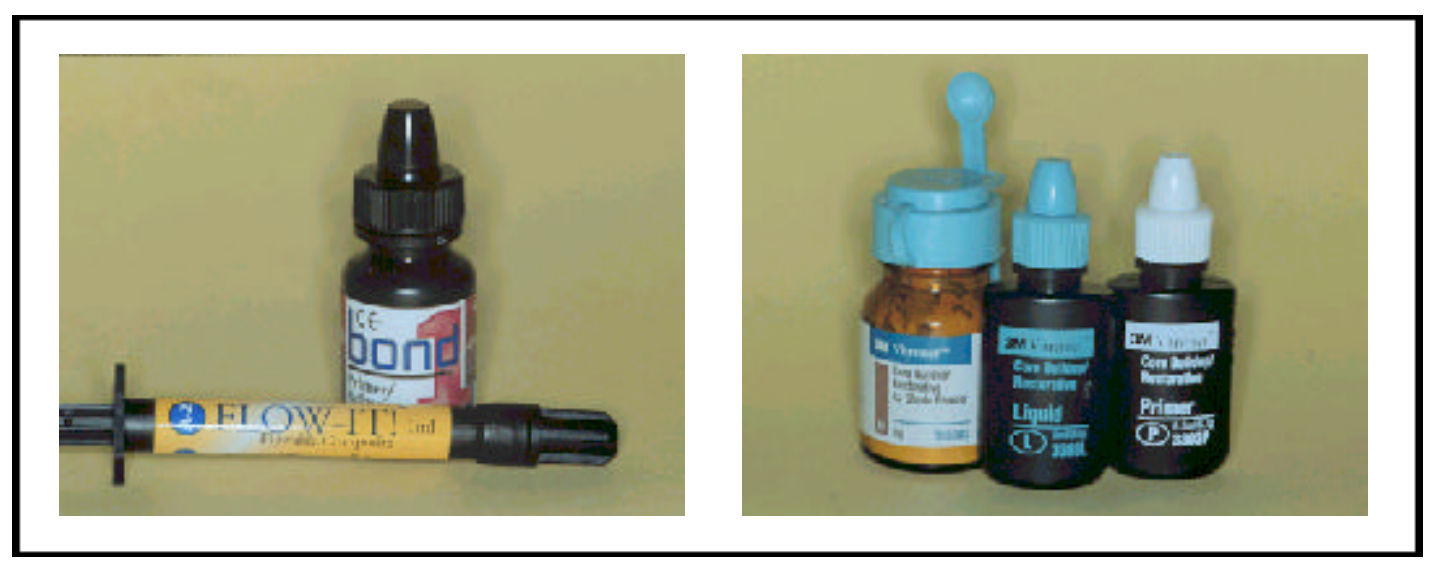

FIGURA 4.9- Materiais empregados como base e avaliadøpesquisa. 


\section{3 - PROCEDIMENTOS RESTAURADORES}

Os dentes, após preparados, foram separados aleatoriamente em 9 grupos de 10 dentes cada, para receber tratamentos, ilustrado na Figura 4.10.

\begin{tabular}{|c|c|c|c|c|}
\hline \multicolumn{2}{|c|}{ GRUPO } & $\begin{array}{c}\text { MATERIAL } \\
\text { RESTAURADOR (MR) }\end{array}$ & $\begin{array}{c}\text { AGENTE } \\
\text { INTERMEDIÁRIO (AI) }\end{array}$ & SISTEMA ADESIVO \\
\hline \multirow{2}{*}{\multicolumn{2}{|c|}{ I }} & \multirow[t]{2}{*}{$\begin{array}{l}\mathrm{P} 60^{\mathscr{1}} \\
(3 \mathrm{M})\end{array}$} & \multirow[t]{2}{*}{$\begin{array}{l}\text { Flow-It!! } \\
\text { (Jeneric/Pentron) }\end{array}$} & $\begin{array}{c}\mathrm{MR}^{(4)}-\text { Single Bond } \\
(3 \mathrm{M})\end{array}$ \\
\hline & & & & $\begin{array}{l}\mathrm{AI}^{(5}-\text { Bond } 1 \\
\quad \text { (Jeneric/Pentron) }\end{array}$ \\
\hline \multirow{2}{*}{\multicolumn{2}{|c|}{ II }} & \multirow[t]{2}{*}{$\begin{array}{l}\text { Solitaire }^{\circledR} \\
\text { (Haraeus Kulzer) }\end{array}$} & \multirow[t]{2}{*}{$\begin{array}{l}\text { Flow-It!! } \\
\text { (Jeneric/Pentron) }\end{array}$} & $\begin{array}{r}\text { MR }^{\oplus} \text {-Gluma One Bond } \\
\text { (Haraeus Kulzer) }\end{array}$ \\
\hline & & & & $\begin{array}{l}\mathrm{AI}^{(5)}-\text { Bond } 1 \\
\quad \text { (Jeneric/Pentron) }\end{array}$ \\
\hline \multirow{2}{*}{\multicolumn{2}{|c|}{ III }} & \multirow[t]{2}{*}{$\begin{array}{l}\text { SureFil }^{(1)} \\
\text { (Dentsply) }\end{array}$} & \multirow[t]{2}{*}{$\begin{array}{l}\text { Flow-It!! } \\
\text { (Jeneric/Pentron) }\end{array}$} & $\begin{array}{l}\text { MR }^{\oplus} \text {-Prime \& Bond } 2.1 \\
\text { (Dentsply) }\end{array}$ \\
\hline & & & & $\begin{array}{l}\mathrm{AI}^{(5)}-\text { Bond } 1 \\
\quad(\text { Jeneric/Pentron })\end{array}$ \\
\hline IV & \multirow{3}{*}{ 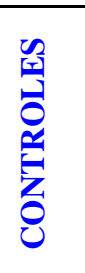 } & $\begin{array}{l}\mathrm{P} 60^{(1)} \\
(3 \mathrm{M})\end{array}$ & Sem agente intermediário & $\begin{array}{c}\mathrm{MR}^{\Phi}-\text { Single Bond } \\
(3 \mathrm{M})\end{array}$ \\
\hline $\mathbf{V}$ & & $\begin{array}{l}\text { Solitaire }^{(1)} \\
\text { (Haraeus Kulzer) }\end{array}$ & Sem agente intermediário & $\begin{array}{c}\mathrm{MR}^{(\Phi)} \text { - Gluma One Bond } \\
\text { (Haraeus Kulzer) }\end{array}$ \\
\hline $\begin{array}{l}\text { VI } \\
\end{array}$ & & $\begin{array}{l}\text { SureFil }^{\mathbb{1}} \\
\text { (Dentsply) }\end{array}$ & Sem agente intermediário & $\begin{array}{c}\mathrm{MR}^{\Phi}-\text { Prime \& Bond } 2.1 \\
\text { (Dentsply) }\end{array}$ \\
\hline \multirow{2}{*}{\multicolumn{2}{|c|}{ VII }} & \multirow[t]{2}{*}{$\begin{array}{l}\mathrm{P} 60^{11} \\
(3 \mathrm{M})\end{array}$} & \multirow[t]{2}{*}{$\begin{array}{l}\text { Vitremer }^{(3)} \\
(3 \mathrm{M})\end{array}$} & $\begin{array}{c}\mathrm{MR}^{\oplus}-\text { Single Bond } \\
(3 \mathrm{M})\end{array}$ \\
\hline & & & & 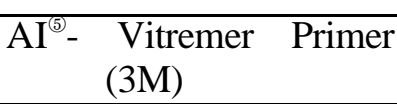 \\
\hline \multirow{2}{*}{\multicolumn{2}{|c|}{ VIII }} & \multirow[t]{2}{*}{$\begin{array}{l}\text { Solitaire }^{(\mathbb{1}} \\
\text { (Hareus Kulzer) }\end{array}$} & \multirow[t]{2}{*}{$\begin{array}{l}\text { Vitremer }^{(3)} \\
(3 \mathrm{M})\end{array}$} & $\begin{array}{c}\text { MR }^{\otimes} \text { - Gluma One Bond } \\
\text { Hareus Kulzer }\end{array}$ \\
\hline & & & & $\begin{array}{cc}\mathrm{AI}^{(5)}-\text { Vitremer } \\
(3 \mathrm{M})\end{array}$ \\
\hline \multirow{2}{*}{\multicolumn{2}{|c|}{ IX }} & \multirow[t]{2}{*}{$\begin{array}{l}\text { SureFil }{ }^{1 / 2} \\
\text { (Dentsply) }\end{array}$} & \multirow[t]{2}{*}{$\begin{array}{l}\text { Vitremer }^{3} \\
(3 \mathrm{M})\end{array}$} & $\begin{array}{l}\text { MR }{ }^{\oplus} \text { - Prime \& Bond } 2.1 \\
\text { (Dentsply) }\end{array}$ \\
\hline & & & & $\begin{array}{c}\mathrm{AI}^{(5)} \text { - Vitremer Primer } \\
(3 \mathrm{M})\end{array}$ \\
\hline
\end{tabular}

(1)Resinas para dentes posteriores.

(2) Resina de baixa viscosidade.

(3)Ionômero de vidro modificado por resina composta.

(4) Sistema Adesivo do Material Restaurador.

(5)Sistema Adesivo do Agente Intermediário.

FIGURA 4.10 - Grupos classificados em função dos materiais e agentes intermediários empregados. 


\subsection{1 - GRUPOS I, II e III}

Após preparados, os dentes receberam tratamento ácido (Conditionador Dental $\mathrm{Ge}^{*}$ ) na dentina, correspondente às paredes de fundo (axial e pulpar) e paredes circundantes (gengivais), tomando-se o cuidado (com auxílio de lupa 10x) de só aplicar o gel ácido, onde seria inserida a resina de baixa viscosidade (Flow$\left.\mathrm{It}^{(}\right)$, sendo a $1 \mathrm{~mm}$ do cavo superficial na caixa mesial e ao nível da JAD caixa distal. Os passos do condicionamento ácido da dentina, bem como a aplicação do adesivo, seguiram as instruções dos fabricantes com relação ao tempo, às condições de umidade, ao número de camadas e à forma de polimerização.

Cuidados foram tomados, no momento da aplicação, para que a área a receber $\mathrm{o}$ adesivo Bond $1^{\star}$ correspondesse apenas às paredes condicionadas para receber a resina Flow-It! ${ }^{\oplus}$.

Após os passos de tratamento da dentina e da aplicação do adesivo, os dentes receberam matrizes de poliéster para pré-molares*, devidamente ajustadas para a posterior aplicação da resina. A resina Flow-It! ${ }^{\star}$ foi inserida, por intermédio de sua ponta aplicadora, até o nível de $0,8 \mathrm{~mm}$ acima da parede pulpar que era conferida através de uma sonda milimetrada antes do procedimento de fotopolimerização, para que posteriormente à regularização essa base tivesse uma espessura de $\pm 0,5 \mathrm{~mm}$. Posteriormente, foi realizado o processo de fotopolimerização, seguindo o princípio de polimerização gradual ${ }^{95,}{ }^{96}$, utilizando-se o aparelho fotopolimerizador ${ }^{{ }^{3}}$, aferido na potência de $640 \mathrm{~mW} / \mathrm{cm}^{2}$, utilizando um radiômetro $\bullet$. A ponta do fotopolimerizador foi mantida a uma distância de $1 \mathrm{~cm}$ da superfície oclusal por um tempo de $10 \mathrm{~s}$. Em seguida, a resina foi fotopolimerizada pelo tempo recomendado pelo fabricante $(40 \mathrm{~s})$. Essa ativação, porém, foi realizada com a ponta do fotopolimerizador na proximidade da superfície oclusal do dente, de modo que, ao final, a resina fosse fotopolimerizada

\$DENTSPLY Indústria e Comércio Ltda.

๘ JENERIC PENTRON Incorporated - USA.

\$ TDV Dental Ltda.

3M Dental Products Division St. Paul MV/ 3 Curing Light 2500 (Model 55600AA 120V .50/60Hz).

Demetron Research Corp. SyeOlde Road, Danbury. 
por um tempo máximo de $50 \mathrm{~s}$ (10 segundos iniciais e 40 segundos adicionais).

Após o processo de fotoativação, as matrizes foram removidas e iniciou-se a retirada dos excessos de resina, que porventura houvessem permanecido nas margens da restauração e que pudessem prejudicar a visualização do cavo-superficial. Esse procedimento foi realizado com lâminas de bisturi ${ }^{\times}$( $\mathrm{n}^{\mathrm{os}} 11$ e 12). Posteriormente, o material intermediário $\left(\right.$ Flow-It $^{\star}$ ) foi regularizado, fazendo-se uso de brocas carbide $\mathrm{n}^{\mathrm{o}}$ 245** em baixa velocidade, com micromotor (tipo INTRAmatic) e contra-ângulo ${ }^{\star}$ (Tipo 1:1). Esse processo possibilitou o acabamento da cavidade com a remoção de possíveis resquícios de adesivo e resina das paredes circundantes. Ao final, o material intermediário deveria estar localizado no nível da junção amelo-dentinária (JAD) da parede gengival na caixa proximal distal, e a $1 \mathrm{~mm}$ do cavo-superficial na caixa proximal mesial, conforme ilustrado na Figura 4.11. Para garantir um bom acabamento, instrumentos cortantes manuais* (recortadores de margem gengival, machados e enxadas) também foram utilizados nessa fase do teste, para garantir uma boa adaptação e união entre o material restaurador e o remanescente dental, com a menor interferência possível do sistema restaurador intermediário.

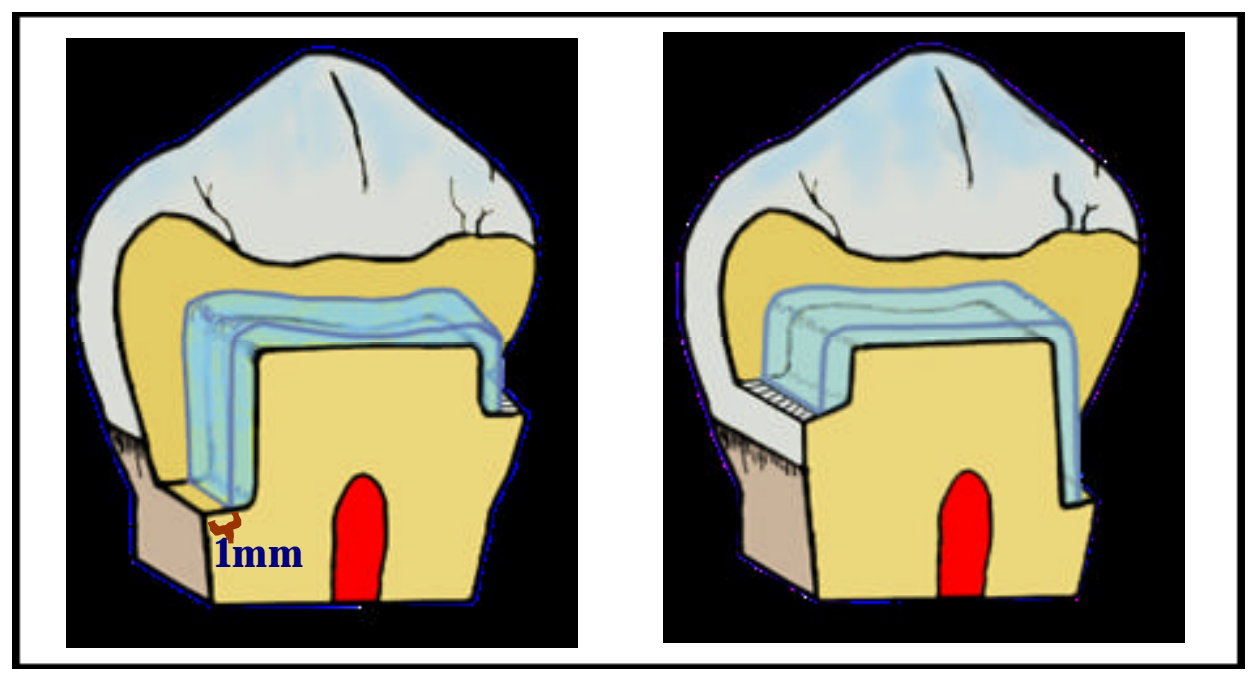

FIGURA4.11 - Ilustração da localização gengival dos materiais intermediários empregados na pesquisa.

X BectonDickson Indústria Brasileira.

\JENERIC PENTRON IncorporatedUSA.

** K G Sorensen Indústria e Comércio Ltda.

$\uparrow$ Kavo do Brasi S/A.

* Dental Duflex., Juiz de Fora, Minas Gerais, Brasil. 
Após a regularização do material intermediário (Flow-It! $\left.\right|^{\star}$ ), todos os dentes receberam condicionamento total (esmalte, dentina e material de base) com ácido fosfórico a $37 \%$ (Condicionador Dental Gel${ }^{*}$ ), por 30 segundos no esmalte e por 15 segundos na dentina e no material intermediário. Foram lavados com jatos de ar/água, também por 30 segundos, e o excesso de umidade foi removido com papel absorvente, de modo que a superfície cavitária apresentasse um leve brilho, que indicasse a presença de certa umidade. Os adesivos foram aplicados em toda a cavidade, de acordo com cada material, seguindo-se as especificações dos fabricantes quanto ao número de camadas, ao modo de aplicação e ao tempo de fotopolimerização, como pode ser verificado nas Figuras 4.13, 4.14, 4.15 e 4.16, que resumem a sequiência de utilização de cada sistema restaurador resinoso empregado na pesquisa.

$\mathrm{O}$ excesso de adesivo foi eliminado com um pincel seco, para evitar seu acúmulo, principalmente nos ângulos; e um leve jato de ar foi aplicado de maneira indireta e à distância para eliminar possíveis excessos de solvente. Finalmente, a fotoativação foi então executada por intermédio do aparelho fotopolimerizador ${ }^{3}$.

Matrizes de poliéster para pré-molares foram novamente ajustadas para que os materiais restauradores (Figura 4.10) fossem aplicados. Para tal, foi respeitado o princípio de inserção incremental da resina, por meio de condensação do material, fazendo-se uso de espátulas anti-aderentes para inserção de resinas*. Os incrementos (1-1,5mm) foram inseridos de forma diagonal, como na Figura 4.12, sendo os mesmos fotopolimerizados por 10s iniciais a uma distância de $1 \mathrm{~cm}$ da superfície oclusal do dente, e pelo tempo adicional recomendado pelo fabricante com a ponta do fotopolimerizador o mais próximo possível do material restaurador. Esse procedimento visou respeitar o fator de configuração cavitária, permitindo a liberação de tensões provenientes da contração de polimerização ${ }^{13,95,96}$, minimizando seus efeitos. A inserção foi iniciada pela caixa proximal mesial

3M Dental Products Division St. Paul MV/3 Curing Light 2500 (Model 55600AA 120V .50/60Hz).

TDV Dental Ltda.

$\star$ Hu-Fredi. 
com margem em dentina. Ao final, foram realizados 04 incrementos. Conforme já foi mencionado, os incrementos foram inseridos de forma diagonal, evitando o contato simultâneo da resina com paredes opostas (V e L), sendo o primeiro incremento das caixas proximais e oclusal envolvendo inicialmente a parede vestibular, como verificado na Figura 4.12. A caixa proximal distal, recebeu 02 incrementos e a caixa oclusal 03 incrementos (Figura 4.12).

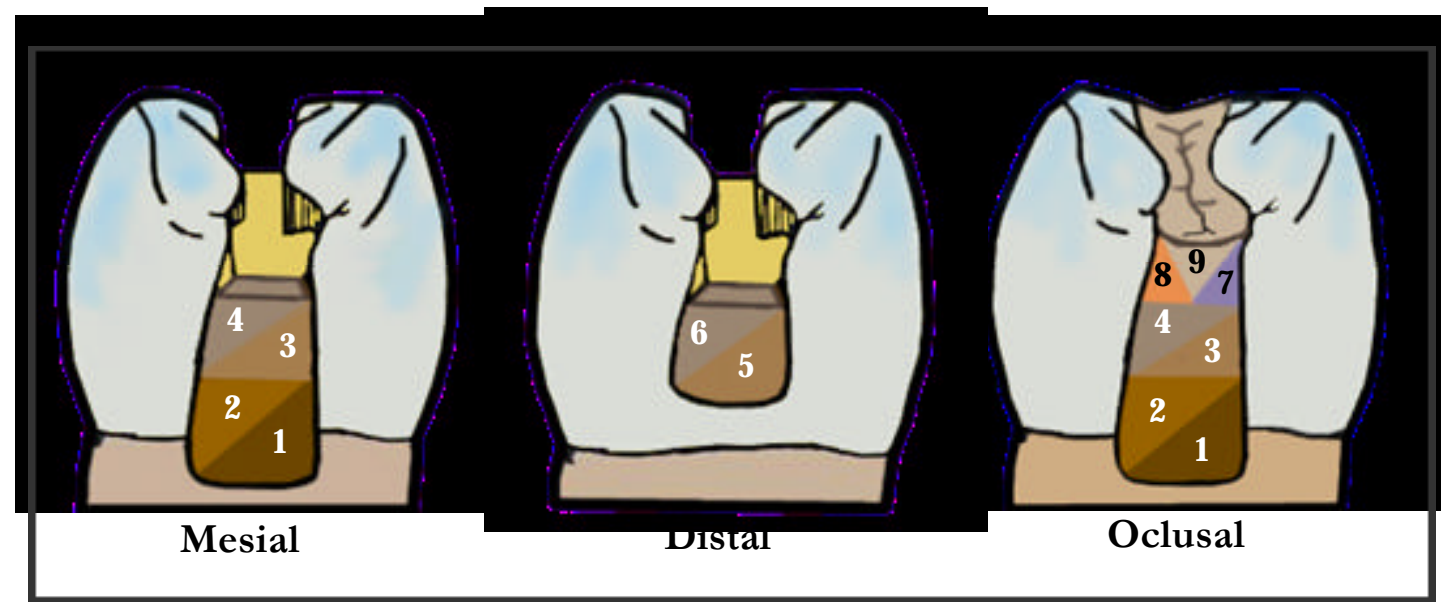

FIGURA 4.12 - Ilustração da seqüência de inserção das resinas em incrementos distal (4 incrementos), mesial ( 2 incrementos) e oclusal ( 3 incrementos).

\begin{tabular}{|c|c|}
\hline RESINA/ADESIVO & SEQÜÊNCIA RESTAURADORA \\
\hline $\begin{array}{l}\text { Single Bond } \\
\text { Primer/Adesivo }\end{array}$ & $\begin{array}{l}1 \quad \text { Ataque ácido - } 30 \text { s (esmalte), } 15 \text { s (dentina); } \\
2 \text { Lavagem - } 30 \text { s; } \\
3 \text { Secagem - papel absorvente; } \\
4 \text { Aplicação do adesivo - duas camadas consecutivas; } \\
5 \text { Secagem - leve ( } 2-5 \mathrm{~s}) ; \\
6 \text { Fotopolimerização - } 10 \mathrm{~s} \text {; } \\
\text { Obs.: Nova camada foi aplicada quando a superfície não se } \\
\text { apresentou brilhante. }\end{array}$ \\
\hline P60 & $\begin{array}{l}1 \text { Aplicação do material - camadas de } \pm 1,5 \mathrm{~mm} ; \\
2 \text { Fotopolimerização Gradual: } \\
10 \mathrm{~s} / \mathrm{a} \text { uma distância de } 1 \mathrm{~cm} \text { da superfície oclusal; } \\
20 \mathrm{~s} / \text { nas proximidades da superfície. }\end{array}$ \\
\hline
\end{tabular}

FIGURA 4.13- Seqüência restauradora do sistema Filtek $^{\mathrm{TM}}$ P60 Posterior Restorative System/3M do Brasil Ltda - Produtos Dentários. 


\begin{tabular}{|c|c|}
\hline RESINA/ADESIVO & SEQÜÊNCIA RESTAURADORA \\
\hline $\begin{array}{l}\text { Gluma One Bond } \\
\text { Primer/Adesivo }\end{array}$ & $\begin{array}{ll}1 & \text { Ataque ácido - } 30 \mathrm{~s} \text { (esmalte), } 15 \mathrm{~s} \text { (dentina); } \\
2 & \text { Lavagem - } 30 \mathrm{~s} ; \\
3 & \text { Secagem - papel absorvente; } \\
4 & \text { Aplicação do adesivo - duas camadas consecutivas; } \\
5 & \text { Secagem - leve }(5 \mathrm{~s}) ; \\
6 & \text { Fotopolimerização - } 20 \mathrm{~s} ; \\
\text { Obs.: Nova camada foi aplicada quando a superfície não se } \\
\text { apresentou brilhante. }\end{array}$ \\
\hline Solitaire & \begin{tabular}{|l} 
Aplicação do material - camadas de $\pm 1,5 \mathrm{~mm} ;$ \\
Fotopolimerização Gradual: \\
$10 \mathrm{~s} /$ a uma distância de $1 \mathrm{~cm}$ da superfície oclusal; \\
$40 \mathrm{~s} /$ nas proximidades da superfície.
\end{tabular} \\
\hline
\end{tabular}

FIGURA 4.14 - Sequiência restauradora do sistema SOLITAIRE ${ }^{\circledR} /$ HARAEUS KULZER South America Ltda.

\begin{tabular}{|c|c|}
\hline RESINA/ADESIVO & SEQÜÊNCIA RESTAURADORA \\
\hline $\begin{array}{l}\text { Primer \& Bond } 2.1 \\
\text { Primer/Adesivo }\end{array}$ & $\begin{array}{ll}1 & \text { Ataque ácido - } 30 \text { s (esmalte), } 15 \mathrm{~s} \text { (dentina); } \\
2 & \text { Lavagem - } 30 \mathrm{~s} ; \\
3 & \text { Secagem - papel absorvente; } \\
4 & \text { Aplicação do adesivo - duas camadas com intervalo entre elas; } \\
5 & \text { Secagem - leve }(5 \mathrm{~s}) ; \\
6 & \text { Fotopolimerização - } 20 \mathrm{~s} ; \\
\text { Obs.: Nova camada foi aplicada quando a superfície não se } \\
\text { apresentou brilhante. }\end{array}$ \\
\hline SureFil & $\begin{array}{l}1 \text { Aplicação do material - camadas de } \pm 1,5 \mathrm{~mm} ; \\
2 \text { Fotopolimerização Gradual: } \\
10 \mathrm{~s} / \text { a uma distância de } 1 \mathrm{~cm} \text { da superfície oclusal; } \\
40 \mathrm{~s} / \text { nas proximidades da superfície. }\end{array}$ \\
\hline
\end{tabular}

FIGURA 4.15 - Seqüência restauradora do sistema SureFil ${ }^{\mathrm{TM}}$ High Density Posterior Restaurative/Dentsply Indústria e Comércio Ltda. 


\begin{tabular}{|c|c|}
\hline RESINA/ADESIVO & SEQÜÊNCIA RESTAURADORA \\
\hline $\begin{array}{l}\text { Bond } 1 \\
\text { Primer/Adesivo }\end{array}$ & \begin{tabular}{|ll}
1 & Ataque ácido - $30 \mathrm{~s}$ (esmalte), $15 \mathrm{~s}$ (dentina); \\
2 & Lavagem - $30 \mathrm{~s} ;$ \\
3 & Secagem - papel absorvente; \\
4 & Aplicação do adesivo - duas camadas com intervalo de $10 \mathrm{~s}$ \\
& entre elas; \\
5 & Secagem - leve (mínimo $10 \mathrm{~s}) ;$ \\
6 & Fotopolimerização - $10 \mathrm{~s} ;$ \\
7 & Aplicação do adesivo remanescente no pincel - sem \\
& polimerizar \\
Obs.: Nova camada foi aplicada quando a superfície não se \\
apresentou brilhante
\end{tabular} \\
\hline Flow-It! & \begin{tabular}{|l} 
Aplicação do material - ponta aplicadora; \\
2 Fotopolimerização Gradual: \\
10 s/ a uma distância de $1 \mathrm{~cm}$ da superfície oclusal; \\
40 s/ nas proximidades da superfície.
\end{tabular} \\
\hline
\end{tabular}

FIGURA 4.16 - Sequiência restauradora do sistema Flow-It! ${ }^{\mathrm{TM}}$ Light Cure Flowable Composite/ Jeneric Pentron.

\subsection{2 - GRUPOS IV, V e VI}

Nesses grupos como já descrito na Figura 4.10, não foi feita a utilização de bases. Após o preparo e a limpeza, os dentes receberam condicionamento ácido total (esmalte e dentina), adesivo, de acordo com as recomendações do fabricante do produto; e foram restaurados segundo os passos já descritos para os grupos I, II e III. 


\subsection{3 - GRUPOS VII, VIII e IX}

Após preparados e limpos os dentes receberam uma camada de Primer (Vitremer Primer") nas paredes de fundo (axial e pulpar) e paredes circundantes (gengivais) sem condicionamento prévio, mantido por 30 segundos. Em seguida, foi fotopolimerizado por 20 segundos, como pode ser verificado na figura de resumo da seqüência restauradora do sistema (Figura 4.17).

Como nos grupos I, II e III, os dentes receberam matrizes de poliéster para pré-molares*, devidamente ajustadas para a posterior aplicação do ionômero. $\mathrm{O}$ ionômero (Vitremer") foi manipulado em uma placa de vidro, seguindo-se a proporção recomenda (1:1 pó/líquido), por um tempo máximo de 45 segundos de espatulação, controlado por meio de um cronômetro. O material foi inserido em pontas de seringa Centrix • (pontas accudose anterior) até o nível de 0,8 mm acima da parede pulpar. Posteriormente foi realizado o processo de fotopolimerização, utilizando-se o aparelho fotopolimerizador ${ }^{*}$. A respectiva ponta foi mantida o mais próximo possível da superfície pelo espaço de tempo recomendado pelo fabricante (40 s).

Passado o processo de fotopolimerização, as matrizes foram removidas e iniciou-se a remoção dos excessos de ionômero, para posterior regularização do material intermediário (Vitremer ) e acabamento do preparo, à semelhança dos grupos I, II e III

Terminada essa fase, as cavidades foram novamente condicionadas, aplicados os respectivos sistemas adesivos, adaptadas as matrizes de poliéster e restauradas as cavidades conforme já descrito para os grupos anteriores.

3M Dental Products Division St. Paul MV/3 Curing Light 2500 (Model 55600AA 120V 50/60Hz). 


\begin{tabular}{|c|c|}
\hline IONÔMERO & SEQÜÊNCIA RESTAURADORA \\
\hline $\begin{array}{l}\text { Vitremer }^{\mathrm{TM}} \\
\text { Primer }\end{array}$ & $\begin{array}{ll}1 & \text { Aplicação do primer - durante } 30 \mathrm{~s} ; \\
2 & \text { Secagem - leve }(15 \mathrm{~s}) \\
3 & \text { Fotopolimerização - } 20 \mathrm{~s}\end{array}$ \\
\hline $\begin{array}{l}\text { Vitremer }^{\mathrm{TM}} \\
\text { Liquid/Vitremer }^{\mathrm{TM}} \\
\text { Primer }\end{array}$ & $\begin{array}{ll}1 & \text { Manipulação do material - pó/líquido na proporção de } 1: 1 ; \\
& \text { manipulação por, no máximo, } 45 \mathrm{~s} ; \\
2 & \text { Aplicação do material - seringa Centrix; } \\
3 & \text { Fotopolimerização: } \\
40 & \text { s/ nas proximidades da superfície }\end{array}$ \\
\hline
\end{tabular}

FIGURA 4.17 - Sequiência de aplicação do material de base Vitremer ${ }^{\mathrm{TM}}$ (Core Buildup/Restorative) 3M do Brasil Ltda - Produtos Dentários.

Finalizados os passos restauradores todos os dentes foram armazenados em água deionizada, a temperatura de $37^{\circ} \mathrm{C}$, por 6 dias. Após isso, foram submetidos a acabamento e polimento, utilizando-se lâminas de bisturi ${ }^{\mathbf{x}} \mathrm{n}^{\mathrm{os}} 11 \mathrm{e}$ 12 , brocas multilaminadas**, borrachas abrasivas** de coloração branca, pastas diamantadas * para polimento de resina composta, e discos de lixa Soflex ${ }^{\star}$ de granulações média e fina. Em seguida, foram armazenados em solução fisiológica, à temperatura ambiente, por 24 horas, para adequada hidratação.

\section{4 - TESTE DE MICROINFILTRAÇÃO.}

Vinte e quatro horas após a conclusão das restaurações e polimento, os dentes foram fixados numa base de resina acrílica autopolimerizável" com auxílio de cilindros de PVC com $3 \mathrm{~cm}$ de altura e $1 / 2$ polegada de diâmetro. As margens cervicais das restaurações foram posicionadas a uma distância de $2 \mathrm{~mm}$ da borda superior do cilindro. No centro da face oclusal de cada restauração, foi confeccionado um pequeno nicho, com diâmetro de $2 \mathrm{~mm}$, usando uma ponta

* Becton-Dickson Indústria Brasileira.

** K G Sorensen Indúdtria e Comérco Ltda.

\& TDV Dental Ltda.

- 3M Dental Products Division St. Paul MV.

- Policron DencrilCom. E. Ind. de Plásticos Ltda. 
diamantada esférica $\mathrm{n}^{0}$ 1014** montada em turbina de alta rotação ${ }^{\star}$. Esse nicho serviu como referência para a aplicação da força de compressão, empregando-se um dispositivo desenvolvido pelo SENAI - Bauru (Serviço de Aprendizagem Industrial), como ilustrado na Figura 4.18. Esse dispositivo apresentava plataformas ajustáveis ao peso necessário para a aplicação da pressão, conforme definido no projeto, de acordo com a Figura 4.19.

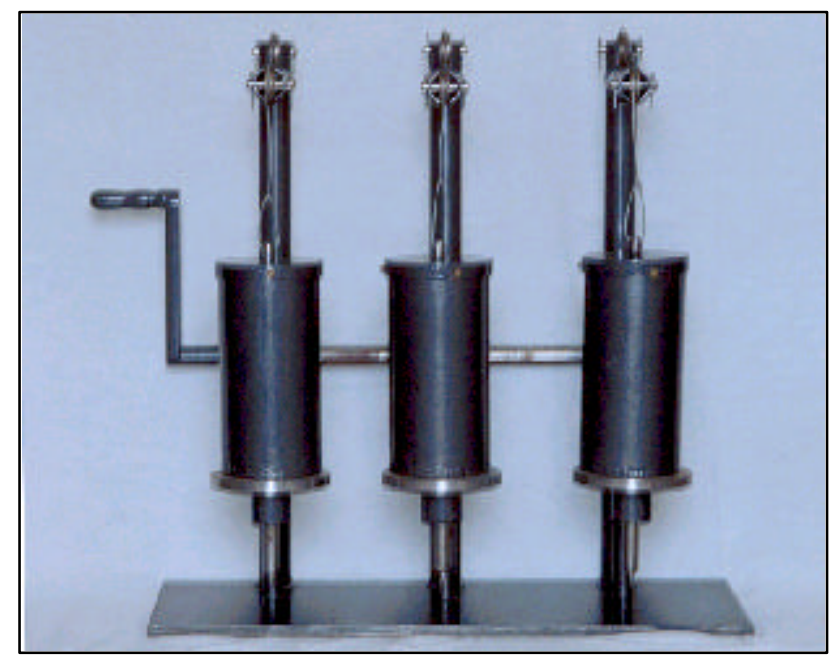

FIGURA 4.18 - Dispositivo elaborado pelo SENAI, para aplicação do estresse mecânico sobre as restaurações

Antes da utilização do dispositivo propriamente dito, todos os seus componentes foram aferidos no Departamento de Engenharia Mecânica da UNESP/Bauru (laboratório de refrigeração e ar condicionado), fazendo-se uso de balança eletrônica (KLD Balanças Eletrônicas Ltda, modelo KLD com carga máxima de $16.995 \mathrm{~kg}$ e carga mínima de $0.025 \mathrm{~kg}$ ). Este procedimento foi realizado para se determinar o peso correto de seus componentes, e a carga que seria efetivamente aplicada à superfície das restaurações.

** K G Sorensen Indústria e Comércio Ltda.

$\uparrow$ Kavo do Brasil S/A. 


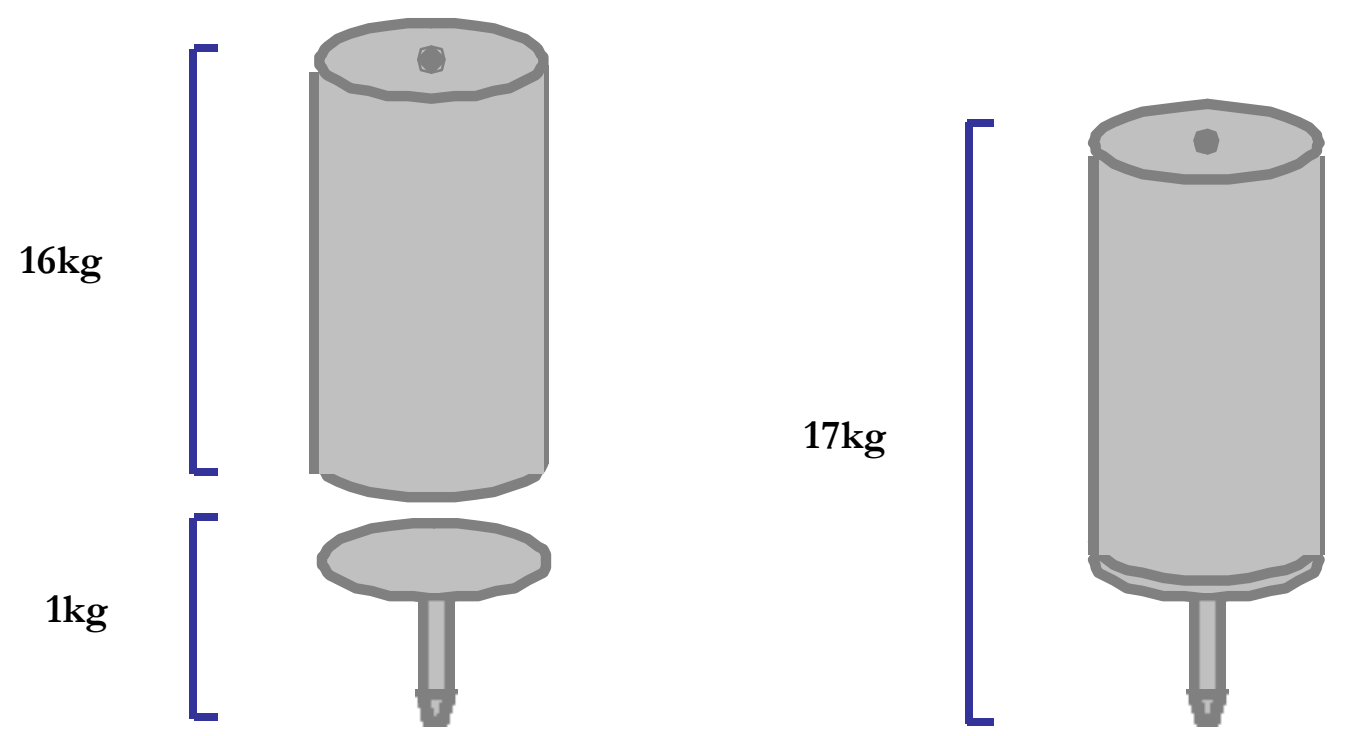

'FIGURA 4.19- Esquema detalhado dos componentes do dispositivo que eram responsáveis pela carga aplicada a superfície das restaurações

Inicialmente foi aplicada uma carga de $1 \mathrm{~kg}$ (peso original da base), que permaneceu por 01 minuto. Em seguida o cilindro de $16 \mathrm{~kg}$ foi liberado por meio da alavanca. Atingida a força de $17 \mathrm{~kg}$, aguardou-se um tempo adicional de 01 minuto e então o cilindro foi removido, para que apenas a plataforma de $1 \mathrm{~kg}$ permanecesse por mais 01 minuto. Este procedimento foi repetido por 10 vezes a cada dia (10 ciclos/dia), durante 7 dias para cada dente (Figura 4.19).

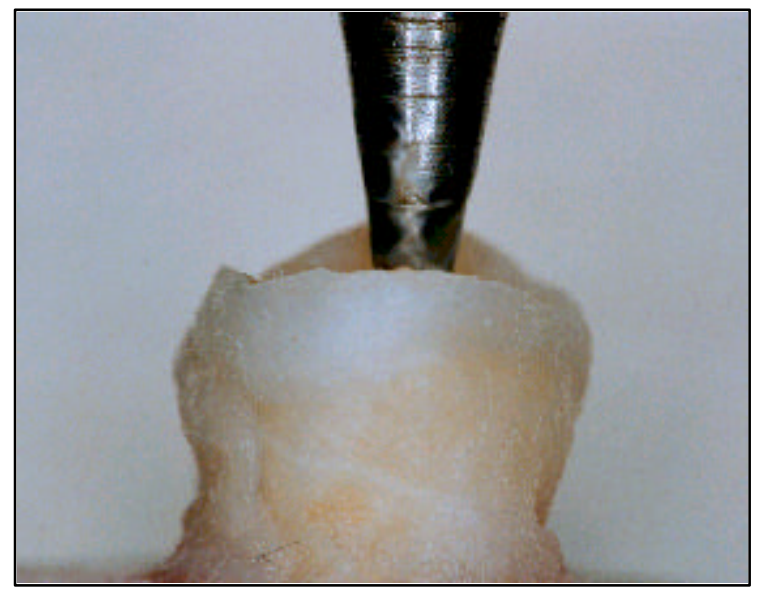

FIGURA 4.19. Vista aproimada do momento da aplicação do estresse mecânico sobre o dente envolvido por algodão molhado. 
Como já verificado na Figura 4.19, durante a aplicação da carga, as amostras foram envoltas em uma mecha de algodão molhado, exceto na face oclusal, para evitar desidratação. Após cada dia de sessão de aplicação de carga, as amostras foram colocadas em solução fisiológica e mantidas a $37^{\circ} \mathrm{C}$, em uma estufa.

No sétimo dia, após a aplicação da carga, os espécimes foram removidos da base de acrílico, os ápices das raízes foram seccionados com disco de carborundum e vedados com Vitremer e Super Bonder ${ }^{\star}$. Posteriormente, todos os espécimes tiveram suas superfícies protegidas com esmalte ${ }^{x}$ para unhas, com exceção da restauração e $1 \mathrm{~mm}$ ao seu redor. Essa cobertura foi executada aplicando-se duas camadas de esmalte para assegurar um bom vedamento e impedir que o corante penetrasse por eventuais defeitos das estruturas dentárias. Após a secagem do esmalte, os dentes foram novamente armazenados em solução salina, para reidratação; pois que, durante o procedimento de secagem, os dentes sofrem uma severa desidratação, o que poderia acarretar uma absorção excessiva de corante, atrapalhando a interpretação futura dos resultados. Após 24 horas de reidratação, os dentes foram colocados em solução de fucsina básica a $0,5 \%$, em temperatura ambiente, por 24 horas. Em seguida, foram lavados em água corrente, também por 24 horas.

Para avaliação da microinfiltração, os espécimes foram incluídos em resina resapol $^{\circ}$ (T 208), aguardando-se 24 horas para a total polimerização da resina. Posteriormente, os espécimes foram submetidos a secções longitudinais, no sentido mésio-distal com disco diamantado especial ${ }^{\circledR}$ (XL 12205) montados em uma máquina para cortes ${ }^{\otimes 2}$. Para cada dente, obtiveram-se 04 cortes de aproximadamente 0,8mm de espessura, com a máquina em uma velocidade de $\pm 300 \mathrm{rpm}$, sob refrigeração. As seções obtidas foram observadas com utilização de lupa binocular Optivision ${ }^{*}$ de 10x (10 vezes) de aumento. O corte com maior infiltração foi

3M Dental Products Division St. Paul MV.

$\Delta$ LOCTITE do Brasil Ltda.

x Maybelline Express Finish Fast-Dry.

- Redefibra Comércio de produtos para Fiberglass Ltda.

(๖) EXTEC - Division of Exc el Tecchnologies, Inc., Enfield, Connecticut, USA/(Labcut 1010 EXTEC). \% Donegan Optical Company - USA. 
selecionado para obtenção da área de infiltração. As secções selecionadas foram levadas a um "scanner" 田, juntamente com uma régua de aço (como ilustrado na Figura 4.20), para ser feita a captura da imagem e sua transferência ao programa Adobe Photoshop ${ }^{\circledR}$, até ser feito o ajuste do brilho e do contraste para evidenciar com mais clareza a área de infiltração do corante.

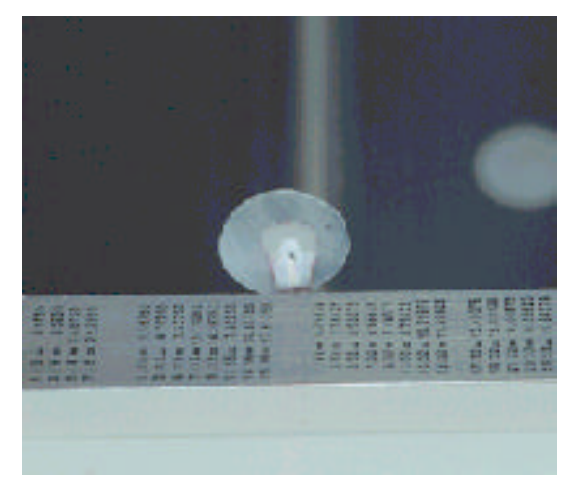

FIGURA 4.20- Seção sendo escaneada.

Após tratadas e ajustadas, as imagens obtidas foram transferidas para o programa ImageTool (UTHSCSA - University of Texas Health Science Center San Antonio) e submetidas a aumento de $2 \mathrm{x}$ (duas vezes), para melhor visualização. Diante da área a ser analisada no centro da tela do computador, a área infiltrada pelo corante foi delineada por meio de uma ferramenta do referido programa para a realização do cálculo. Inicialmente fez-se a calibração das dimensões, utilizando a régua como referência. Após esta calibração, partiuse para a medida da área infiltrada pelo corante, a qual era calculada em $\mathrm{mm}^{2}$, por meio de uma ferramenta que converte as medidas em pixels para $\mathrm{mm}^{2}$, a partir das referências da imagem da régua.

As Figuras 4.21, 4.22, 4.23 ilustram graficamente, por meio das imagens da tela do computador como era feita a calibração e medida da área infiltrada.

itit HP 6100-C (Hawlett Packard).

๑ Adobe. 


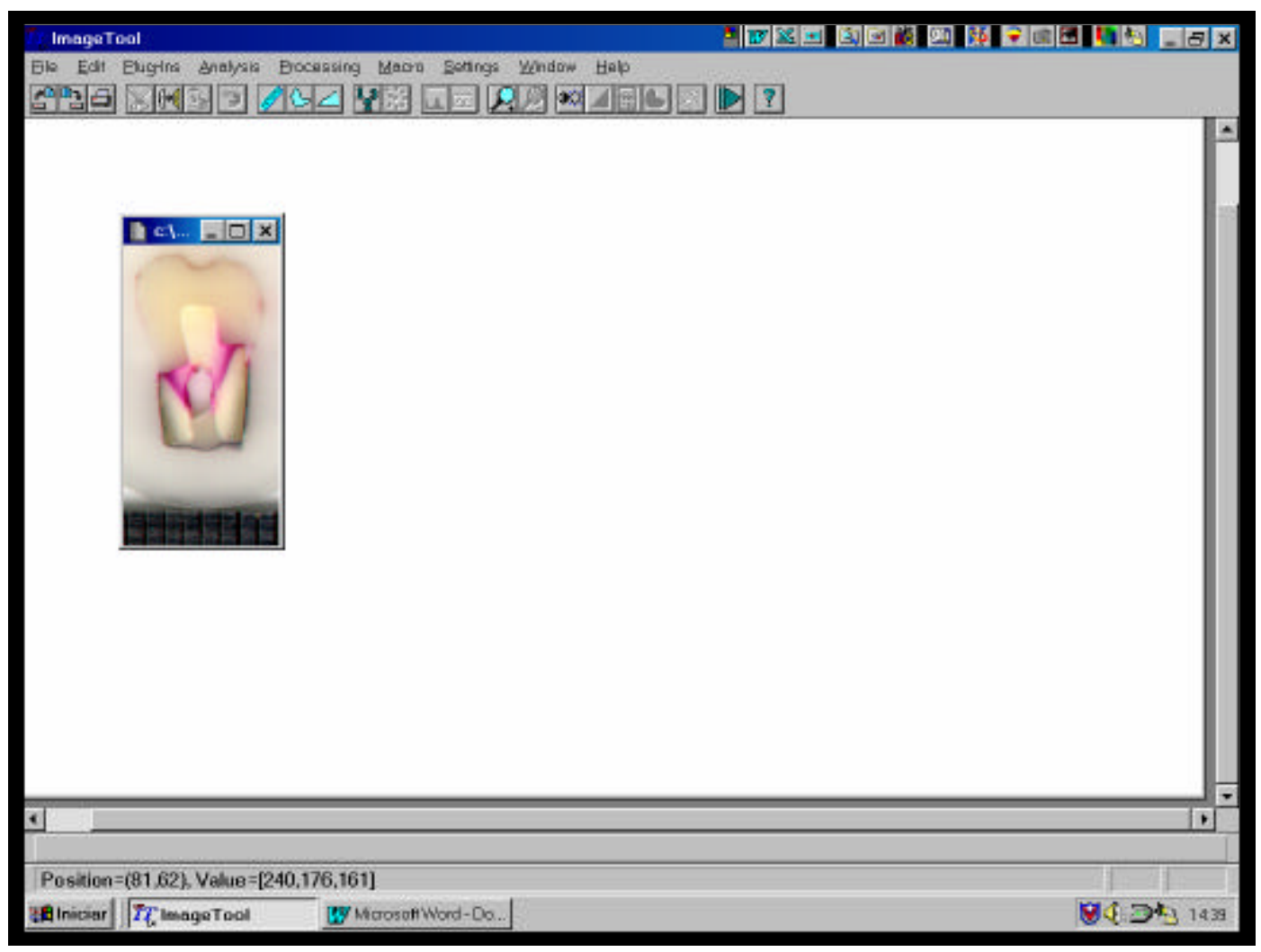

FIGURA 4.21- Ilustração da tela do ImageTool

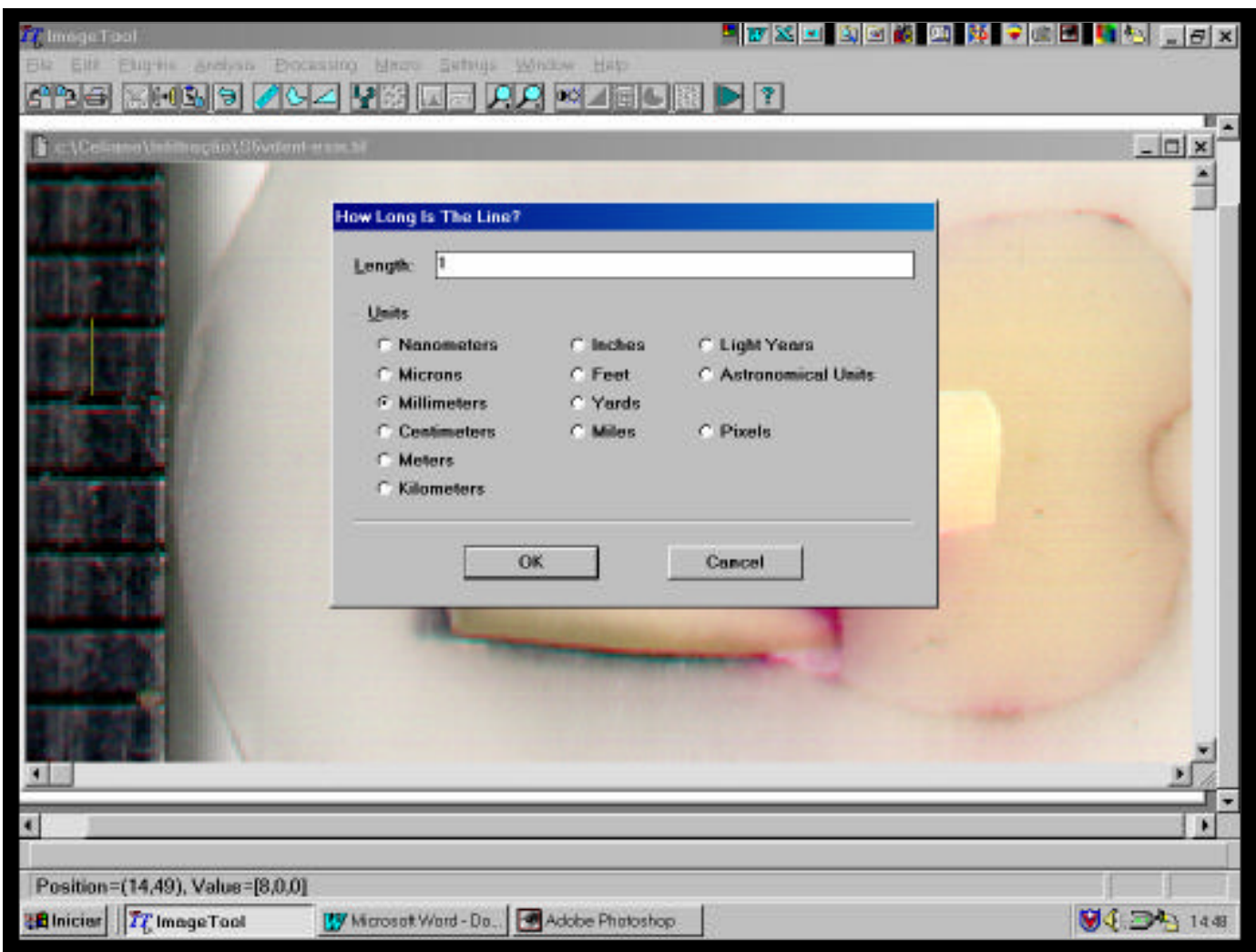

FIGURA 4.22- Ilustração da conversão das medidas de pixels para milímetros 


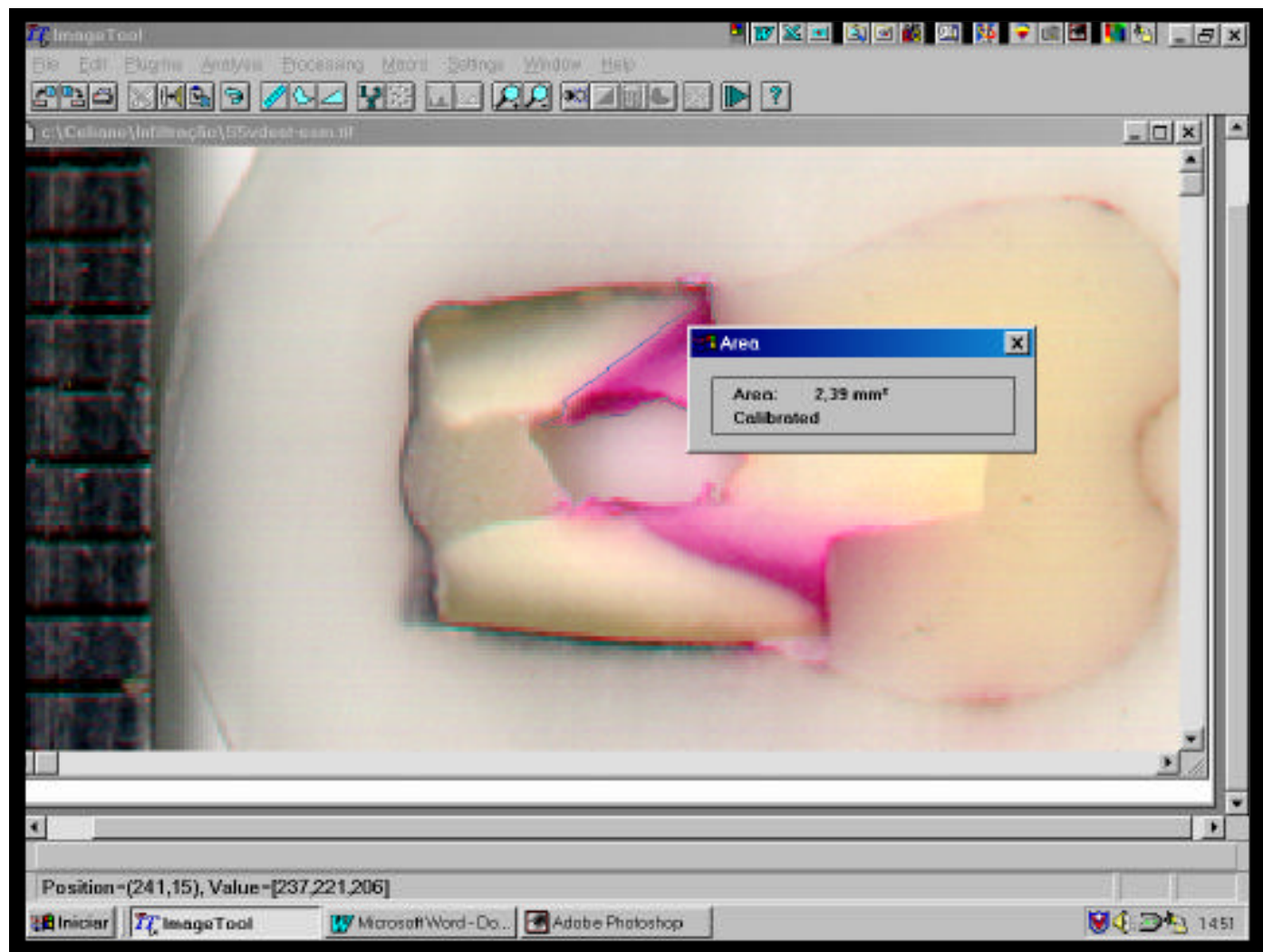

FIGURA 4.23- Área de infiltração calculada

Convém salientar que era feito um treinamento prévio para se verificar a fidelidade nos resultados obtidos a partir da análise das imagens. Sem saber qual sistema havia sido empregado nos cortes, fazia-se a delimitação da área várias vezes, até que fosse possível obter os mesmos resultados. Esse treino foi realizado em vários cortes diferentes para evitar vício da análise. Uma vez conseguida esta calibração, partiu-se, efetivamente, para a análise e determinação das áreas infiltradas pelo corante. 


\section{5 - ANÁLISE DOS RESULTADOS.}

É importante também salientar aqui dois aspectos com relação às medidas obtidas. Primeiro, somente foram consideradas as duas maiores áreas de infiltração de cada dente, uma para a margem cervical em esmalte e outra para a margem cervical em dentina. Segundo, foi tomado um cuidado especial para descartar possíveis áreas de infiltração que não tenham ocorrido pela interface, mas ocasionadas por defeitos da restauração ou mesmo por pequenas imperfeições ao seu redor, por exemplo.

Outro ponto importante a ser ressaltado é que o tipo de análise feita pela medida da área, expressa em $\mathrm{mm}^{2}$, pode ser analisada por meio de testes paramétricos. A possibilidade de análise paramétric a torna o teste mais preciso, daí a preferência por este tipo de análise ao invés da aplicação de escores subjetivos, como é realizado muitas vezes.

A análise estatística foi realizada pelo professor assistente do Departamento de Odontopediatria, Ortodontia e Saúde coletiva da Faculdade de Odontologia de Bauru, Professor José Roberto Pereira Lauris. Após tabulação, as medidas (anexo1, Figuras 1 a 18) foram submetidas à análise de variância a três critérios fixos e ao teste de comparação individual de Tukey-Kramer. 


\section{6 - DIAGRAMA RESUMO DE MATERIAIS E MÉTODOS.}

90 pré-molares

Cavidade classe II (MOD) - Margens gengivai $<$ Mesiar- $1 \mathrm{~mm}$ além da JAC

Distal- $1 \mathrm{~mm}$ aquém da JAC

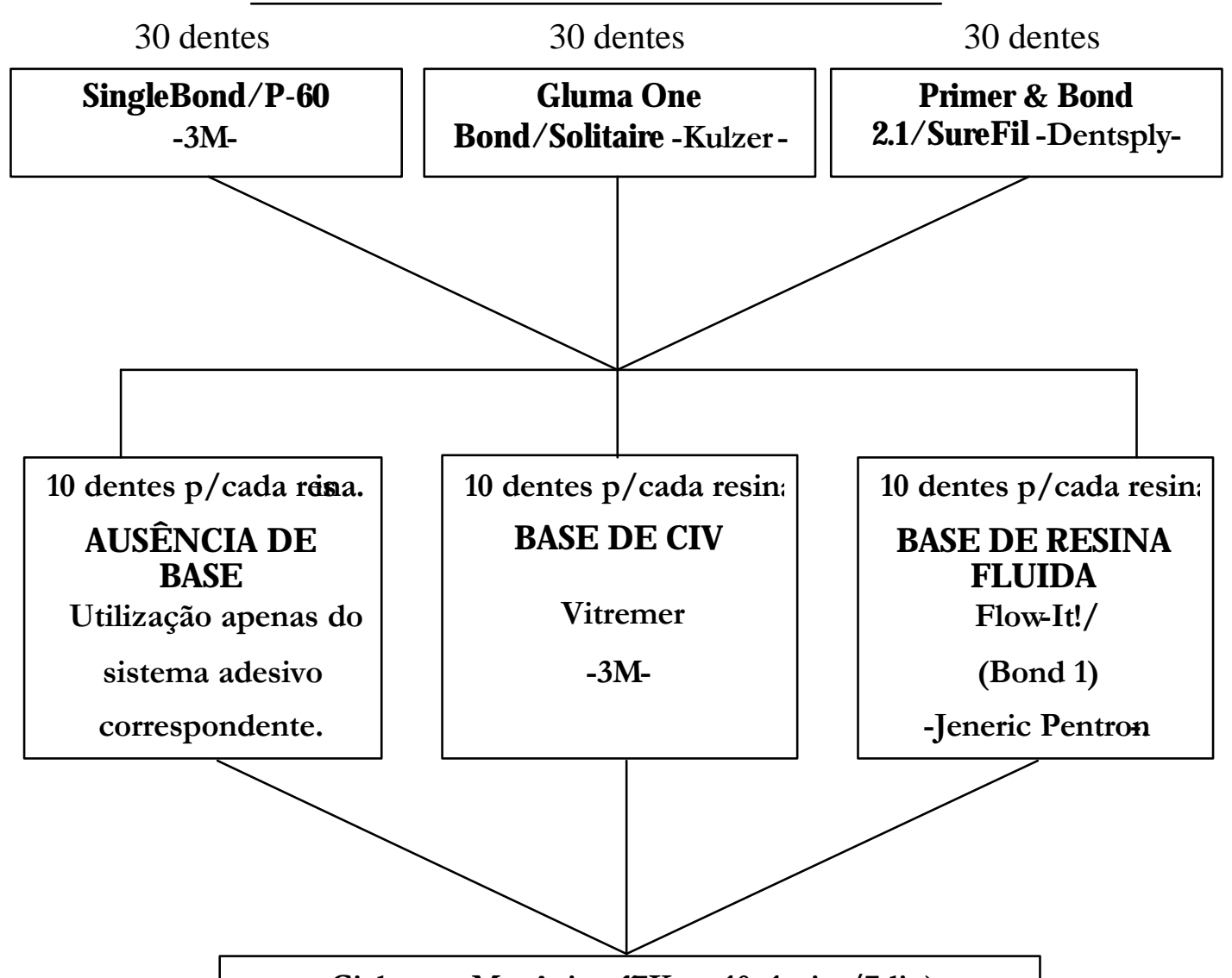

Ciclagem Mecânica-(17Kg x 10, 1min./7dìs)

Isolamento/Imersão em Fuccina Básica a $0,5 \%$ por $24 \mathrm{~h} . /$ Lavagem por $24 \mathrm{~h}$. Seccionamento/ Escolha do corte mais infiltrado

Mensuração, em mản da penetração do corante através do programa Image]

Análise Estatística

ANOVA a três

critérioß Comparação

individual de Tukey

Kramer 


$$
\text { 5-Resultados }
$$




\section{5 - RESULTADOS}

As Tabelas 5.1, 5.2 e 5.3, bem como o gráfico 5.1, apresentam as médias e desvio padrão dos grupos estudados, observados com variação dos materiais $\left(\mathrm{P}^{*} 0^{\vee}\right.$, Solitaire ${ }^{\nexists}$ e SureFil ${ }^{\leftarrow}$ ) e das bases (ausência de base, Flow-It! ${ }^{\vartheta}$ e Vitremer ${ }^{\vee}$ ), em função das margens (de esmalte e de dentina) das restaurações estudadas.

TABELA 5.1 - Média e desvio padrão $\left(\mathrm{em}^{2} \mathrm{~mm}^{2}\right.$ ) dos grupos restaurados com as resinas Filtek ${ }^{\mathrm{TM}} \mathrm{P}^{\star}{ }^{\star}$, Solitaire ${ }^{\nexists}$ e SureFil ${ }^{<}$, na ausência de base, em margens de dentina e de esmalte (Grupos controle).

\begin{tabular}{lcc}
\hline Materiais/ Base/Margens & Média $\left(\mathbf{m m}^{2}\right)$ & Desvio Padrão \\
\hline MARGEM EM DENTINA & 0,58 & 0,36 \\
P60/ausência de base & 2,18 & 0,95 \\
Solitaire/ ausência de base & 1,01 & 0,68 \\
SureFil/ ausência de base & & \\
MARGEM EM ESMALTE & 0,05 & 0,04 \\
P60/ ausência de base & 1,02 & 0,94 \\
Solitaire/ ausência de base & 0,18 & 0,32 \\
SureFil / ausência de base & &
\end{tabular}

3M Dental Products Division St. Paul MV.

8 HARAEUS KULZER South America Ltda.

$<$ DENTSPLY Indústria e Comércio Ltda.

$\vartheta$ JENERIC PENTRON Incorporated - USA. 
TABELA 5.2 - Média e desvio padrão $\left(\mathrm{em}^{\mathrm{m}} \mathrm{mm}^{2}\right.$ ) dos grupos restaurados com as resinas Filtek ${ }^{\mathrm{TM}} \mathrm{P} 60^{\nu}$, Solitaire ${ }^{8}$ e SureFil $^{\leftarrow}$, com base de resina de baixa viscosidade (Flow-It!') em margens de dentina e de esmalte.

\begin{tabular}{lcc}
\hline Materiais/ Base/Margens & Média $\left(\mathbf{m m}^{\mathbf{2}}\right)$ & Desvio Padrão \\
\hline MARGEM EM DENTINA & 0,44 & 0,50 \\
P60/Flow-It! & 0,78 & 0,65 \\
Solitaire/Flow-It! & 0,61 & 0,90 \\
SureFil /Flow-It! & & \\
MARGEM EM ESMALTE & 0,12 & 0,24 \\
P60/Flow-It! & 0,19 & 0,24 \\
Solitaire/Flow-It! & 0,39 & 0,95 \\
SureFil /Flow-It! & &
\end{tabular}

TABELA 5.3 - Média e desvio padrão $\left(\mathrm{em}^{2} \mathrm{~mm}^{2}\right.$ ) dos grupos restaurados com as resinas Filtek ${ }^{\mathrm{TM}} \mathrm{P}^{\star} 0^{\star}$, Solitaire ${ }^{\mathrm{E}}$ e SureFil ${ }^{<}$, com base de ionômero modificado por resina (Vitremer ${ }^{\boldsymbol{}}$ ), em margens de dentina e de esmalte.

\begin{tabular}{lll}
\hline Materiais/ Base/Margens & Média $\left(\mathrm{mm}^{2}\right)$ & Desvio Padrão
\end{tabular}

MARGEM EM DENTINA

P60/Vitremer

$0,61 \quad 0,73$

Solitaire/Vitremer

$0,57 \quad 0,53$

SureFil /Vitremer

$0,53 \quad 0,36$

MARGEM EM ESMALTE

P60/Vitremer

$0,15 \quad 0,18$

Solitaire/Vitremer

$0,09 \quad 0,09$

SureFil /Vitremer

0,09

0,17 


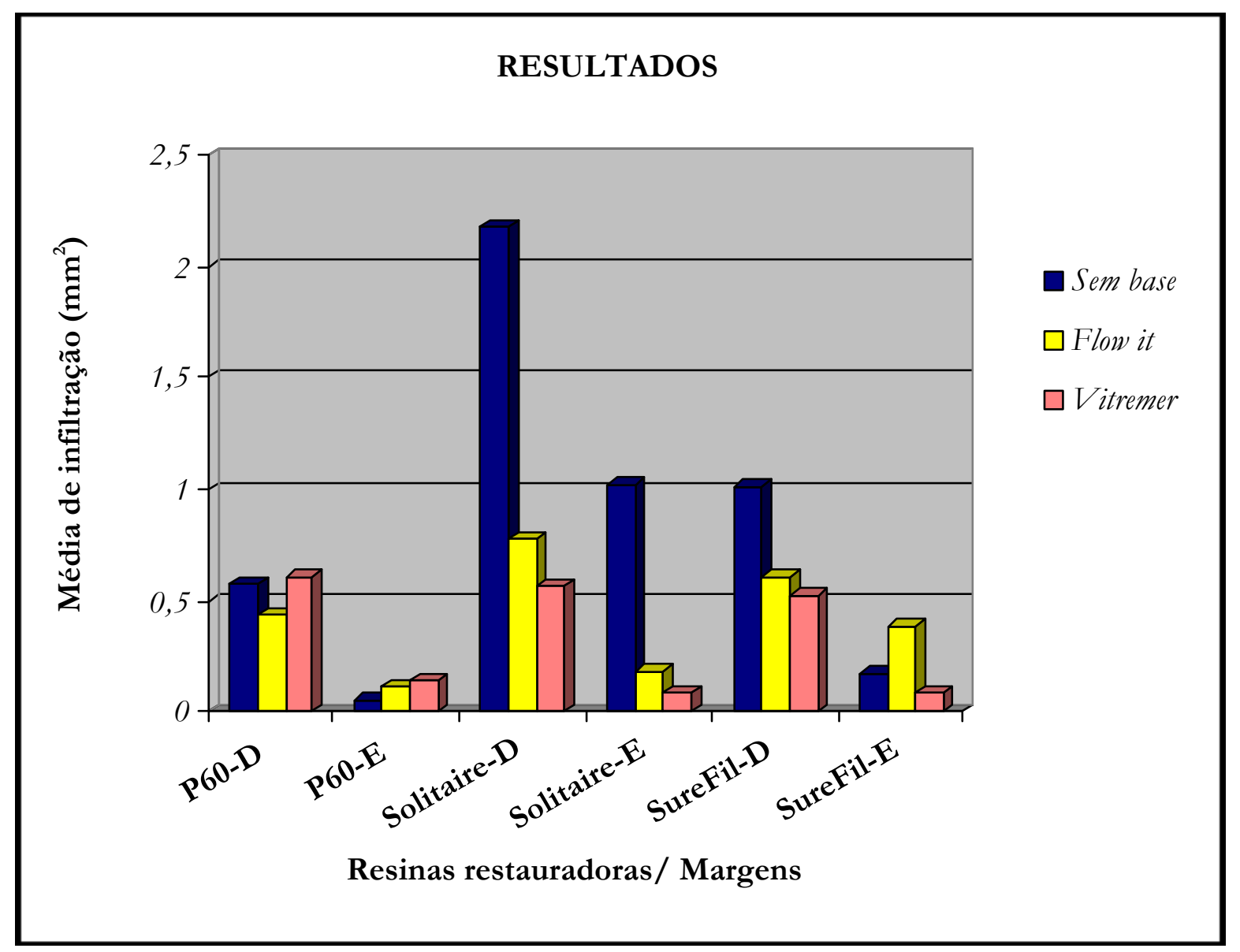

Gráfico 5.1 - Médias das áreas infiltradas $\left(\mathrm{em} \mathrm{mm}^{2}\right)$ das restaurações com as resinas P60, Solitaire e SureFil, observadas variando-se as bases (ausência de base, Flow-It! e Vitremer), em função da margem estudada: dentina (D) e de esmalte (E). 
Para comparação entre os materiais, bases e margens, aplicou-se a análise de variância (ANOVA) a três critérios, como pode ser observado na tabela 5.4.

TABELA 5.4 - Análise de Variância a três critérios para comparação entre materiais, bases e margens.

\begin{tabular}{lcc}
\hline Variáveis & $\mathbf{F}$ & $\mathbf{P}$ \\
\hline Material & 7,236 & $0,001 *$ \\
Base & 8,399 & $0,000 *$ \\
Margem & 83,314 & $0,000 *$ \\
Material/Base & 5,734 & $0,000^{*}$ \\
Material/Margem & 2,370 & $0,099 \mathbf{n s}$ \\
Base/Margem & 5,374 & $0,006 *$ \\
Material/Base/Margem & 0,831 & $0,509 \mathbf{n s}$ \\
\hline
\end{tabular}

ns - Não houve diferença estatisticamente significante.

* - Diferença estatisticamente significante ao nível de $p>0,05$.

Como a análise de variância (ANOVA) a três critérios mostrou haver interação entre Materiais/Bases e Bases/Margens, foi realizada a análise de variância a dois critérios para cada margem, separadamente (Tabelas 5.5 e 5.7).

TABELA 5.5 - Análise de Variância a dois critérios para comparação entre materiais e bases, em margens localizadas em dentina.

\begin{tabular}{lll}
\hline Variáveis & $\mathbf{F}$ & $\mathbf{p}$
\end{tabular}




$\begin{array}{lcc}\text { Material } & 7,310 & 0,001 * \\ \text { Base } & 10,048 & 0,000 * \\ \text { Material/Base } & 4,439 & 0,002 *\end{array}$

* Diferença estatisticamente significante ao nível de p>0,05.

As Tabelas 5.5 e 5.7 mostraram haver interação estatisticamente significante entre os grupos estudados para as margens em dentina e em esmalte, respectivamente. Para comparações múltiplas entre os grupos, utilizou-se o teste de Tukey, cujos resultados podem ser observados na Tabela 5.6 (para margens em dentina) e na Tabela 5.8 (para margens em esmalte).

Para o sistema Solitaire, na ausência de base, os níveis de infiltração foram significantemente maiores, em margens em dentina e em esmalte (Tabelas 5.6 e 5.8), quando comparado a mesma resina na presença de bases e aos demais sistemas e suas associações.

TABELA 5.6 - Teste de Tukey, para comparação entre Materiais e Base, em margens localizadas em dentina.

\begin{tabular}{llc}
\hline Material & Base & Média $\left(\mathbf{m m}^{2}\right)$ \\
\hline P60 & Flow-It! & 0,44 \\
SureFil & Vitremer & 0,53 \\
Solitaire & Vitremer & 0,57 \\
P60 & Ausência de base & 0,58 \\
P60 & Vitremer & 0,61 \\
SureFil & Flow-It! & 0,61 \\
Solitaire & Flow-It! & 0,78 \\
SureFil & Ausência de base & 1,01
\end{tabular}

- Grupos unidos por linha vertical não possuem diferença estatisticamente significante. 
TABELA 5.7 - Análise de variância a dois critérios para comparação entre materiais e bases, em margens localizadas em esmalte.

\begin{tabular}{lcc}
\hline Variáveis & $\mathbf{F}$ & $\mathbf{P}$ \\
\hline Material & 3,546 & $0,033^{*}$ \\
Base & 3,062 & $0,052 \mathbf{n s}$ \\
Material/Base & 4,616 & $0,002^{*}$ \\
\hline
\end{tabular}

* Diferença estatisticamente significante ao nível de $\mathrm{p}>0,05$.

TABELA 5.8 - Teste de Tukey, para comparação entre Material e Base, em margens localizadas em esmalte.

\begin{tabular}{|c|c|c|}
\hline Material & Base & Média \\
\hline P60 & Ausência de base & 0,05 \\
\hline Solitaire & Vitremer & 0,09 \\
\hline SureFil & Vitremer & 0,09 \\
\hline P60 & Flow-It! & 0,12 \\
\hline P60 & Vitremer & 0,15 \\
\hline SureFil & Ausência de base & 0,18 \\
\hline Solitaire & Flow-It! & 0,19 \\
\hline SureFil & Flow-It! & 0,39 \\
\hline Solitaire & Ausência de base & 1,02 \\
\hline
\end{tabular}

- Grupos unidos por linha vertical não possuem diferença estatisticamente significante

A Tabela 5.3 mostrou haver diferença estatisticamente significante entre as margens. As margens em dentina apresentaram maiores valores de área de infiltração $(\mathrm{x}=0,81)$ que as em esmalte $(\mathrm{x}=0,25)$. 


\section{6-Discussão}




\section{6- DISCUSSÃO}

\section{1- MATERIAIS TESTADOS}

As resinas compostas "condensáveis", "compactáveis", de alta densidade de carga ou resinas para dentes posteriores (RDP) surgiram há pouco mais de dois anos ${ }^{97}$, no curso de uma longa e incessante busca por um material estético que pudesse substituir o amálgama ${ }^{59}$. Os últimos trinta anos foram de extrema importância para a evolução dos sistemas restauradores adesivos. Ao longo desses anos, as resinas compostas sofreram progressivas melhorias em suas qualidades estéticas e adesivas e em suas propriedades mecânicas. De modo que os tipos atualmente utilizados são bem mais resistentes ao desgaste do que aquelas de que se fazia uso outrora. Embora não tenha chegado a substituir o uso do amálgama, constituíram-se, sem dúvida, em mais uma alternativa para as restaurações em dentes posteriores ${ }^{27,59,78}$.

SILVA E SOUZA JÚNIOR; CARVALHO; MONDELLI ${ }^{97}$, em 2000, propuseram, para as resinas compostas, com base em sua densidade de carga, a seguinte classificação: baixa densidade - as com porcentagem menor que $60 \%$ de carga inorgânica (peso); média densidade - as com porcentagem entre $60 \%$ e $80 \%$; alta densidade - as com maior que $80 \%$. As resinas compostas denominadas de RDP estão incluídas nas categorias de média e de alta densidade de carga; e as alterações sofridas por elas incluem modificações na quantidade de carga, no volume, no tamanho e no tipo de partículas ${ }^{51,58,59,97,107}$. Algumas modificações na estrutura da matriz orgânica também foram feitas por alguns fabricantes ${ }^{51,97}$.

A propaganda acerca dessas resinas gira em torno de: uma provável diminuição da contração de polimerização, devido à menor quantidade de matriz orgânica ou a modificações desta; uma maior resistência ao desgaste, pela maior quantidade incorporada de partículas; um possível aumento na profundidade de polimerização (até $5 \mathrm{~mm}$ ); e uma maior estabilidade de $\operatorname{cor}^{3,40,51}$. 
No presente estudo, foram avaliadas as resinas P60 (3M), Solitaire (Kulzer) e SureFil (Dentsply).

A resina Solitaire (Kulzer) foi a primeira resina específica para dentes posteriores a ser introduzida no mercado $(1997)^{59}$. É um material constituído de $66 \%$, em peso, por uma carga poliglobular composta por vidro de bário, alumínio, boro e silicato, associados a um óxido de silício poroso. $\mathrm{O}$ formato polig lobular garante uma superfície irregular, o que dificulta o deslizamento do monômero entre as partículas durante a compactação do material dentro da cavidade. ${ }^{59,97}$.

A resina SureFil (Dentsply), introduzida no mercado em 1998, é composta de flúor-alumínio-silicato e vidros de bário, totalizando $82 \%$, em peso. Suas partículas apresentam-se em três tamanhos médios. Essa associação de diferentes tamanhos de partículas, que facilita a compactação do material, foi denominada pelo fabricante de "Tecnologia de Partículas Entrelaçadas" (Interlocking Particle Technology). A matriz orgânica consiste em uma associação de Bis-GMA e UDMA modificada ${ }^{3,33,40,112,97 .}$

A resina P60 é uma das mais recentes, o quê justifica a escassez de dados encontrados na literatura. Nessa resina, a companhia 3M substituiu o TEGDMA por uma mistura de UDMA (Uretana dimetacrilato) e Bis-EMA (Bisfenol A polietileno-glicol-diéter-dimetacrilato). Além de aumentarem a viscosidade, esses monômeros geram, devido ao maior peso molecular, um menor grau de conversão por unidade de peso, o que acarreta menor contração.

Pela adição de uma maior quantidade de carga, as resinas RDP apresentam uma tendência a possuírem maior consistência e não apresentam o mesmo escoamento que as resinas de menor viscosidade ${ }^{33}$. A falta de adaptação aumenta o potencial de sensibilidade pós-operatória e a predisposição à

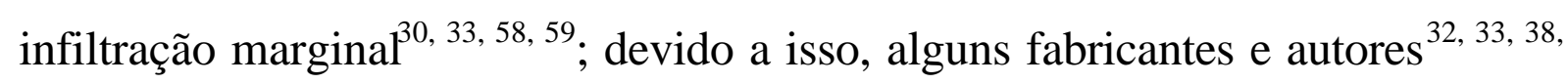
51, 59, 105 recomendam a utilização de bases cavitárias com resinas de baixa viscosidade (RBV). 
As RBV surgiram há cerca de três anos e têm sido indicadas, segundo BAYNE et $\mathrm{al}^{10}$, em 1998, em pequenos reparos nas restaurações de amálgama, de resina, de ionômero ou de restaurações indiretas; em cavidades classe V de erosão, abrasão e abfração; em selamento de cicatrículas e fissuras; mas principalmente como base cavitária. Possuindo em torno de 60 a $70 \%$ de carga em peso $^{81}$, essas resinas apresentam escoamento, promovendo maior adaptação nas paredes cavitárias ${ }^{86}$, possuem um baixo módulo de elasticidade ${ }^{2,81,86,105}$; apresentam, entretanto, propriedades mecânicas inferiores às das resinas compostas tradicionais ${ }^{10}$

UNTERBRINK, LIEBENBERG ${ }^{105}$, em 1999, indicaram o uso de RBV como base, seguindo o conceito de "parede cavitária elástica". Segundo os autores, o baixo módulo de elasticidade das resinas de baixa viscosidade, associado a uma espessura fina da resina, proporciona a formação de uma camada elástica, que absorve o estresse gerado pela contração de polimerização e também pela carga mastigatória a que são submetidos os dentes posteriores. Corroborando essa afirmação, alguns autores ${ }^{2,10,21,81,86}$ afirmam que a baixa viscosidade proporciona uma melhor adaptação às paredes cavitárias, com maior penetração da resina nas irregularidades, melhorando a resistência adesiva e diminuindo a infiltração marginal.

Avaliando algumas propriedades de resinas de baixa viscosidade (Aelite flo/Bisco; CrystalEssence/Confi-Dental; FloRestore/Dent-Mat.; Flow-it/Jeneric Pentron; Revolution/Kerr; True-Look/Denpac; UltraSeal Xt Plus/Ultradent; Versaflo/Centrix), BAYNE et al. ${ }^{10}$, em 1998, concluíram que nenhuma das resinas estudadas possuía propriedades semelhantes às resinas convencionais, pois apresentaram menor resistência mecânica, embora alguns sistemas tenham demonstrado maior fluidez que as resinas convencionais. A resina Flow-It! apresentou, contudo, maior conteúdo de partículas que as demais resinas testadas, e resistência à compressão e à tensão diametral semelhante à dos controles (Prodigy/Kerr, Z100/3M). Baseados nos resultados obtidos, os autores 
aconselharam que ainda é necessário cautela no uso de RBV, que clinicamente devem ter sua indicação evitada em áreas sujeitas a estresse; e que, todavia, são bem indicadas como base de restaurações de Classe II.

Outro material indicado como base de restaurações classe II de resina composta são os ionômeros de vidro ${ }^{56,71,73,89}$. Esses materiais têm sido estudados, incansavelmente, desde sua introdução por Wilson e Kent, em 1971. A sua grande popularidade é explicada pelas excelentes propriedades que possui, tais como: adesividade, biocompatibilidade, liberação de flúor e coeficiente de expansão térmica semelhante ao da estrutura dentária ${ }^{69}$.

Os cimentos de ionômero de vidro evoluíram no sentido de se conseguir melhor controle sobre algumas propriedades, tais como: manipulação, estética, resistência, sensibilidade à umidade e sobre o tempo de trabalho ${ }^{71}$. Para tal, componentes resinosos e iniciadores de polimerização foram adicionados aos ionômeros convencionais, possibilitando o surgimento de novas formulações com melhores propriedades mecânicas e estéticas ${ }^{69}$.

Dentre os cimentos de ionômero de vidro modificados por resina, o Vitremer/3M é um dos mais testados ${ }^{15,41,64,71,98}$, com comprovação laboratorial e clínica de suas excelentes propriedades. Além disso, os ionômeros apresentam o potencial de prevenir cáries secundárias, pela liberação de flúor ${ }^{43,56,67,97,98}$.

O progresso sofrido pelas resinas é evidente, todas as resinas estudadas no presente trabalho são evoluções de resinas já avaliadas e estudadas ao longo dos anos. Isso não obstante, como todo material deve ser avaliado e estudado previamente a uma utilização clínica. Não se deve levar em consideração apenas o que dizem os fabricantes dos produtos, e assim aplicar esses materiais de forma negligente. É importante verificar a validade de suas propriedades através de estudos in vitro e in vivo ${ }^{87}$.

Devido às dúvidas sobre as RDP, principalmente no que diz respeito à sua capacidade de selamento das margens cavitárias, resolveu-se avaliar a infiltração marginal de algumas delas, com e sem interposição de bases cavitárias. Dentre 
os inúmeros materiais indicados para base cavitária, foi escolhido o CIV modificado por resina, Vitremer (3M), e a resina de baixa viscosidade Flow-it! (Jeneric Pentron). Isso com fulcro no trabalho de COSTA et al. ${ }^{15}$, 1999, que avaliando, ionômeros de vidro e resinas fluidas quanto à sua capacidade de minimizar a infiltração marginal, verificaram que os grupos restaurados com Vitremer e Flow-it! demonstraram maior resistência a microinfiltração quando comparados com os outros grupos.

\section{2 - METODOLOGIA}

A microinfiltração é definida como sendo a passagem de bactérias, fluidos, moléculas ou íons entre as paredes das cavidades e o material restaurador aplicado sobre estas ${ }^{44,53,94,100}$ o que, conforme CRIM, GARCIAGODOY $^{20}$, 1987, leva a manchamento, resposta pulpar adversa, sensibilidade pós-operatória e cáries recorrentes.

Muitas são as técnicas in vitro utilizadas para testar a capacidade de selamento dos materiais: o uso de corantes, isótopos radioativos, exame microscópico, pressão de ar, cáries artificiais, análise de ativação de neutrons, microscopia eletrônica de varredura, difusão radioquímica, etc. ${ }^{53,94}$. A detecção da penetração de corante é uma das técnicas mais antigas e utilizadas em face da sua simplicidade e do seu baixo custo. Além disso, de acordo com ALANI; $\mathrm{TOH}^{5}, 1997$, possui as vantagens de não produzir toxicidade e de detectar infiltração em concentrações diluídas. Essa técnica carrega, entretanto, as desvantagens de exigir a destruição do espécime (para realização da leitura) e de não quantificar a infiltração total, o que resulta em ser considerada uma avaliação subjetiva.

Existe muita discussão a respeito da validade dos testes laboratoriais, devido a ausência de aspectos importantes presentes clinicamente, como a pressão pulpar e placa bacteriana, por exemplo. Isso não obstante, PASHLEY ${ }^{73}$, 1990, afirmou que, se os materiais testados em laboratório apresentarem baixos 
níveis de infiltração, terão maiores probabilidades de alcançar sucesso clínico, pois que os testes laboratoriais são mais severos. Por exemplo, em dentes extraídos não existe a pressão hidrostática e os fatores imunológicos que dificultam a progressão da infiltração in vivo. Ainda de acordo com o mesmo autor, em algumas situações clínicas, ainda ocorre a presença de dentina esclerosada, que diminui a permeabilidade dentinária, dificultando a invasão de bactérias através desse tecido.

RETIEF $^{87}$, em 1991, numa revisão sobre os testes laboratoriais, chamou atenção para a falta de padronização dos testes, o que tem dificultado a comparação dos resultados. Não foi também observada, por alguns autores ${ }^{20,24,33,44,94}$, uma correlação entre os resultados laboratoriais e clínicos; o que pode ser explicado pelas diferenças entre os meios em que cada teste é analisado.

Para SORTALL ${ }^{94}$, 1982, os testes laboratoriais são importantes por levantarem questões relevantes, como as causas e as conseqüências da microinfiltração. Ressalta ainda que os resultados desses testes revelam características dos materiais, possibilitando que, ao serem aplicados in vivo, seja feito de forma mais segura.

Para o presente trabalho foi escolhida a análise da penetração de corante orgânico, em face da facilidade que proporciona e dos resultados satisfatórios observados em trabalhos recentes ${ }^{71,76,77,109}$. Para a escolha da solução corante, alguns fatores devem ser analisados, tais como: método de detecção empregado, pH da solução, custo e facilidade de manipulação. Dentre as várias soluções corantes, optou-se pela fucsina básica a $0,5 \%$, em razão do seu baixo peso molecular ${ }^{71}$.

Outra grande discussão quanto aos testes laboratoriais de microinfiltração gira em torno da quantidade de espécimes necessárias para serem detectadas, com segurança, diferenças clínicas. No presente estudo, a partir do teste piloto, foram utilizados 3 dentes para cada grupo, para poder calcular qual a mínima diferença aceitável pela ANOVA no caso de utilização de 10 unidades em cada grupo. Cálculos feitos segundo ZAR (1996) e adotando poder do teste de 0,80, para as medidas de extensão linear, foi detectado, que uma diferença de $0,2 \mathrm{~mm}$ na 
média entre grupos seria percebida, e para as medidas de área uma diferença de $0,3 \mathrm{~mm}^{2}$. Baseado neste fato, o número de espécimes (corpos de prova) a ser utilizado para a parte experimental foi estimado em 10, por acreditar-se que a diferença detectável era clinicamente relevante.

Posteriormente à definição do número de dentes, partiu-se para a confecção dos preparos. Foram utilizados pré-molares hígidos, livres de trincas ou defeitos estruturais. A preferência pelos dentes pré-molares, deveu-se à menor variação de forma e tamanho que apresentam, quando comparados aos dentes molares. Os preparos foram padronizados, sendo confeccionadas cavidades classe II amplas.

As margens cervicais foram localizadas em dentina e em esmalte, para avaliar-se o selamento marginal nos dois tipos de substrato, o que ocorre clinicamente $^{13,74,75}$. Assim os resultados se poderiam aproximar ao máximo de uma condição real, para a qual são indicados os materiais testados no presente trabalho.

Com relação ao processo restaurador, optou-se pela utilização dos sistemas adesivos correspondentes de cada material usado (materiais de base e restauradores). Segundo a literatura consultada, foram muitos os trabalhos que avaliaram a infiltração marginal de resinas compostas com os sistemas adesivos correspondentes, conseguindo resultados mais satisfatórios quando essa condição é aplicada ${ }^{63,76}$. É sabido também que alguma perda acontece por falta de padronização, pois vários sistemas adesivos são empregados em vez de um só. Mesmo com algum prejuízo, deve-se considerar que, clinicamente, é o que acontece, ou seja, operadores normalmente procuram empregar os sistemas adesivos correspondentes aos materiais restauradores.

No que diz respeito ao bloqueio da infiltração gengival, a técnica incremental da resina composta vem mostrando melhores resultados que a técnica de incremento único ${ }^{11,17,27,50,55,56,78,94}$. PEREIRA $^{76}$, 1999, em seu recente trabalho de dissertação de mestrado, comparando a técnica incremental e incremento único 
de resinas compostas, obteve resultados mais satisfatórios com o uso da técnica incremental para a resina $\mathrm{Z} 100(3 \mathrm{M})$.

AFFLECK et al. ${ }^{4}$, em 1999, e FRANCCI et al. ${ }^{39}$, em 2000, avaliando a infiltração marginal de resinas RDP, com e sem técnica incremental não demonstraram haver interferência do tipo de técnica de inserção na infiltração marginal, para essas resinas (RDP).

Apesar de os resultados atuais de avaliações de RDP, quanto à técnica de inserção, não terem demonstrado melhora na infiltração, também não foi encontrada influência negativa na sua utilização. Assim, optou-se pela técnica incremental em face de seus resultados satisfatórios, até o momento, com as resinas compostas; e por acreditar-se ser uma técnica mais segura quanto ao controle dos efeitos da contração de polimerização, seguindo o conceito do fator de configuração cavitária $^{13}$, com melhor distribuição das tensões. A técnica de polimerização gradual também foi aplicada com fundamento no trabalho de YAMAUTI $^{109}$, 1999, em que foram encontrados resultados mais satisfatórios, em relação a infiltração marginal, quando a polimerização gradual foi empregada.

Também é controverso o tempo de armazenagem dos dentes restaurados, para que a resina composta sofra a adequada expansão higroscópica, previamente a serem submetidos a acabamento e polimento. Nenhuma padronização foi observada na literatura, mas grande diversidade: $21 \operatorname{dias}^{71}, 2$ semanas $^{66}$, 1 semana $^{85}, 15$ minutos $^{16,}$ 17, 18, 19, 20, 3 minutos $^{83}$, e até mesmo imediatamente após a confecção das restaurações ${ }^{61,90}$. O retardamento dos processos de acabamento das restaurações em resina composta é importante, pois que permite um maior grau de conversão dos monômeros em polímeros sem interferência prematura do aquecimento provocado pela baixa e pela alta rotação além de permitir a expansão higroscópica ${ }^{47,48,70,84,88}$.

Considerando o trabalho de OLIVA; LOWE $^{70}$, em 1986, no qual verificaram um equilíbrio na sorpção de água e na expansão linear pelas resinas compostas a 
partir do $6^{\circ}$ dia, resolveu-se optar por aguardar apenas 6 dias até a realização do acabamento e polimento, o que condiz com a realidade clínica.

As mudanças de temperatura e a presença de carga na superfície das restaurações são fatores constantemente presentes no ambiente oral. Até pouco tempo, apenas a ciclagem térmica era utilizada nos trabalhos realizados em laboratório. A partir de algumas discussões acerca do real efeito das mudanças térmicas sobre as restaurações é que se começou a questionar e a pesquisar outras formas de reprodução da realidade clínica.

ASMUSSEN, JÖRGENSEN ${ }^{8}$, em 1978, realizaram uma revisão do trabalho feito, em 1952, por NELSEN et al., primeiro autor a falar sobre percolação marginal conseqüente a variações térmicas de vários materiais, dentre eles, resinas acrílica e cimento de silicato. Os autores também procuraram comparar estudos já realizados sobre adaptação marginal de resinas acrílicas e; finalmente, reconsiderar a importância clínica do coeficiente de expansão térmica e linear para restaurações, agora, de resinas compostas. Concluíram que o alto coeficiente de expansão térmica das resinas compostas não necessariamente implica alto grau de percolação marginal e, ainda que a presença da expansão higroscópica, nas faixas de temperatura condizentes com a realidade clínica, contribui para a manutenção da integridade marginal.

Muitos autores ${ }^{7,54,62,71,72,84,94,108}$ confirmaram essa conclusão. De acordo com OLIVEIRA ${ }^{71}$, 1999, o comportamento não linear do coeficiente de expansão térmica dos materiais, correlacionado aos extremos de temperatura dos alimentos $\left(5^{\circ}-55^{\circ} \mathrm{C}\right)$ deve ser analisado, levando-se em consideração três pontos importantes: o volume, a composição do material restaurador e a localização do dente restaurado. Afirma que a termociclagem deve ser feita de maneira específica para cada material. O que é corroborado por $\operatorname{ASMUSSEN}^{7}, 1974$, que ainda acrescenta como fatores importantes, o tamanho da cavidade e a utilização (ou não) de base cavitária. 
Consultando a literatura, pode-se observar uma falta de padronização também quanto aos extremos de temperatura utilizados na duração dos banhos e no número de ciclos. ROSSOMANDO, WENDT JUNIOR ${ }^{91}$, em 1995, estudaram o efeito da duração de banhos (10 s ou $60 \mathrm{~s}$ ), em cada temperatura durante a ciclagem térmica. Os autores observaram que o grau de infiltração foi maior para aqueles subgrupos submetidos ao maior tempo de imersão em cada banho (60 s), o que significa que a maior duração do estresse térmico é capaz de anular as propriedades de isolamento térmico do material. Porém, quando o menor tempo de estresse térmico foi utilizados (10 s), tempo este mais compatível com a realidade clínica, não ocorreu diferença estatística, quando comparado com os grupos de controle.

$\mathrm{KIDD}^{53}$, em 1976, afirmou que a infiltração marginal ocorria devido a diferenças de expansão térmica linear entre a restauração e o dente. No entanto, a mesma autora, juntamente com HARRINGTON; GRIEVE ${ }^{54}$, em 1978, chegaram a conclusão que a correlação da infiltração, conseqüente à diferença entre o coeficiente de expansão térmica do material e o das estruturas dentárias tem importância clínica duvidosa. Muitos autores ${ }^{7,54,71,94}$, argumentaram ainda que o tempo de duração dos banhos em testes laboratoriais não eqüivale à realidade clínica, pois que é impossível que os pacientes suportem temperaturas extremas por tanto tempo.

QVIST $^{85}$, em 1983, realizou um estudo clínico em que foram avaliadas restaurações, com e sem seu respectivo antagonista, após extração sobre o aspecto de microinfiltração. Os resultados demonstraram um aumento de infiltração bacteriana de $28 \%$ para $71 \%$, quando os dentes foram submetidos a cargas oclusais pela presença do antagonista. Os autores concluíram, então, que a mastigação exerce maior influência na integridade marginal de restaurações de resina composta que outros fatores do meio ambiente bucal, tais como: estresse térmico e desgaste, dentre outros. 
JÖRGENSEN; MATONO; SHIMOKOBE ${ }^{52}$, em 1976, estudaram a deformação de cavidades classe II e V submetidas a carga axial, e a possibilidade do efeito dessa deformação na qualidade das restaurações. Os autores concluíram que a instabilidade dimensional das cavidades submetidas a cargas oclusais indica um risco potencial de percolação das restaurações e de fratura das margens de restaurações feitas com materiais friáveis. Em 1991, LUNDIN, NORÉN ${ }^{60}$ avaliaram, in vitro, a microinfiltração de restaurações classe II (MO e DO) feitas com dois sistemas restauradores resinosos, submetidas a carga oclusal. Concluíram que, em dentes posteriores, a aplicação repetida de cargas aumenta consideravelmente $(61 \%)$ o risco de infiltração marginal.

Os efeitos de estresse mecânico e térmico na microinfiltração marginal de restaurações classe II com dois sistemas resinosos (Scotchbond Multi-Uso Z100/3M; Optibond - Herculite XRV/Kerr) foram avaliados por GONÇALVES ${ }^{45}$, em 1996. Independentemente do estresse aplicado nenhum sistema foi capaz de bloquear totalmente a infiltração marginal. Maior infiltração marginal foi encontrada nos espécimes submetidos a ciclagem mecânica, quando comparados às amostras termocicladas e ao controle, para ambos os materiais testados.

Muitos trabalhos $2,5,37,45,52,61,62,63,65,76,77,88,102$ vêm demonstrando a influência que a ciclagem mecânica exerce sobre a infiltração marginal. Alguns autores, no entanto, concluíram que o estresse mecânico não interfere na infiltração $\left(\mathrm{PRATI}^{84}\right.$, em 1994, e TAYLOR; LYNCH ${ }^{100}$, 1992); ou que apenas exerce influência se associado com a ciclagem térmica (RIGSBY et al. ${ }^{90}$ em 1992).

Baseados na revisão da literatura, optou-se por aplicação, no presente trabalho, apenas da ciclagem mecânica, principalmente em face da utilização de diferentes materiais, cada um com suas particularidades no que diz respeito ao coeficiente de expansão térmica linear. Neste estudo, os dentes restaurados foram submetidos a ciclagem com carga, simulando os estresses mecânicos decorrentes da função mastigatória. Na literatura, observa-se muita divergência nas cargas aplicadas, variando de $8 \mathrm{~kg}$ a $20 \mathrm{~kg}$. Resolveu-se aplicar ciclos de cargas de 1 e 
$17 \mathrm{~kg}$, com base no trabalho de FIELDS et al. ${ }^{36}$, 1986, no qual estudaram as variáveis, que afetam a mensuração das forças oclusais durante os processos de deglutição, mastigação e esforço máximo de mordida, em 3 faixas etárias. Os valores encontrados demonstraram uma média da força mastigatória em adultos jovens (de 25 a 29 anos) de 17,6 kg com abertura bucal de $20 \mathrm{~mm}$.

Na grande maioria dos trabalhos onde se emprega detecção da penetração do corante, a análise é feita subjetivamente, por meio de atribuição de escores ${ }^{2}$, $31,45,50,63,64,65,76,77,81,89,90,92,94,97,98,106$. No estudo piloto deste trabalho, avaliouse a infiltração utilizando-se o método subjetivo na análise da infiltração do corte mais infiltrado de cada dente, por meio de escores pré-determinados; e o método objetivo, na quantificação dessa infiltração pelo cálculo da área ou da extensão linear de infiltração. Esta medição foi realizada através do programa de computador ImageTool, onde a área infiltrada pelo corante foi delineada por intermédio de uma ferramenta adaptada para a realização do cálculo em $\mathrm{mm}^{2}$ (Figura 6.1) de acordo com trabalhos atuais ${ }^{71,109}$.

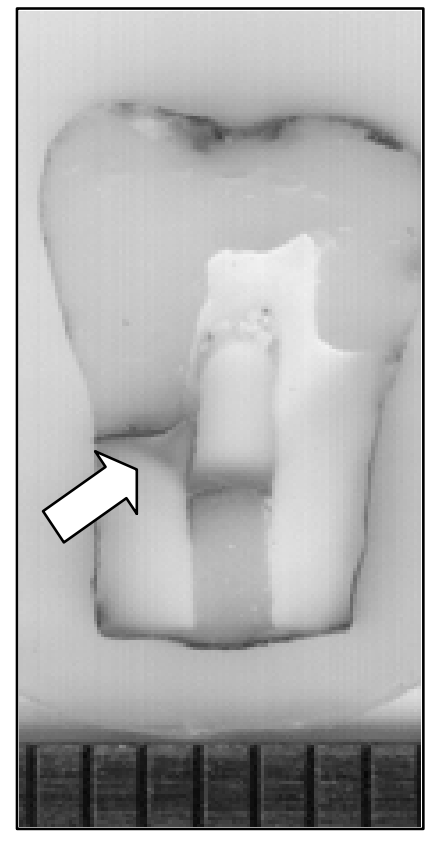

Figura 6.1.

Imagem ilustrativa da área de infiltração de corante 
Os resultados foram submetidos às respectivas análises estatísticas (paramétrica e não paramétrica). Para que a escolha do tipo de método de medição de infiltração fosse feito da forma mais segura possível, foi aplicado ainda teste de correlação como verificado na Tabela 1, Anexo 2.

De acordo com os resultados, pôde-se observar correlação estatística significante entre os métodos estudados. O método de medição escolhido foi o de área de infiltração, por se acreditar ser este o mais completo, ou seja, aquele que representa melhor, dentro de cada fatia, a quantidade de corante penetrado, para definir a infiltração. Porém, todos os dados foram determinados tanto por extensão linear como por escores, e ainda submetidos a análise estatística. Os resultados apresentaram-se semelhantes para os três métodos de medição, de acordo com as análises feitas.

\section{3 - RESULTADOS}

Seguindo a proposição do presente trabalho, onde se verificou o comportamento das novas resinas em paredes com margens em esmalte e em dentina, os resultados mostraram uma resposta superior de bloqueio da infiltração em paredes localizadas em estrutura de esmalte, independentemente do material utilizado ou da associação com bases cavitárias.

Esse resultado corrobora os estudos que têm demonstrado existir maior infiltração nas margens situadas em dentina do que nas situadas em esmalte ${ }^{11,13,18,35,42 \text {, }}$ 43, 55, 56, 62, 63, 71, 73, 76, 88, 89, 90, 93, 97, 98, 102. De acordo com CARVALHO ${ }^{13}$, 1998, apesar da grande evolução dos sistemas adesivos, não se conseguiu ainda, para a dentina, um resultado tão eficaz quanto a adesão ao esmalte, principalmente a longo prazo.

A adesão ocorre de maneiras diferentes, em esmalte e em dentina pela própria diferença morfológica dessas estruturas. $\mathrm{O}$ esmalte é bastante homogêneo, composto basicamente por mineral (97\%), com quantidades insignificantes de matéria orgânica e água. Os procedimentos adesivos em esmalte são simples. A 
uniformidade composicional desse substrato torna a técnica adesiva menos sensível $^{13,73}$.

Por outro lado, a dentina é uma estrutura mais complexa. Apresenta, comparada ao esmalte, uma maior quantidade de água e de matéria orgânica. Ademais, possui os túbulos dentinários, que permitem passagem de fluidos, o que pode aumentar a permeabilidade da dentina à medida que se aproxima da câmara pulpar, por apresentar maior diâmetro e maior quantidade por unidade de área nessa região ${ }^{13,74,75}$. Dessa forma, a dentina é um substrato poroso e úmido, cuja composição varia dependendo da profundidade do preparo cavitário. Conseqüentemente, os procedimentos adesivos na dentina também são mais complexos.

No início dos anos 50, BUONOCORE ${ }^{12}$, realizou as primeiras tentativas de unir as resinas à dentina. Apesar de não ter obtido êxito, foi o início do entendimento do complexo que envolveria essa adesão. Com NAKABAYASHI, KOJIMA E MASUHARA ${ }^{68}$, em 1982, surgiu a camada híbrida que é atualmente considerada o principal mecanismo de adesão à dentina ${ }^{13}$.

Ao longo dos anos, os sistemas adesivos sofreram modificações, passando por alterações profundas nas suas constituições e princípios de ativação. Hoje, os mais comuns são aqueles cujos primer e adesivo são acondicionados juntos em um mesmo frasco. No presente trabalho, todos os sistemas adesivos utilizados são constituídos dessa maneira, com o primer associado ao agente de união (Prime \& Bond 2.1/Dentsply; Gluma One Bond/Kulzer; Single Bond/3M e Bond $1 /$ Jeneric Pentron).

Nos grupos foram utilizados apenas as resinas composta com os respectivos adesivos foram utilizados, sem interposição de base, o sistema Solitaire/Gluma One Bond (Kulzer) apresentou os piores resultados quanto à infiltração marginal, quando comparado aos demais sistemas P60/Single Bond (3M) e SureFil/Prime e Bond 2.1 (Dentsply). Esse resultado confirmou o trabalho de PEREIRA, 1999, que, avaliando a resina Solitaire associada ao 
adesivo Solid Bond S (primeiro adesivo a ser lançado no Kit da Solitaire) e a Z100 (3M) com os sistemas adesivos Single Bond (3M) e Snapbond/Cooley \& Cooley., em relação à microinfiltração, encontrou os maiores índices de penetração de corante para o sistema Solitaire/Solid Bond S (Kulzer), independentemente da técnica de inserção utilizada e da aplicação (ou não) de carga .

Trabalhos recentes também corroboram esses resultados. AFFLECK et al. ${ }^{4}$, em 1999, e PRAKKI, CILLI, ARAÚJO ${ }^{82}$, em 2000, também encontraram in vitro, resultados não satisfatórios para o sistema Solitaire/Gluma One Bond (Kulzer) com relação à infiltração marginal.

Quando a interposição de bases foi avaliada neste trabalho, encontrou-se algum benefício apenas para o sistema Solitaire/Gluma One Bond (Kulzer). Não ocorreu diferença estatisticamente significante entre a presença ou a ausência de base, tanto de cimento de ionômero de vidro (Vitremer/3M) quando de resina de baixa viscosidade (Flow-It!), para os sistemas P60/Single Bond (3M) e SureFil/ Prime \& Bond 2.1 (Dentsply).

A ação de cimentos de ionômero de vidro como base, na redução da infiltração marginal vem sendo estudada há alguns anos, havendo uma

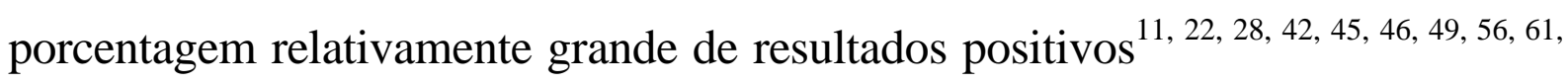
64, 66, 71, 73, 83, 89, 97, 98 . Estudando o efeito que materiais restauradores, como o cimento de ionômero de vidro modificado por resina, exercem na infiltração marginal de restaurações classe II, MILLER et al. ${ }^{64}$, em 1996, observaram que o cimento de ionômero de vidro (Vitermer/3M) demonstrou ser significativamente mais eficiente que os outros materiais em minimizar a infiltração nas margens cervicais do preparo.

Alguns autores ${ }^{25,26,43}$, no entanto, têm questionado a ação dos ionômeros de vidro, uma vez que os novos sistemas adesivos proporcionam um bom selamento. Essa afirmação se baseia em análises comparativas da utilização (ou não) de base de ionômero de vidro, não tendo sido encontrados resultados mais satisfatórios quando comparados ao uso apenas do sistema adesivo. 
A adaptação marginal de restaurações em resina composta com e sem interposição de ionômero de vidro tem sido estudada por alguns autores por meio de microscopia eletrônica de varredura. Utilizando esse método, DIETRICH et al. ${ }^{25}$, em 1999, avaliaram a adaptação marginal de restaurações classe II, com e sem interposição de ionômeros de vidro como base cavitária, e pela técnica do sanduíche aberto. Observaram que, para as margens em dentina, a adaptação foi significantemente melhor com a técnica sanduíche aberto, quando comparada às outras técnicas. Para os autores, a utilização de base de ionômero de vidro não melhora a adaptação marginal e, conseqüentemente, a infiltração marginal. Tal afirmação foi confirmada por GARCIA-GODOY; MALONE $^{43}$, em 1988; e por THONEMANN et al. ${ }^{101}$, em 1999. Para DIETSCH et al. ${ }^{26}$, em 1995, os novos sistemas adesivos parecem promover uma melhoria significativa m qualidade do selamento marginal, já que nos seus achados, os adesivos mostraram-se mais eficientes quando utilizados isoladamente que quando usados em associação com as bases de ionômero de vidro.

Entretanto, CHUANG, LIU e JIN ${ }^{14}$, em 2000, investigando a influência de base em restaurações classe II, na microinfiltração por penetração de corante e na adaptação marginal por microscopia eletrônica de varredura, e determinando a correlação entre as técnicas utilizadas, mostraram não ter ocorrido correlação significante entre os resultados da adaptação marginal e da microinfiltração.

A respeito da ação de RBV em bloquear ou minimizar a infiltração marginal, os resultados encontrados na literatura têm sido controversos. TUNG, ESTAFAN e SCHERER $^{104}$, em 2000 investigaram a infiltração marginal em dentes posteriores restaurados com SureFil (Dentsply), com e sem base de RBV. Os resultados desse estudo indicaram que o grupo onde a resina Prema Flow (Ultradent) foi utilizada como base mostrou significantemente menos infiltração que os demais grupos. Concluíram, os autores, que as resinas de baixa viscosidade, quando usadas como base, demonstraram diminuir a microinfiltração em margens de esmalte e de dentina. Esse resultado vem ao encontro de muito outros resultados de trabalhos 
que estudaram a ação de resinas de baixa viscosidade como material de base ou restaurador $2,31,38,51,59,103,105$.

O que é corroborado por BATITUCCI et al. ${ }^{9}$, em 2000, que avaliaram os efeitos da associação entre RBV (Flow-it!/Jeneric Pentron) e RDP (Surefil/Dentsply; Definite/Degussa) na microinfiltração em restaurações classe II e concluíram que as resinas de baixa viscosidade, quando associadas a SureFil (Dentsply) e Definite (Degussa) foram eficientes na redução da microinfiltração.

Alguns estudos, porém, não confirmam a boa ação das resinas fluidas com relação à infiltração marginal 6 , 14, 34, 65, 98. RUSSELL; MAZER ${ }^{92}, 1999$, determinaram a extensão de infiltração em cavidades classe II, restauradas com resina composta $(\mathrm{Z100/3M})$ com interposição de base de resina fluida (Aelite Flo, Florestore, Tetric Flow). Os autores concluíram que as resinas fluidas testadas não foram capazes de reduzir a infiltração ao longo da parede gengival, onde o esmalte em termos de qualidade e quantidade é deficiente.

HAGGE et al. ${ }^{46}$, em 2000, avaliaram a infiltração marginal de restaurações classe II de resina composta com interposição de 5 materiais intermediários, dentre eles RBV e cimento de ionômero de vidro (Fuji II LC/GC). Os resultados demonstraram que nas restaurações onde o ionômero de vidro modificado por resina foi aplicado como base, a infiltração marginal foi significativamente menor que nos demais grupos.

Nos resultados do presente estudo, diferenças estatísticas significantes não foram encontradas entre a ação das duas bases, assim como nos trabalhos especificados anteriormente. A despeito da interposição dessas bases (Vitremer/3M e do sistema Flow-It! - Bond 1 - Jeneric Pentron) em restaurações feitas com o sistema P60/Single Bond (3M) e SureFil/Prime \& Bond 2.1 (Dentsply) não foi encontrada uma redução significante na infiltração quando comparadas as mesmas resinas sem a presença das bases. No entanto a presença das bases diminuiu significantemente a infiltração marginal para o sistema Solitaire/Gluma One Bond (Kulzer), a ponto de 
as associações Solitaire/Vitremer e Solitaire/Flow-It! não mostrarem diferença estatística em relação às demais resinas e suas associações.

A não interferência das bases nos sistemas P60/Single Bond (3M) e SureFil/Prime \& Bond 2.1 (Dentsply) provavelmente se deve a um melhor selamento alcançado por seus adesivos Single Bond e Prime \& Bond 2.1, respectivamente. Por outro lado, os resultados negativos para o sistema Solitaire/Gluma One Bond (Kulzer) provavelmente se devam, pelo menos em parte, ao sistema adesivo da resina, que necessita de maiores estudos, como todo material recentemente lançado no mercado.

Outra explicação pode estar no grau da contração de polimerização. A resina Solitaire (Kulzer) apresenta um grau de contração de polimerização de 3,4 (\% em volume), considerado alto, quando comparado ao das outras duas resinas (P60/3M e SureFil/Dentsply) que gira em torno de 2,1 (\% em volume $)^{59}$. Talvez este fato explique os resultados inferiores quando foi utilizada sem interposição de bases. A maior resiliência da RBV e do cimento de ionômero de vidro, associada à diminuição do volume da resina pela presença desses materiais, provavelmente tenha interferido nos efeitos da contração e da deformação no momento da aplicação de carga.

Apesar de não ter sido detectada diferença estatística com relação à utilização das bases avaliadas no presente estudo, é prudente, que em situações clinicas onde as margens cervicais localizarem-se em dentina, optar-se pelo cimento de ionômero de vidro. Isso porquê, de acordo com SILVA e SOUZA Jr., CARVALHO, MODELLI ${ }^{97}$, 2000, apesar de esses materiais não terem uma resistência adesiva muito elevada, apresentam resultados bastante regulares em testes de microinfiltração, independentemente da qualidade do substrato; detalhe esse nem sempre observado para alguns adesivos resinosos. Ademais têm a propriedade de liberação de flúor, o que condiciona um bloqueio às caries secundárias ${ }^{67}$. 
Finalizando, seria interessante mencionar que se percebe, por parte dos estudos e das pesquisas, uma tendência em desenvolver sistemas adesivos que sejam efetivos no sentido físico da sua união com as estruturas dentárias e, também, no que diz respeito às suas propriedades mecânicas. O grande desafio dos sistemas adesivos são as modificações que o substrato sofre, de natureza fisiológica e patológica, e também suas variações regionais ${ }^{13,}$ 74, 75, 97 . Além disso, deve-se alertar que os dentes empregados neste estudo apresentam menores variabillidades do que o clínico encontra normalmente, no dia-a-dia do consultório.

A obtenção de uma adesão ideal, clinicamente, é ainda um objetivo a ser alcançado. Por isso, o uso de bases, como os ionômeros, pode, em certos casos, melhorar a qualidade da interface em restaurações com resinas compostas. Não é demais lembrar que outros aspectos, como o grau de conversão das resinas, a profundidade de polimerização e, principalmente, a contração de polimerização atuam adversamente ao selamento marginal. Dessa forma, associado ao uso de bases, devem ser tomados cuidados redobrados durante a inserção e fotoativação das resinas, visando a minimizar ao máximo os efeitos deletérios dos aspectos mencionados. 


$$
\text { 7-Conclusões }
$$




\section{7- CONCLUSÕES}

Considerando as proposições deste estudo e de acordo com análise estatística aplicada aos valores obtidos, é válido concluir que:

$\checkmark \quad$ O sistema Solitaire/Gluma One Bond (Kulzer) apresentou maiores níveis de infiltração que os sistemas P60/Single Bond (3M) e SureFil/Prime \& Bond 2.1(Dentsply), tanto em margens de esmalte e de dentina, sem interposição de base.

$\checkmark \quad \mathrm{O}$ cimento de ionômero de vidro, Vitremer/3M, mostrou-se eficiente em minimizar a infiltração marginal em margens de dentina e de esmalte para o sistema Solitaire/Gluma One Bond (Kulzer).

$\checkmark \quad$ A resina de baixa viscosidade, Flow-It!/Bond 1 (Jeneric Pentron), também minimizou a microinfiltração em margens de dentina e de esmalte, para o sistema Solitaire/Gluma One Bond (Kulzer).

$\checkmark \quad$ Não ocorreu diferença estatisticamente significante entre a presença ou ausência de base para os sistemas P60/Single Bond (3M) e SureFil/Prime \& Bond 2.1 (Dentsply), tanto em margens de dentina quanto de esmalte.

\section{Resumidamente e considerando as hipóteses testadas:}

$\checkmark \quad$ A presença das bases (Resina composta de baixa viscosidade e Ionômero de vidro modificado por resina) podem minimizar os níveis de infiltração em margens de esmalte e dentina, porém está na dependência do sistema restaurador empregado. 
$\checkmark \quad$ As margens em esmalte apresentaram, independentemente dos materiais utilizados e das associações entre os mesmos, menores áreas infiltradas quando comparadas as margens em dentina. 


\section{Anexos}




\section{ANEXO 1}

\begin{tabular}{|l|l|l|l|}
\hline MATERIAL & BASE & MARGEM & ÁREA $\mathbf{~ ( m m ~}^{2}$ ) \\
\hline P60 & Ausência de base & Dentina & 0,50 \\
\hline P60 & Ausência de base & Dentina & 0,54 \\
\hline P60 & Ausência de base & Dentina & 0,26 \\
\hline P60 & Ausência de base & Dentina & 1,21 \\
\hline P60 & Ausência de base & Dentina & 0,05 \\
\hline P60 & Ausência de base & Dentina & 0,87 \\
\hline P60 & Ausência de base & Dentina & 0,58 \\
\hline P60 & Ausência de base & Dentina & 0,75 \\
\hline P60 & Ausência de base & Dentina & 0,17 \\
\hline P60 & Ausência de base & Dentina & 0,95 \\
\hline
\end{tabular}

FIGURA 1 - Resultados originais, em $\mathrm{mm}^{2}$, das áreas de infiltração relativas as margens em dentina para o material ${\mathrm{P} 60^{\star}}^{\star} \mathrm{com}$ ausência de base. 


\begin{tabular}{|l|l|l|l|}
\hline MATERIAL & BASE & MARGEM & ÁREA $\mathbf{( m m}^{2}$ ) \\
\hline P60 & Ausência de base & Esmalte & 0,07 \\
\hline P60 & Ausência de base & Esmalte & 0,09 \\
\hline P60 & Ausência de base & Esmalte & 0,10 \\
\hline P60 & Ausência de base & Esmalte & 0,02 \\
\hline P60 & Ausência de base & Esmalte & 0,16 \\
\hline P60 & Ausência de base & Esmalte & 0,02 \\
\hline P60 & Ausência de base & Esmalte & 0,04 \\
\hline P60 & Ausência de base & Esmalte & 0,04 \\
\hline P60 & Ausência de base & Esmalte & 0,00 \\
\hline P60 & Ausência de base & Esmalte & 0,01 \\
\hline
\end{tabular}

FIGURA 2 - Resultados originais, em $\mathrm{mm}^{2}$, das áreas de infiltração relativas as margens em esmalte para o material $\mathrm{P} 60^{\star}$ com ausência de base. 


\begin{tabular}{|l|l|l|l|}
\hline MATERIAL & BASE & MARGEM & AREA $\left.\mathbf{( m m}^{2}\right)$ \\
\hline Solitaire & Ausência de base & Dentina & 2,80 \\
\hline Solitaire & Ausência de base & Dentina & 2,97 \\
\hline Solitaire & Ausência de base & Dentina & 0,26 \\
\hline Solitaire & Ausência de base & Dentina & 2,30 \\
\hline Solitaire & Ausência de base & Dentina & 2,28 \\
\hline Solitaire & Ausência de base & Dentina & 2,24 \\
\hline Solitaire & Ausência de base & Dentina & 0,84 \\
\hline Solitaire & Ausência de base & Dentina & 3,41 \\
\hline Solitaire & Ausência de base & Dentina & 2,17 \\
\hline Solitaire & Ausência de base & Dentina & 2,59 \\
\hline
\end{tabular}

FIGURA 3 - Resultados originais, em $\mathrm{mm}^{2}$, das áreas de infiltração relativas as margens em dentina para o material Solitaire ${ }^{8}$ com ausência de base.

8 HARAEUS KULZER South America Ltda. 


\begin{tabular}{|l|l|l|l|}
\hline MATERIAL & BASE & MARGEM & ÁRA $\mathbf{( m m}^{2}$ ) \\
\hline Solitaire & Ausência de base & Esmalte & 2,29 \\
\hline Solitaire & Ausência de base & Esmalte & 0,14 \\
\hline Solitaire & Ausência de base & Esmalte & 0,06 \\
\hline Solitaire & Ausência de base & Esmalte & 0,95 \\
\hline Solitaire & Ausência de base & Esmalte & 2,09 \\
\hline Solitaire & Ausência de base & Esmalte & 1,71 \\
\hline Solitaire & Ausência de base & Esmalte & 0,13 \\
\hline Solitaire & Ausência de base & Esmalte & 2,15 \\
\hline Solitaire & Ausência de base & Esmalte & 0,14 \\
\hline Solitaire & Ausência de base & Esmalte & 0,57 \\
\hline
\end{tabular}

FIGURA 4 - Resultados originais, em $\mathrm{mm}^{2}$, das áreas de infiltração relativas as margens em esmalte para o material Solitaire ${ }^{8}$ com ausência de base.

8 HARAEUS KULZER South America Ltda. 


\begin{tabular}{|l|l|l|l|}
\hline MATERIAL & BASE & MARGEM & ÁREA $\mathbf{( m m}^{2}$ ) \\
\hline SureFil & Ausência de base & Dentina & 0,74 \\
\hline SureFil & Ausência de base & Dentina & 0.47 \\
\hline SureFil & Ausência de base & Dentina & 1,46 \\
\hline SureFil & Ausência de base & Dentina & 1,82 \\
\hline SureFil & Ausência de base & Dentina & 2,30 \\
\hline SureFil & Ausência de base & Dentina & $1,-01$ \\
\hline SureFil & Ausência de base & Dentina & 0,00 \\
\hline SureFil & Ausência de base & Dentina & 0,66 \\
\hline SureFil & Ausência de base & Dentina & 0,56 \\
\hline SureFil & Ausência de base & Dentina & 1,11 \\
\hline
\end{tabular}

FIGURA5 - Resultados originais, em $\mathrm{mm}^{2}$, das áreas de infiltração relativas as margens em dentina para o material SureFil ${ }^{*}$ com ausência de base. 


\begin{tabular}{|l|l|l|l|}
\hline MATERIAL & BASE & MARGEM & ÁREA $\mathbf{( m m}^{2}$ ) \\
\hline SureFil & Ausência de base & Esmalte & 0,16 \\
\hline SureFil & Ausência de base & Esmalte & 0,10 \\
\hline SureFil & Ausência de base & Esmalte & 0,44 \\
\hline SureFil & Ausência de base & Esmalte & 1,02 \\
\hline SureFil & Ausência de base & Esmalte & 0,00 \\
\hline SureFil & Ausência de base & Esmalte & 0,00 \\
\hline SureFil & Ausência de base & Esmalte & 0,00 \\
\hline SureFil & Ausência de base & Esmalte & 0,07 \\
\hline SureFil & Ausência de base & Esmalte & 0,00 \\
\hline SureFil & Ausência de base & Esmalte & 0,05 \\
\hline
\end{tabular}

FIGURA 6 - Resultados originais, em $\mathrm{mm}^{2}$, das áreas de infiltração relativas as margens em esmalte para o material SureFil ${ }^{*}$ com ausência de base. 


\begin{tabular}{|l|l|l|l|}
\hline MATERIAL & BASE & MARGEM & ÁREA $\mathbf{( m m}^{2}$ ) \\
\hline P60 & Flow-It! & Dentina & 0,59 \\
\hline P60 & Flow-It! & Dentina & 0,76 \\
\hline P60 & Flow-It! & Dentina & 0,60 \\
\hline P60 & Flow-It! & Dentina & 0,00 \\
\hline P60 & Flow-It! & Dentina & 1,41 \\
\hline P60 & Flow-It! & Dentina & 0,06 \\
\hline P60 & Flow-It! & Dentina & 1,02 \\
\hline P60 & Flow-It! & Dentina & 0,00 \\
\hline P60 & Flow-It! & Dentina & 0,00 \\
\hline P60 & Flow-It! & Dentina & 0,04 \\
\hline
\end{tabular}

FIGURA 7 - Resultados originais, em $\mathrm{mm}^{2}$, das áreas de infiltração relativas as margens em dentina para o material $\mathrm{P} 60^{\star}$ com base de Flow-It! ${ }^{\oplus}$. 


\begin{tabular}{|l|l|l|l|}
\hline MATERIAL & BASE & MARGEM & ÁREA $\mathbf{( m m}^{2}$ ) \\
\hline P60 & Flow-It! & Esmalte & 0,00 \\
\hline P60 & Flow-It! & Esmalte & 0,17 \\
\hline P60 & Flow-It! & Esmalte & 0,14 \\
\hline P60 & Flow-It! & Esmalte & 0,08 \\
\hline P60 & Flow-It! & Esmalte & 0,80 \\
\hline P60 & Flow-It! & Esmalte & 0,00 \\
\hline P60 & Flow-It! & Esmalte & 0,00 \\
\hline P60 & Flow-It! & Esmalte & 0,00 \\
\hline P60 & Flow-It! & Esmalte & 0,04 \\
\hline P60 & Flow-It! & Esmalte & 0,00 \\
\hline
\end{tabular}

FIGURA 8 - Resultados originais, em $\mathrm{mm}^{2}$, das áreas de infiltração relativas as margens em esmalte para o material $\mathrm{P} 60^{\star} \mathrm{com}$ base de Flow-It! ${ }^{\oplus}$. 


\begin{tabular}{|l|l|l|l|}
\hline MATERIAL & BASE & MARGEM & ÁREA $\left.\mathbf{( m m}^{2}\right)$ \\
\hline Solitaire & Flow-It! & Dentina & 0,20 \\
\hline Solitaire & Flow-It! & Dentina & 0,62 \\
\hline Solitaire & Flow-It! & Dentina & 1,15 \\
\hline Solitaire & Flow-It! & Dentina & 0,16 \\
\hline Solitaire & Flow-It! & Dentina & 1,14 \\
\hline Solitaire & Flow-It! & Dentina & 1,65 \\
\hline Solitaire & Flow-It! & Dentina & 0,00 \\
\hline Solitaire & Flow-It! & Dentina & 1,93 \\
\hline Solitaire & Flow-It! & Dentina & 0,55 \\
\hline Solitaire & Flow-It! & Dentina & 0,49 \\
\hline
\end{tabular}

FIGURA 9 - Resultados originais, em $\mathrm{mm}^{2}$, das áreas de infiltração relativas as margens em dentina para o material Solitaire ${ }^{8}$ com base de Flow-It! ${ }^{\oplus}$. 


\begin{tabular}{|l|l|l|l|}
\hline MATERIAL & BASE & MARGEM & ÁREA $\left.\mathbf{( m m}^{2}\right)$ \\
\hline Solitaire & Flow-It! & Esmalte & 0,22 \\
\hline Solitaire & Flow-It! & Esmalte & 0,73 \\
\hline Solitaire & Flow-It! & Esmalte & 0,04 \\
\hline Solitaire & Flow-It! & Esmalte & 0,00 \\
\hline Solitaire & Flow-It! & Esmalte & 0,43 \\
\hline Solitaire & Flow-It! & Esmalte & 0,37 \\
\hline Solitaire & Flow-It! & Esmalte & 0,00 \\
\hline Solitaire & Flow-It! & Esmalte & 0,09 \\
\hline Solitaire & Flow-It! & Esmalte & 0,08 \\
\hline Solitaire & Flow-It! & Esmalte & 0,00 \\
\hline
\end{tabular}

FIGURA 10 - Resultados originais, em $\mathrm{mm}^{2}$, das áreas de infiltração relativas as margens em esmalte para o material Solitaire ${ }^{8}$ com base de Flow-It! $!^{\oplus}$. 


\begin{tabular}{|l|l|l|l|}
\hline MATERIAL & BASE & MARGEM & ÁREA $\left.\mathbf{( m m}^{2}\right)$ \\
\hline SureFil & Flow-It! & Dentina & 0,30 \\
\hline SureFil & Flow-It! & Dentina & 1,12 \\
\hline SureFil & Flow-It! & Dentina & 0,53 \\
\hline SureFil & Flow-It! & Dentina & 0,00 \\
\hline SureFil & Flow-It! & Dentina & 0,13 \\
\hline SureFil & Flow-It! & Dentina & 0,00 \\
\hline SureFil & Flow-It! & Dentina & 2,88 \\
\hline SureFil & Flow-It! & Dentina & 0,10 \\
\hline SureFil & Flow-It! & Dentina & 0,00 \\
\hline SureFil & Flow-It! & Dentina & 1,12 \\
\hline
\end{tabular}

FIGURA11 - Resultados originais, em $\mathrm{mm}^{2}$, das áreas de infiltração relativas as margens em dentina para o material SureFil* com base de Flow-It! ${ }^{\oplus}$. 


\begin{tabular}{|l|l|l|l|}
\hline MATERIAL & BASE & MARGEM & ÁREA $\left.\mathbf{( m m}^{2}\right)$ \\
\hline SureFil & Flow-It! & Esmalte & 0,05 \\
\hline SureFil & Flow-It! & Esmalte & 0,00 \\
\hline SureFil & Flow-It! & Esmalte & 0,13 \\
\hline SureFil & Flow-It! & Esmalte & 0,19 \\
\hline SureFil & Flow-It! & Esmalte & 0,05 \\
\hline SureFil & Flow-It! & Esmalte & 0,00 \\
\hline SureFil & Flow-It! & Esmalte & 3,10 \\
\hline SureFil & Flow-It! & Esmalte & 0,15 \\
\hline SureFil & Flow-It! & Esmalte & 0,19 \\
\hline SureFil & Flow-It! & Esmalte & 0,12 \\
\hline
\end{tabular}

FIGURA 12 - Resultados originais, em $\mathrm{mm}^{2}$, das áreas de infiltração relativas as margens em esmalte para o material SureFil ${ }^{*}$ com base de Flow-It! ${ }^{\oplus}$. 


\begin{tabular}{|l|l|l|l|}
\hline MATERIAL & BASE & MARGEM & ÁREA $\left.\mathbf{( m m}^{2}\right)$ \\
\hline P60 & Vitremer & Dentina & 0,05 \\
\hline P60 & Vitremer & Dentina & 0,66 \\
\hline P60 & Vitremer & Dentina & 0,08 \\
\hline P60 & Vitremer & Dentina & 2,33 \\
\hline P60 & Vitremer & Dentina & 0,85 \\
\hline P60 & Vitremer & Dentina & 0,23 \\
\hline P60 & Vitremer & Dentina & 0,57 \\
\hline P60 & Vitremer & Dentina & 0,00 \\
\hline P60 & Vitremer & Dentina & 0,08 \\
\hline P60 & Vitremer & Dentina & 1,30 \\
\hline
\end{tabular}

FIGURA13 - Resultados originais, em $\mathrm{mm}^{2}$, das áreas de infiltração relativas as margens em dentina para o material $\mathrm{P} 60^{\star} \mathrm{com}$ base de Vitremer".

3M do Brasil Ltda Produtos Dentários. 


\begin{tabular}{|l|l|l|l|}
\hline MATERIAL & BASE & MARGEM & ÁREA $\left.\mathbf{( m m}^{2}\right)$ \\
\hline P60 & Vitremer & Esmalte & 0,03 \\
\hline P60 & Vitremer & Esmalte & 0,30 \\
\hline P60 & Vitremer & Esmalte & 0,00 \\
\hline P60 & Vitremer & Esmalte & 0,15 \\
\hline P60 & Vitremer & Esmalte & 0,45 \\
\hline P60 & Vitremer & Esmalte & 0,47 \\
\hline P60 & Vitremer & Esmalte & 0,12 \\
\hline P60 & Vitremer & Esmalte & 0,00 \\
\hline P60 & Vitremer & Esmalte & 0,00 \\
\hline P60 & Vitremer & Esmalte & 0,00 \\
\hline
\end{tabular}

FIGURA 14 - Resultados originais, em $\mathrm{mm}^{2}$, das áreas de infiltração relativas as margens em esmalte para o material $\mathrm{P} 60^{\star}$ com base de Vitremer".

3M do Brasil Ltda Produtos Dentários. 


\begin{tabular}{|l|l|l|l|}
\hline MATERIAL & BASE & MARGEM & ÁREA $\left.\mathbf{( m m}^{2}\right)$ \\
\hline Solitaire & Vitremer & Dentina & 0,00 \\
\hline Solitaire & Vitremer & Dentina & 0,02 \\
\hline Solitaire & Vitremer & Dentina & 0,66 \\
\hline Solitaire & Vitremer & Dentina & 1,24 \\
\hline Solitaire & Vitremer & Dentina & 1,02 \\
\hline Solitaire & Vitremer & Dentina & 0,00 \\
\hline Solitaire & Vitremer & Dentina & 0,68 \\
\hline Solitaire & Vitremer & Dentina & 1,26 \\
\hline Solitaire & Vitremer & Dentina & 0,00 \\
\hline Solitaire & Vitremer & Dentina & 0,91 \\
\hline
\end{tabular}

FIGURA 15 - Resultados originais, em $\mathrm{mm}^{2}$, das áreas de infiltração relativas as margens em dentina para o material Solitaire ${ }^{8}$ com base de Vitremer". 


\begin{tabular}{|l|l|l|l|}
\hline MATERIAL & BASE & MARGEM & ÁREA $\left.\mathbf{( m m}^{2}\right)$ \\
\hline Solitaire & Vitremer & Esmalte & 0,00 \\
\hline Solitaire & Vitremer & Esmalte & 0,00 \\
\hline Solitaire & Vitremer & Esmalte & 0,02 \\
\hline Solitaire & Vitremer & Esmalte & 0,13 \\
\hline Solitaire & Vitremer & Esmalte & 0,06 \\
\hline Solitaire & Vitremer & Esmalte & 0,00 \\
\hline Solitaire & Vitremer & Esmalte & 0,27 \\
\hline Solitaire & Vitremer & Esmalte & 0,21 \\
\hline Solitaire & Vitremer & Esmalte & 0,13 \\
\hline Solitaire & Vitremer & Esmalte & 0,10 \\
\hline
\end{tabular}

FIGURA 16 - Resultados originais, em $\mathrm{mm}^{2}$, das áreas de infiltração relativas as margens em esmalte para o material Solitaire ${ }^{8}$ com base de Vitremer". 


\begin{tabular}{|l|l|l|l|}
\hline MATERIAL & BASE & MARGEM & ÁREA $\left.\mathbf{( m m}^{2}\right)$ \\
\hline SureFil & Vitremer & Dentina & 0,63 \\
\hline SureFil & Vitremer & Dentina & 0,00 \\
\hline SureFil & Vitremer & Dentina & 0,06 \\
\hline SureFil & Vitremer & Dentina & 0,10 \\
\hline SureFil & Vitremer & Dentina & 0,86 \\
\hline SureFil & Vitremer & Dentina & 0,66 \\
\hline SureFil & Vitremer & Dentina & 0,58 \\
\hline SureFil & Vitremer & Dentina & 0,94 \\
\hline SureFil & Vitremer & Dentina & 1,00 \\
\hline SureFil & Vitremer & Dentina & 0,48 \\
\hline
\end{tabular}

FIGURA 17 - Resultados originais, em $\mathrm{mm}^{2}$, das áreas de infiltração relativas as margens em dentina para o material SureFil ${ }^{*}$ com base de Vitremer". 


\begin{tabular}{|l|l|l|l|}
\hline MATERIAL & BASE & MARGEM & ÁREA $\left.\mathbf{( m m}^{2}\right)$ \\
\hline SureFil & Vitremer & Esmalte & 0,09 \\
\hline SureFil & Vitremer & Esmalte & 0,00 \\
\hline SureFil & Vitremer & Esmalte & 0,16 \\
\hline SureFil & Vitremer & Esmalte & 0,00 \\
\hline SureFil & Vitremer & Esmalte & 0,00 \\
\hline SureFil & Vitremer & Esmalte & 0,58 \\
\hline SureFil & Vitremer & Esmalte & 0,00 \\
\hline SureFil & Vitremer & Esmalte & 0,09 \\
\hline SureFil & Vitremer & Esmalte & 0,05 \\
\hline SureFil & Vitremer & Esmalte & 0,00 \\
\hline
\end{tabular}

FIGURA 18 - Resultados originais, em $\mathrm{mm}^{2}$, das áreas de infiltração relativas as margens em esmalte para o material SureFil* com base de Vitremer". 


\section{ANEXO 2}

TABELA 1 - Correlação entre métodos técnicos de medição de infiltração

\begin{tabular}{lcc}
\hline \multicolumn{1}{c}{ Métodos } & r & p \\
\hline Área x Extensão & 0,94 & $0,000^{*}$ \\
\hline Área x Escore & 0,77 & $0,000^{*}$ \\
\hline Extensão x Escore & 0,82 & $0,000^{*}$ \\
\hline
\end{tabular}

*Correlação estatística significante $(\mathrm{p}<0,001)$ 
Referências

Bibliográficas 


\section{REFERÊNCIAS BIBLIOGRÁFICAS*}

1 ABDALLA, A.I.; ALHADAINY, H.A. 2-year clinical evaluation of class I posterior composites. Amer. J. Dent., v.9, n.4 , p.150-2, Aug. 1996.

2 ABDALLA, A.I.; DAVIDSON, C.L. Effect of mechanical load cycling on the marginal integrity of adhesive class I resin composite restorations. J. Dent., v.24, n.1, p.87-90, Jan./Mar. 1996.

3 ADAMS, T.C. A high-density posterior composite used for an amalgam replacement. Dent. Today, v.78, n.2, p.74-7, 1999.

4 AFFLECK, M.S. et al. Microleakage with incremental vs bulk placement utilizing condensable composites. J. dent. Res., v.78, p.155, 1999. Special issue./Abstract n.393/

5 ALANI, A.H.; TOH, C.G. Detection of microleakage around dental restorations: a review. Oper. Dent., v.22, n.4, p.173-85, July/Aug. 1997.

6 ALVES, A. et al. Infiltração marginal em restaurações classe II de molares decíduos utilizando-se uma resina composta de baixa viscosidade como base. JBP, v.1, n.3, p.35-40, 1998.

ASMUSSEN, E. The effect of temperature changes on adaptation of resin fillings II. Acta Odont. Scand., v.32, n.5, p.291-7, June 1974.

8 ASMUSSEN, E.; JÖRGENSEN, K.D. Restorative resins: coefficient of thermal expansion - a factor of clinical significance? Quintessence Int., v.9, n.9, p.79-83, Sept. 1978. /Trabalho apresentado no International Dental Meeting, 1978, Report 1677/

9 BATITUCCI, M. et al. Microleakage control in class II resin restoration: in vitro study. J. dent. Res., v.79, p.182, 2000. Special issue./Abstract n.311/

10 BAYNE, S.C. et al. A characterization of first-generation flowable composites. J. Amer. dent. Ass., v.129, n.5, p.567-77, May 1998.

\footnotetext{
* - Normas recomendadas para uso no âmbito da universidade de São Paulo, com base no documento "Referências Bibliográficas: exemplos", emanado do Conselho Supervisor do Sistema Integrado de Bibliotecas da USP, em reunião de 20 de setembro de 1990 .
} 
11 BRYANT, R.W. Direct posterior composite resin restorations: a review 2 - clinical technique. Aust. dent. J., v.37, n.3, p.161-71, June 1992.

12 BUONOCORE, M.G. A simple method of increasing the adhesion of acrylic filling materials to enamel surfaces. J. dent. Res., v.37, p.849-53, Dec. 1955.

13 CARVALHO, R.M. Adesivos dentinários: fundamentos para aplicação clínica. Rev. Dent. Rest., v.1, n.2, p.1-96, abr./jun.1998.

14 CHUANG, S.F.; LIU, J.K.; JIN, Y.T. Microleakage of class II composite restoration with flowable composite lining. J. dent. Res., v.79, p.182, 2000. Special issue./Abstract n.308/

15 COSTA, A.M. et al. Microleakage of flowable composites: an in vitro study. J. dent. Res., v.78, p.304, 1999. Special issue./Abstract n.1589/

16 CRIM, G.A. Influence of bonding agents and composites on microleakage. J. prosth. Dent., v.61, n.5, p.571-4, May 1989.

17 CRIM, G.A. Microleakage of three resin placement techniques. Amer. J. Dent., v.4, n.2, p.69-72, Apr. 1991.

18 CRIM, G.A.; CHAPMAN, K.W. Effect of placement techniques on microleakage of a dentin-bonded composite resin. Quintessence Int., v.17, n.1, p.21-4, Jan. 1986

19 CRIM, G.A.; CHAPMAN, K.W. Reduncing microleakage in class II restorations: an in vitro study. Quintessence Int., v.25, n.11, p.781-5, Nov. 1994.

20 CRIM, G.A.; GARCIA-GODOY, F. Microleakage: the effect of storage and cycling duration. J. prosth. Dent., v.57, n.5, p.574-6, May 1987.

21 DAVIDSON, C.L.; GEE, A.J. de. Relaxation of polymerization contraction stresses by flow in dental composites. J. dent. Res., v.63, n.2, p.146-8, Feb. 1984.

22 DAVIDSON, C.L.; ABDALLA, A.I. Effect of thermal and 
mechanical load cycling on the marginal integrity of $\mathrm{Cl}$ II resin comparative restorations. Amer. J. Dent., v.6, n.1, p.39-42, Feb. 1993.

23 DAVIDSON, C.L.; GEE, A.J. de; FEILZER, A. The competition between the composite-dentin bond strength and the polymerization contraction stress. J. dent. Res., v.63, n.12, p.1396-9, Dec. 1984.

24 DÉJOU, J.; SINDRES, V.; CAMPS, J. Influence of criteria on the results of in vitro evaluation of microleakage. Dent. Mat., v.12, n.6, p.342-9, Nov. 1996.

25 DIETRICH, T. et al. Marginal adaptation of direct composite and sandwich restorations in class II cavities with cervical margins in dentine. J. Dent., v.27, n.2, p.119-28, Feb. 1999.

26 DIETSCHI, D. et al. Influence of the restorative technique and new adhesives on the dentin marginal seal and adaptation of resin composite class II restorations: in vitro evaluation. Quintessence Int., v.26, n.10, p.717-27, Oct. 1995.

27 DONLY, K.J.; JENSEN, M.E. Posterior composite polymerization shrinkage in primary teeth: an in vitro comparison of three techniques. Pediat. Dent., v.8, n.3, p.209-12, Sept. 1986.

28 DONLY, K.J.; WILD, T.W.; JENSEN, M.E. Posterior composite class II restorations: in vitro comparison of preparation designs and restoration techniques. Dent. Mat., v.6, n.2, p.88-93, Apr. 1990.

29 DOUGLAS, W.H. Posterior composites for modern operative dentistry. J. Calif. dent. Ass., v.24, n.9, p.44-7, Sept. 1996.

30 EICK, J.D.; WELCH, F.H. Polymerization shrinkage of posterior composite resins and its possible influence on postoperative sensitivity. Quintessence Int., v.17, n.2, p.103-11, 1986.

31 ESTAFAN, D.; ESTAFAN, A.; ARTEAGA, Y. Flowable composite: a microleakage study. J. Dent. Res., v.77, p.938, 1998. Special issue./Abstract n.2456/ 
32 FARAH, J.W.; POWERS, J. M. Resinas compostas fluidas. Dent. Adv., v.3, n.4, p.8, Oct. 1996.

33 FARAH, J.W.; POWERS, J. M. Resinas compostas condensáveis. Dent. Adv., v.5, n.8, p. 1-12, Sept. 1998

34 FERDIANAKIS, K. Microleakage reduction from newer esthetic restorative materials in permanent molars. J. clin. pediat. Dent., v.22, n.3, p.221-9, 1998.

35 FERRARI, M. The micromorphologic relationship between resin and dentin in class $\mathrm{V}$ restorations: an in vivo and in vitro investigation. Quintessence Int., v.25, n.3, p.621-5, Sept. 1994.

36 FIELDS, H.W. et al. Variables affecting measurements of vertical occlusal force. J. dent. Res., v.65, n.2, p.135-8, Feb. 1986.

37 FISSORE, B.; NICHOLLS, J.I.; YUODELIS, R.A. Load fatigue of teeth restored by a dentin bonding agent and a posterior composite resin. J. prosth. Dent., v.65, n.1, p.80-5, Jan.1991.

38 FRANCCI, C. et al. The effect of composite resin, adhesive system and low-viscosity liner on microleakage. J. dent. Res., v.78, p.388, 1999. Special issue./Abstract n.2263/

39 FRANCCI, C. et al. Microelakage of class II composite restorations: in vitro comparison of restoration techniques. J. dent. Res., v.79, p.183, 2000. Special is sue. /abstract n.317/

40 FREEDMAN, G. Condensable composites: the new paradigm in amalgam alternatives. Dent. Today, v.17, n.10, p.72-4, 1999.

41 FRIEDL, K.H. et al. Marginal adaptation of composite restorations versus hybrid ionomer/composite sandwich restorations. Oper. Dent., v.22, n.1, p.21-9, Jan./Feb. 1997.

42 FUTATSUKI, M.; NAKATA, M. In vitro marginal leakage of class II composite resin restorations by thermal cycling. J. clin. pediat. Dent., v.18, n.3, p.191-6, June 1994.

43 GARCIA-GODOY, F.; MALONE, W.F.P. Microleakage of posterior 
composite resins using glass ionomer cement bases. Quintessence Int., v.19, n.1, p.13-7, Jan.1988.

44 GOING, R.E. Reducing marginal leakage: a review of materials and techniques. J. Amer. dent. Ass., v.99, n.4, p.646-51, Oct. 1979.

45 GONÇALVES, A.M. Influência do tipo de estresse e da interposição de ionômero de vidro para forramento na infiltração margina; de cavidades restauradas com dois adesivos restauradores. Bauru, 1996. Dissertação (Mestrado)Faculdade de Odontologia de Bauru, Universidade de São Paulo.

46 HAGGE, M.S. et al. Gengival margin microleakage of proximocclusal resins incorporating five intermediate layers. J. dent. Res., v. 79, p.181, 2000. Special issue./Abstract n.303/

47 HANSEN, E.K.; ASMUSSEN, E. Effect of postponed polishing on marginal adaptation of resin used with dentin-bonding agent. Scand. J. dent. Res., v.96, n.3, p.260-4, June 1988.

48 HANSEN, E. K.; ASMUSSEN, E. Marginal adaptation of posterior resins: effect of dentin-bonding agent and hygroscopic expansion. Dent. Mat., v.5, n.2, p.122-6, Mar. 1989.

49 HEMBREE JÚNIOR, J.H. Microleakage at the gingival margin of class II composite restorations with glass-ionomer liner. J. prosth. Dent., v.61, n.1, p.28-30, Jan.1989.

50 HOOD, J.A.A.; LOO, C. Marginal leakage of bonded restorative under simulated. In: CONFERENCE ON CRITICAL REVIEWS OF RESTORATIVE QUANDARIES, Canada, 1998. Proceedings. Canada, Academy of Dental Materials, 1998. p.204. Proceeding P2.

51 JACKSON, R.D.; MORGAN, M. The new posterior resins and a simplified placement technique. J. Amer. dent. Ass., v.131, n.3, p.375-83, Mar. 2000.

52 JÖRGENSEN, K.D.; MATONO, R.; SHIMOKOBE, H. Deformation of cavities and resin fillings in loaded teeth. Scand J. dent. Res., v.84, n.1, p.46-50, Jan. 1976.

53 KIDD, E.A.M. Microleakage: a review. J. Dent., v.4, n.5, p.199-206, 
Sept. 1976.

54 KIDD, E.A.M.; HARRINGTON, E.; GRIEVE, A.R. The cavity sealing ability of composite restorations subjected to thermal stress. J. oral Rehab., v.5, n.3, p.279-86, July 1978.

55 KOENIGSBERG, S.; FUKS, A.; GRAJOWER, R. The effect of three filling techniques on marginal leakage around class II composite resin restorations in vitro. Quintessence Int., v.20, n.2, p.117-21, Feb. 1989.

56 LEINFELDER, K.F. Using composite resin as a posterior restorative material. J. Amer. dent. Ass., v.122, n.4, p.65-70, Apr. 1991.

57 LEINFELDER, K.F.; LYLES, M.B.; RITSCO, R.G. A new polymer rigid matrix material. J. Calif. dent. Ass., v.24, n.9, p.78-82, Sept. 1996.

58 LEINFELDER, K.F.; RADZ, G.M.; NASH, R.W. A report on a new condensable composite resin. Comp. Continuing Educ. Dent., v.19, n.3, p.230-7, Mar. 1998.

59 LEINFELDER, K.F.; BAYNE, S.C.; SWIFT JUNIOR, E.J. Packable composite: overview and technical considerations. J. Esth. Dent., v.11, n.5, p.234-49, 1999.

60 LUNDIN, S.A.; NORÉN, J.G. Marginal leakage in occlusally loaded, etched, class-II composite resin restorations. Acta odont. scand., v.49, n.4, p.247-54, Aug. 1991.

61 LUTZ, F.; KREJCI, I.; OLDENBURG, T.R. Elimination of polymerization stresses at the margins of posterior composite resin restorations: a new restorative technique. Quintessence Int., v.17, n.12, p.777-84, Dec. 1986.

62 MANDRAS, R.S.; RETIEF, D.H.; RUSSELL, C.M. The effect of thermal and occlusal stresses on the microleakage of the Scotchbond 2 dentinal bonding system. Dent. Mat., v.7, n.1, p.63-7, Jan. 1991.

63 MELLO, F. S. -T. da C. et al. Sealing ability of eight bonding systems in a class II restoration after mechanical fatiguing. Dent. Mat., v.13, n.5/6, p.372-6, Sept./Nov. 1997. 
64 MILLER, M.B. et al. Effect of restorative materials on microleakage of class II composites. J. Esthet. Dent., v.8, n.3, p.107-13, July 1996.

65 MIRANDA, W.G. et al. Microleakage of condensable composite resins combined with a flowable composite. J. dent. Res., v.78, p.306, 1999. Special issue./Abstract n.1603/

66 MOUNT, G.J.; PAPAGEORGIOU, A.; MAKINSON, O.F. Microleakage in the sandwich technique. Amer. J. Dent., v.5, n.4, p.195-8, Aug. 1992.

67 NAGAMINE, M. et al. Effect of resin-modified glass ionomer cements on secondary caries. Amer. J. Dent., v.10, n.4, p.173-8, Aug. 1997.

68 NAKABAYASHI, N.; KOJIMA, K.; MASUHARA, E. The promotion of adhesion by the infiltration of monomers into tooth substrates. J. Biomed. Mater. Res., v.16, n.3, p.265-73, May 1982.

69 NAVARRO, M.F.L.; PASCOTTO, R.C. Cimentos de ionômero de vidro. In: Cimentos de ionômero de vidro: aplicações clínicas em odontologia. São Paulo, Artes Médicas, 1998. Cap. 1, p.3-24.

70 OLIVA, R.A.; LOWE, J.A. Dimensional stability of composite used as a core material. J. prosth. Dent., v.56, n.5, p.554-61, Nov. 1986.

71 OLIVEIRA, A.H. de A. Avaliação in vitro da microinfilttração e ação anticariogênica nas restaurações com resina $e$ associações com outros materiais. Bauru, 1999. 135p. Tese (Doutorado) - Faculdade de Odontologia de Bauru, Universidade de São Paulo.

72 PALMER, D.S.; BARCO, M.T.; BILLY, E.J. Temperature extremes produced orally by hot and cold liquids. J. prosth. Dent., v.67, n.3, p.325-7, Mar. 1992.

73 PASHLEY, D.H. Clinical considerations of microleakage. J. Endod., v.16, n.2, p.70-7, Feb. 1990. 
74 PASHLEY, D.H.; CARVALHO, R.M. Dentine permeability and dentine adhesion. J. Dent., v.25, n.5, p.355-72, Sept. 1997.

75 PASHLEY, D.H. et al. Dentin, a dynamic substrate in dentistry. Scanning Microsc., v.3, n.1, p.161-76, Mar. 1989.

76 PEREIRA, M.A. Avaliação da infiltração marginal em cavidades de classe II restauradas com dois tipos de resinas compostas: efeito do carregamento oclusal e de técnicas de inserção. Bauru, 1999. 130p. Dissertação (Mestrado) - Faculdade de Odontologia de Bauru, Universidade de São Paulo.

77 PERETI NETO, J. Avaliação da deformação e da infiltração marginal das restaurações de resinas compostas em dentes posteriores, submetidas a força de compressão. Bauru, 1992. 109p. Tese (Doutorado) - Faculdade de Odontologia de Bauru, Universidade de São Paulo.

78 PERRY, R.; KUGEL, G.; LEINFELDER, K. One-year clinical evaluation of SureFil packable composite. Comp. Continuing Educ. Dent., v.20, n.6, p.544-53, June 1999.

79 PHILLIPS, R.W. et al. One-year observations on a composite resin for class II restorations. J. prosth. Dent., v.26, n.1, p.68-77, Jan. 1971.

80 PHILLIPS, R.W. et al. Observations on a composite resin for class II restorations: three-year report. J. prosth. Dent., v.30, n.6, p.8917, Dec. 1973.

81 PRAGER, M.C. Using flowable composites in direct posterior restorations. Dent. Today, v.16, n.7, p.62-9, 1997.

82 PRAKKI, A.; CILLI, R.; ARAUJO, M.A.J. de. Posterior condensable composite resins: microleakage studies. J. dent. Res., v.79, p.448, 2000. Special issue./Abstract n.2439/

83 PRATI, C. Early marginal microleakage in class II resin composite restorations. Dent. Mat., v.5, n.6, p.392-8, Nov. 1989.

84 PRATI, C. et al. Permeability and microleakage of class II resin composite restorations. J. Dent., v.22, n.1, p.49-56, Feb. 1994. 
85 QVIST, V. The effect of mastication on marginal adaptation of composite restorations in vivo. J. dent. Res., v.62, n.8, p.904-6, Aug. 1983.

86 RADA, R.E. The versatility of flowable composites. Dent. Today, v.17, n.4, p.78-83, 1998.

87 RETIEF, D.H. Standardizing laboratory adhesion tests. Amer. J. Dent., v.4, n.5, p.231-6, Oct. 1991.

88 RETIEF, D.H. Do adhesives prevent microleakage? Int. dent. J., v.44, n.1, p.19-26, Feb. 1994.

89 RETIEF, D.H.; McCAGHREN, R.A.; RUSSEL, C.M. Microleakage of Viterbond/P-50 class II restorations. Amer. J. Dent., v.5, n.3, p.130-2, June 1992.

90 RIGSBY, D.F. et al. Effect of axial load temperature cycling on microleakage of resin restorations. Amer. J. Dent., v.5, n.3, p.155-9, June 1992.

91 ROSSOMANDO, K.J.; WENDT JUNIOR, S.L., Thermocycling and dwell times in microleakage evaluation for bonded restorations. Dent. Mat., v.11, n.1, p.47-51, Jan. 1995.

92 RUSSEL, R.R.; MAZER, R.B. Should flowable composites be used as liners for class II restorations? J. dent. Res., v.78, p.439, 1999. Special issue./Abstract n. 2266/

93 SCHUCKAR, M.; GEURTSEN, W. Proximo-cervical adaptation of class II-composite restorations after thermocycling: a quantitative and qualitative study. J. oral Rehab., v.24, n.10, p.766-75, Oct. 1997.

94 SHORTALL, A.C. Microleakage, marginal adaptation and composite resin restorations. Brit. Dent. J., v.153, n.5, p.223-7, Sept. 1982.

95 SILVA E SOUZA JÚNIOR, M.H. Procedimentos restauradores estéticos em resina e porcelana para dentes posteriores. Rev. Dent. Rest., v.1, n.1, jan./mar. 1999.

96 SILVA E SOUZA JÚNIOR, M.H.; CARVALHO, R.M.; 
MONDELLI, R.F.L. Odontologia estética: fundamentos e aplicações clínicas. São Paulo, Editora Santos, 2000. 171p.

97 SILVA E SOUZA JÚNIOR, M.H. et al. Avaliação da infiltração marginal em esmalte e cemento em cavidades de classe II MOD restauradas com cinco sistemas adesivos. Rev. Odont. USP., v.5, n.2, p.140-5, jul./dez. 1991.

98 SJÖDIN, L.; UUSITALO, M.; VAN DIJKEN, J.V. Resin modified glass ionomer cements - in vitro microleakage in direct class $\mathrm{V}$ and class II sandwich restorations. Swed. dent. J., v.20, n.3, p.77-86, 1996.

99 SWIFT JUNIOR, E.J. et al. Effect of low-viscosity resins on the perfomance of dental adhesives. Amer. J. Dent., v.9, n.3, p.1004, June 1996.

100 TAYLOR, M.J.; LYNCH, E. Microleakage. J. Dent., v.20, n.1, p.310, Jan. 1992.

101 THONEMANN, B. et al. Total bonding vs select bonding: marginal adaptation of class 2 composite restorations. Oper. Dent., v.24, n.5, p.261-71, Sept./Oct. 1999.

102 TROWBRIDGE, H.O. Model system for determining biologic effects of microleakage. Oper. Dent., v.12, p.164-72, 1987.

103 TUNG, F.; ESTAFAN, D.; HSIEH, W. In vitro microleakage study of a condensable and flowable composite. J. dent. Res., v.79, p.183, 2000. Special issue. /Abstract n.314/

104 TUNG, F.; ESTAFAN, D.; SCHERER, W. Microleakage of condensable composite: an in vitro investigation. J. dent. Res., v.79, p.183, 2000. Special issue. /Abstract n.313/

105 UNTERBRINK, G.L.; LIEBENBERG, W.H. Flowable resin composites as "filled adhesives": literature review and clinical recommendations. Quintessence Int., v.30, n.4, p.249-57, Apr. 1999.

106 WENDT, S.L.; McINNES, P.M.; DACKINSON, G.L. The effect of thermocycling in microleakage analysis. Dent. Mat., v.8, n.3, p.181-4, May 1992. 
107 WILlERSHAUSEN, B.; ERNST, C.P.; MARTIN, M. Clinical perfomance of a new polyglass material for posterior teeth: 6 month results. J. dent. Res., v.77, p.953, 1998. Special issue./Abstract n. 2576/

108 YAMAGUCHI, R.; POWERS, J.M.; DENNISON, J.B. Thermal expansion of visible-light-cured composite resins. Oper. Dent., v.14, n.1, p.64-7, Jan. 1989.

109 YAMAUTI, M. Avaliação da infiltração marginal em restaurações de resina composta empregando-se diferentes técnicas de inserção e de ativação da polimerização do material. Bauru, 1999. 141p. Dissertação (Mestrado) Faculdade de Odontologia de Bauru, Universidade de São Paulo. 
Abstract 


\section{ABSTRACT}

The purpose of this study was to determine the microleakage at cervical margins of class II (MOD) resin composite restorations using (P60/Single Bond ${ }^{\star}$; Solitaire/Gluma One Bond ${ }^{\nexists}$ e SureFil/Prime \& Bond $2.1^{\star}$ ), with and without Flow-It! ${ }^{\star}$ or Vitremer bases. MOD cavity preparations were cut in 90 extracted, caries-free human premolars. One cervical margin was placed in enamel $(1 \mathrm{~mm}$ to the CEJ) and one in dentin $(1 \mathrm{~mm}$ below the CEJ). The teeth were randomly divided in 9 groups: groups I, II and III - a layer of a low viscosity resin composite (Flow It!) was placed on the pulpal, axial and gingival margins up to $1 \mathrm{~mm}$ before the cavosurface margin using their respective proprietary bonding agents and restored with P60, Solitaire or Surefil resin composite systems, respectively; groups IV, V and VI - were restored without placement of any base material with the mentioned restorative systems; groups VII, VIII and IX - a layer of a resin-modified glass-ionomer cement (Vitremer) was applied as described for groups I, II and III. The restored teeth were stored in water at $37^{\circ} \mathrm{C}$ and subjected to load cycles (1-17Kg x10/7 days) before being immersed in $0.5 \%$ basic fucsin for $24 \mathrm{~h}$. The teeth were then washed and serially sectioned in a mesio-distal direction to obtain slices of the gingival margin interface. The slice with the highest degree of leakage as judged by a 10X microscope was selected and scanned image was analyzed by a digital image software (ImageTool, UTHSCSA) to calculate the area of leakage. Multivariable ANOVA showed that the highest degrees of leakage occurred at dentin margins regardless of the presence of base or type of resin filling $(p<0.05)$. The presence of a base did not result in significant differences in the degree of leakage for both Surefil and P60 ( $>0.05)$. Solitaire presented the highest degree of leakage when placed without a base material $(\mathrm{p}<0.05)$. The presence of

\footnotetext{
- 3M Dental Products Division St. Paul MV.

8 HARAEUS KULZER South America Ltda.

† DENTSPLY Indstria e Comércio Ltda.

\ JENERIC PENTRON IncorporatedSA
} 
a base material may decrease the degree of leakage, but this is dependent on the filling material. 